\title{
ELEMENTOS QUÍMICOS COMO CRITÉRIO DE DISCRIMINAÇÃO DE CITROS ORGÂNICOS DE CONVENCIONAIS
}

\author{
CHRISTIAN TURRA
}

Dissertação apresentada à Escola Superior de

Agricultura “Luiz de Queiroz”, Universidade de São

Paulo, para obtenção do título de Mestre em Ecologia de Agroecossistemas.

P I R A C I C A B A

Estado de São Paulo - Brasil

Abril - 2005 


\title{
ELEMENTOS QUÍMICOS COMO CRITÉRIO DE DISCRIMINAÇÃO DE CITROS ORGÂNICOS DE CONVENCIONAIS
}

\author{
CHRISTIAN TURRA \\ Engenheiro Agrônomo \\ Orientadora: Profa. Dra. ELISABETE A. DE NADAI FERNANDES \\ Dissertação apresentada à Escola Superior de \\ Agricultura “Luiz de Queiroz”, Universidade de São \\ Paulo, para obtenção do título de Mestre em Ecologia de \\ Agroecossistemas.
}

P I R A C I C A B A

Estado de São Paulo - Brasil

Abril - 2005 
Dados Internacionais de Catalogação na Publicação (CIP) DIVISÃO DE BIBLIOTECA E DOCUMENTAÇÃO - ESALQ/USP

Turra, Christian

Elementos químicos como critério de discriminação de citros orgânicos de convencionais / Christian Turra. - - Piracicaba, 2005.

82 p. : il.

Dissertação (mestrado) - - Escola Superior de Agricultura Luiz de Queiroz, 2005.

Bibliografia.

1. Agricultura orgânica 2. Análise por ativação neutrônica 3. Citricultura 4. Composição química 5. Sistema de produção 6 . Suco de laranja I. Título

CDD 634.3

"Permitida a cópia total ou parcial deste documento, desde que citada a fonte - $\mathrm{O}$ autor" 
Dedico

A meus pais, meu irmão $e$ Isabela S. Turra pelo amor, carinho e compreensão. 


\section{AGRADECIMENTOS}

à Universidade de São Paulo - USP

ao Centro de Energia Nuclear na Agricultura - CENA

à Escola Superior de Agricultura Luiz de Queiroz - ESALQ

ao Laboratório de Radioisótopos pelas facilidades proporcionadas e pela bolsa de estudo concedida

à minha orientadora, Profa. Dra. Elisabete $A$. De Nadai Fernandes, pela oportunidade de desenvolver um trabalho de pesquisa, pelo apoio e amizade

à Profa. Dra. Siu Mui Tsai pela ajuda, confiança e amizade

ao Dr. Márcio Arruda Bacchi, pela contribuição nos cálculos e amizade

ao Dr. Fábio Sileno Tagliaferro, pelo apoio na análise estatística e amizade

aos colegas do curso de Pós - Graduação Interunidades em Ecologia de Agroecossistemas da ESALQ/CENA-USP

aos amigos e colegas do Laboratório de Radioisótopos, Adriana de Angelis Fogaça, Adriano Di Piero Filho, Angela Aparecida Ferrari, Beatriz Maria Ferrari, Camila Elias, Cássio Franco Moreira, Cláudio Luiz Gonzaga, Elvis Joacir de França, Henrique Takuji Fukuma, Luís Gustavo Cofani dos Santos e Paulo César Fávaro

a todos os meus familiares

aos proprietários das fazendas onde foram realizados os estudos

à Cooperativa Coagrosol pelo fornecimento das amostras de suco de laranja concentrado orgânico 
à Associação de Certificação Instituto Biodinâmico - IBD

a todos que de alguma forma contribuíram para este trabalho 


\section{SUMÁRIO}

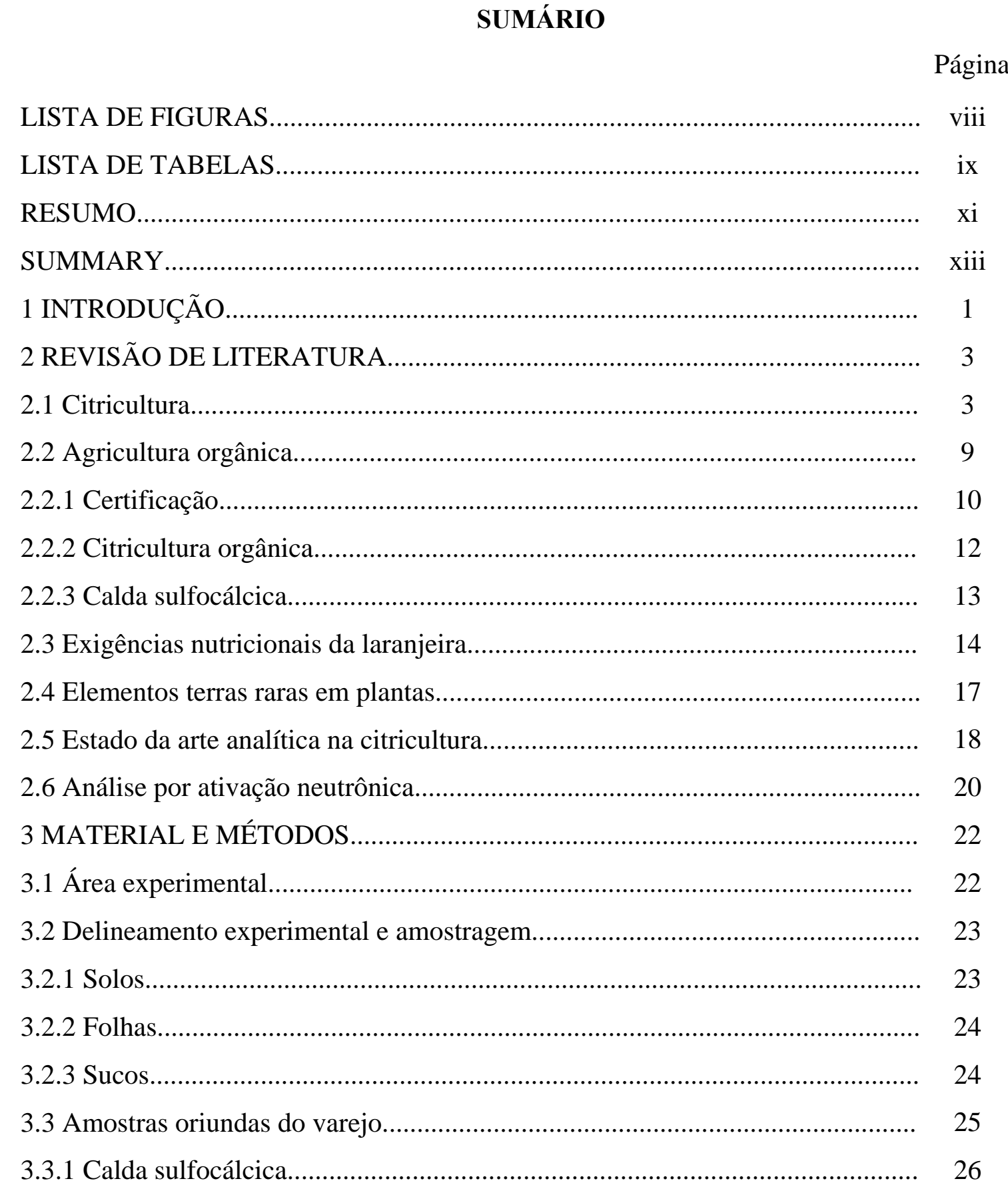


3.4 Análise por ativação neutrônica.................................................................. 27

3.5 Análise estatística................................................................................... 27

4 RESULTADOS E DISCUSSÃO................................................................ 29

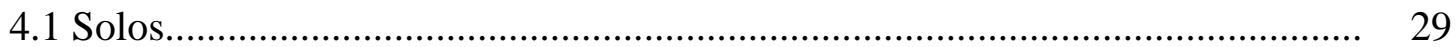

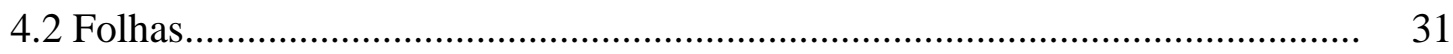

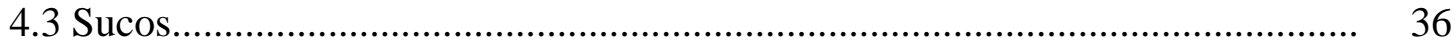

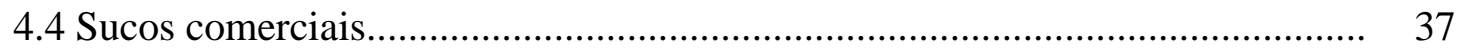

4.5 Calda sulfocálcica.............................................................................. 41

4.6 Considerações finais................................................................................... 42

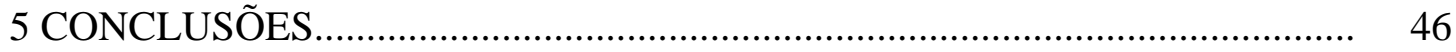

REFERÊNCIAS BIBLIOGRÁFICAS............................................................ 48

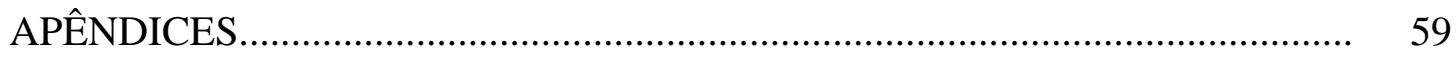




\section{LISTA DE FIGURAS}

1 Subprodutos da laranja...................................................................... 5

2 Gráfico de dispersão com primeiro e segundo componentes principais (72,8 \% de informação total) para folhas.................................................... 35

3 Gráfico de dispersão para amostras de sucos de laranja provenientes das propriedades com sistema de produção orgânico e convencional com primeiro e segundo componentes principais (59,8 \% de informação total)..

4 Gráfico de dispersão com primeiro e segundo componentes principais com todos os elementos (55,3 \% de informação total) dos sucos comerciais.

5 Gráfico de dispersão com primeiro e segundo componentes principais excluindo se Ca e Fe (54,2 \% de informação total).....................................

6 Gráfico de composição elementar (mg. $\mathrm{kg}^{-1}$ ) de amostras de folhas e sucos de de laranja do sistema orgânico e convencional. 


\section{LISTA DE TABELAS}

1 Produção mundial de laranja (milhões de toneladas)................................ 5

2 Área e produção de laranja no Brasil..................................................... 7

3 Principais estados produtores de laranja no Brasil................................. 7

4 Exportações de suco de laranja concentrado e congelado (SLCC) pelo Porto de Santos (em toneladas).............................................................. 8

5 Quantidade de macro e micronutrientes contidas em 1 caixa de laranja

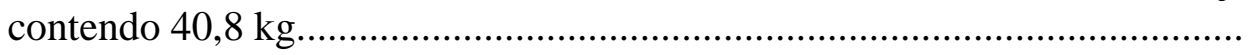

6 Concentrações médias (mg. $\mathrm{kg}^{-1}$ ) de macronutrientes nas partes vegetativas da laranjeira (matéria seca)..................................................................... 15

7 Amostras de sucos de laranja comerciais adquiridas no varejo paulista....... 26

8 Concentração e desvio padrão (mg. $\mathrm{kg}^{-1}$ ) dos elementos químicos determinados em 30 amostras nos solos sob sistema de produção orgânico

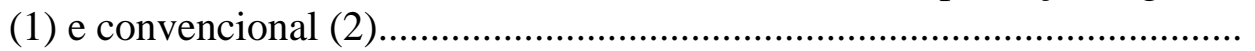

9 Concentrações máximas de metais pesados em solos, segundo o Instituto Biodinâmico

10 Concentração média e desvio padrão (mg. $\mathrm{kg}^{-1}$ ) dos elementos químicos determinados em 30 amostras de folhas de laranjeira dos sistemas de produção orgânico (Org.) e convencional (Conv.)......

11 Concentração média e desvio padrão (mg. $\mathrm{kg}^{-1}$ ) de elementos terras raras em folhas de laranjeira sob sistema de produção orgânico (Org.) e convencional, de Pachystroma longifolium (França et al., 2002) e de Sphagnum sp (Conv.) (Markert \& Li ,1991). * limites de valores.

12 Média das razões $(\mathrm{n}=30)$ folha/solo dos elementos terras raras determinados nos sistemas de produção orgânico (Org) e convencional (Conv)..... 
13 Coeficiente de correlação residual entre os 20 elementos químicos determinados nas 30 amostras de folhas de laranjeira orgânica analisadas.. 34

14 Concentração média e desvio padrão (mg.kg-1) dos elementos químicos determinados em amostras de sucos de laranja dos sistemas de produção orgânico (Org. n=30) e convencional (Conv. n=29).....................................

15 Concentração média $(\mathrm{n}=42)$ e desvio padrão $\left(\mathrm{mg} \cdot \mathrm{kg}^{-1}\right)$ dos elementos químicos determinados em amostras de sucos de laranja comerciais orgânico (o) e convencional (c). Valores com “<” indicam um valor abaixo do limite de deteç̧ão

16 Concentração média e desvio padrão (mg.kg-1) dos elementos químicos determinados em amostras de calda sulfocálcica líquida (li) e calda sulfocálcica em pó (pó)

17 Concentração média e desvio padrão (mg.kg-1) dos elementos químicos determinados em amostras de grãos de café, sucos de laranja e polpa de batata cultivados sob sistemas de produção orgânico (Org.) e

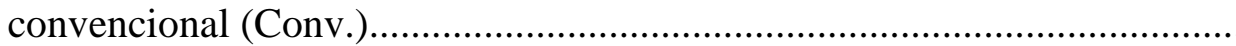




\title{
ELEMENTOS QUÍMICOS COMO CRITÉRIO DE DISCRIMINAÇÃO DE CITROS ORGÂNICOS DE CITROS CONVENCIONAIS
}

\author{
Aluno: CHRISTIAN TURRA \\ Orientadora: Profa. Dra. ELISABETE A. DE NADAI FERNANDES
}

\section{RESUMO}

O Brasil é o maior produtor mundial de citros e também o maior produtor e exportador de suco de laranja concentrado congelado, principal produto da cadeia citrícola. A citricultura brasileira convencional é uma das culturas que mais emprega agroquímicos. Como alternativa ao sistema de produção convencional, propiciando menor agressão ao meio ambiente, a citricultura orgânica oferece ao consumidor um alimento mais seguro à saúde. Objetivando discriminar os citros orgânicos dos citros convencionais, avaliou-se a composição química elementar de laranjas provenientes dos dois sistemas de produção pela análise por ativação neutrônica instrumental (INAA). O experimento foi realizado em pomares cítricos de duas fazendas sob sistema de cultivo orgânico e sistema de cultivo convencional na região de Bebedouro-SP. Selecionou-se a variedade Valência (Citrus sinensis L. Osbeck) enxertada sobre limão cravo (Citrus limonia Osbeck), encontrada nos principais países produtores de citros. Amostraram-se 30 plantas em cada sistema de cultivo, sendo coletados folhas, frutos e solos. Amostras de calda sulfocálcica foram analisadas para verificar sua influência na composição química de frutos e folhas do sistema de produção orgânico. Foram também adquiridas no varejo 14 amostras de sucos de laranjas comerciais 
orgânicos e convencionais. As amostras de sucos foram liofilizadas e as folhas lavadas, secas em estufa e pulverizadas em moinho orbital de alumina. Os solos foram secos em estufa e moídos em gral de porcelana. As amostras foram irradiadas no reator nuclear de pesquisa do Instituto de Pesquisas Energéticas e Nucleares (IPEN/CNEN), São Paulo. A radioatividade induzida foi medida em detectores semicondutores de germânio hiperpuro no Laboratório de Radioisótopos (LRi) do Centro de Energia Nuclear na Agricultura (CENA/USP) por espectrometria gama de alta resolução. As concentrações dos elementos químicos foram calculadas pelo método $k_{0}$. A avaliação dos espectros e os cálculos das concentrações foram realizados pelo programa de computador Quantu. Empregaram-se as técnicas de análise estatística de caráter univariado e multivariado buscando discriminar citros orgânicos de citros convencionais. Determinaram-se os elementos $\mathrm{As}, \mathrm{Br}, \mathrm{Ce}, \mathrm{Co}, \mathrm{Cr}$, Cs, Eu, Fe, Hf, K, La, Na, Nd, Sc, Sm, Ta, Tb, Th, U, Yb e Zn nas amostras de solo; os elementos Ba, Br, Ca, Ce, Co, Cs, Eu, Fe, K, La, Na, Nd, Rb, Sc, Sm, Sr, Tb, Th, Yb e Zn nas amostras de folhas e os elementos $\mathrm{Br}$, Ca, Co, Cs, Fe, K, La, Na, Rb e Zn nas amostras de sucos. Os elementos $\mathrm{Br}$, Ca, Co, Cs, La e Rb foram os discriminantes potenciais para as amostras de folhas e sucos dos sistemas de produção orgânico e convencional. Contudo, $\mathrm{Br}$ foi o melhor discriminante tanto para amostras de sucos provenientes das fazendas do presente estudo como para sucos comerciais. 


\section{CHEMICAL ELEMENTS AS A TOOL TO DISCRIMINATE ORGANIC CITRUS FROM CONVENTIONAL CITRUS}

Author: CHRISTIAN TURRA

Adviser: Prof. Dr. ELISABETE A. DE NADAI FERNANDES

\section{SUMMARY}

Brazil is the world largest producer of citrus and the largest producer and exporter of frozen concentrated orange juice, the principal product of the citrus chain. The Brazilian conventional citriculture is one of the most sprayed culture with agrochemicals. The organic citriculture is an alternative production system, with respect to the environment and offering consumers a safe food. Aiming at discriminating organic citrus from conventional citrus, the elemental composition of oranges from two production systems was evaluated by instrumental neutron activation analysis (INAA). A comprehensive sampling of two citrus farms having different production system, organic and conventional, was carried out in the Bebedouro region, state of São Paulo. The variety Valencia (Citrus sinensis L. Osbeck) budded on Rangpur lime (C. limonia Osbeck) was selected due to its wide distribution in the producing countries. Thirty orange trees of each production system (conventional and organic) were sampled for leaves, fruits and soils. Fourteen samples of retail commercial orange juices (organic and conventional) were purchased. Samples of lime sulfur were analyzed to investigate the influence on the elemental composition of organic fruits and leaves. Sample preparation included freeze-drying for juices, washing, oven-drying and grinding in alumina mill for leaves and oven-drying and grinding in mortar pistle for soils. 
The samples were irradiated in the nuclear research reactor IEA-R1m of the Nuclear and Energetic Research Institute (IPEN/CNEN), São Paulo. The induced radioactivity was measured with germanium detectors at the Radioisotopes Laboratory (LRi) of the Nuclear Energy Center for Agriculture (CENA/USP) by high-resolution gamma ray spectrometry. Elemental concentrations were calculated by the $\mathrm{k}_{0}$-method with an in-house software package. The difference between the two production systems was evidenced by multivariate and univariate analysis. The elements As, Br, Ce, Co, Cr, Cs, Eu, Fe, Hf, K, La, Na, Nd, Sc, Sm, Ta, Tb, Th, U, Yb and Zn were determined for soil samples; Ba, Br, Ca, Ce, Co, Cs, Eu, Fe, K, La, Na, Nd, Rb, Sc, Sm, Sr, Tb, Th, Yb and Zn for leaves samples and $\mathrm{Br}$, Ca, Co, Cs, Fe, K, La, Na, Rb and Zn for juice samples. Br, Ca, Co, Cs, La and $\mathrm{Rb}$ were the key elements for separating samples (leaves and juices) of organic and conventional oranges. $\mathrm{Br}$ has proven to be the best discriminator either for the orange juices from the farms of the present study and the commercial orange juices. 


\section{INTRODUÇÃO}

A laranjeira é uma das árvores frutíferas mais conhecidas, cultivadas e estudadas em todo o mundo. Nativa da Ásia, espalhou-se pelo mundo ficando concentrada nas regiões de clima tropical e sub-tropical. Destacam-se países produtores como Brasil, Estados Unidos, China, Espanha e México. O Brasil tornou-se, na década de 80, o maior produtor mundial de laranja e exportador de suco de laranja concentrado congelado e vem mantendo essa liderança até hoje.

Na década de 60, a indústria brasileira de suco de laranja ganhou impulso, motivada pela grande geada que, em 1962, destruiu grande parte da citricultura dos Estados Unidos. Atualmente, o agronegócio citrícola nacional é altamente competitivo devido a uma série de vantagens comparativas verificadas no país, tais como instituições de pesquisa atuantes voltadas para o setor, menor custo de produção relativamente aos principais países produtores e proximidade do setor produtivo com os canais de escoamento, além de indústrias de grande porte com forte coordenação e atuação no mercado externo.

O principal produto da citricultura brasileira é o suco de laranja concentrado congelado (SLCC) que, em sua maior parte, é exportado. No mercado interno predominam os sucos de laranja reconstituídos. Os sucos de laranja comerciais são constituídos por diferentes variedades de várias regiões, passam por processamentos tecnológicos distintos, podendo receber a adição de conservantes e açúcares para regularização do grau brix e ajuste de acidez.

A citricultura brasileira caracteriza-se pelo sistema intensivo de produção, sendo fortemente dependente do uso de agroquímicos. Neste aspecto, situa-se entre as dez principais culturas que mais consomem este tipo de insumo, correspondendo a aproximadamente $50 \%$ dos custos totais de produção. 
Em contrapartida à agricultura intensiva, a agricultura orgânica visa um sistema agrícola sustentável. É baseada na otimização da capacidade produtiva do solo e redução da utilização de insumos externos, buscando o equilíbrio do agroecossistema. A demanda por produtos orgânicos é crescente, mas faltam informações técnicas e científicas para fomentar o desenvolvimento do setor e dar maior confiança ao consumidor em relação à qualidade e à segurança do produto final.

Atualmente, mais de 30 países produzem citros orgânicos. A citricultura orgânica é incipiente no Brasil, mas tem potencial para se tornar o maior produtor mundial. O suco de laranja orgânico é um dos principais sucos orgânicos consumidos na Europa e Estados Unidos, sendo o Brasil o principal fornecedor deste produto.

Atributos intrínsecos (sabor, aroma, textura e nutrientes) do produto têm sido considerados tão importantes quanto os atributos extrínsecos (embalagem, design, rótulo, selos e praticidade) durante o processo de decisão de compra. A qualidade dos alimentos está relacionada com as características tangíveis, perceptíveís ao consumidor - cor, sabor, odor, textura e características intangíveis (não perceptíveis ao consumidor). As características intangíveis dependem de técnicas e procedimentos analíticos para serem determinados. A técnica de análise por ativação neutrônica instrumental (INAA), que fornece resultados confiáveis e rastreáveis com exatidão, é utilizada para determinação da composição química elementar de alimentos.

Há muitas causas de variação afetando a composição química do suco de laranja, como variedade, período de maturação, região produtora, manejo de condução da lavoura e etapas da industrialização. O presente trabalho consistiu na avaliação da composição química elementar de sucos de laranja obtidos de frutas in natura, folhas e solos provenientes de cultivos orgânicos e convencionais em propriedades da região de Bebedouro, e sucos de laranja comerciais disponibilizados no mercado consumidor, utilizando-se do método da INAA, visando a identificação de elementos químicos que pudessem atuar como “fingerprints” para a discriminação dos sistemas de produção orgânico e de produção convencional de laranja. 


\section{REVISÃO DE LITERATURA}

\subsection{Citricultura}

O gênero Citrus representa o ponto mais alto de um longo período evolutivo, cujo início remonta há mais de 20 milhões de anos (Swingle \& Reece, 1967). As plantas do gênero Citrus são originárias da Ásia, mas o exato local de origem é motivo de controvérsia. Alguns historiadores afirmam que os citros teriam surgido no sudeste asiático nas regiões que incluem hoje Índia, China, Butão, Birmânia e Malásia (ABECITRUS, 2002a).

As plantas de citros são verdes durante o ano todo (persistentes), não apresentando período de repouso (Smith, 1966). As folhas podem persistir durante 1 a 3 anos, havendo, então, num mesmo ramo folhas de ciclos diferentes. Uma planta adulta apresenta de 50 a 100 mil folhas, produzindo na primavera aproximadamente 10 mil flores, das quais somente 1000 a 2000 podem chegar à maturação (Malavolta \& Netto, 1989).

Plantas e frutos de citros são suscetíveis a danos em condições extremas de calor e frio. Os danos dependem da intensidade e duração das condições desfavorávies e também da espécie de citros. A taxa de crescimento máximo da maioria das espécies de citros é obtida entre as temperaturas de $25^{\circ} \mathrm{C}$ e $31^{\circ} \mathrm{C}$. Acima de $31^{\circ} \mathrm{C}$, a taxa de crescimento decresce gradativamente até $36^{\circ} \mathrm{C}$ e, praticamente, cessa entre os limites de $38^{\circ} \mathrm{C}$ a $40^{\circ} \mathrm{C}$ (Reuther, 1973). Os citros são cultivados entre as latitudes $40^{\circ} \mathrm{N}$ a $40^{\circ} \mathrm{S}$ (Davies \& Albrigo, 1994), regiões de clima tropical e subtropical, que abrigam os pomares mais produtivos atualmente, resultantes de uma citricultura estruturada. 
A laranjeira é uma árvore frutífera do gênero Citrus, família das rutáceas. Ela é a planta de citros mais conhecida, cultivada e estudada. As laranjas constituem cerca de $65 \%$ da produção mundial de citros, seguidas das mandarinas (19\%), limas e limões (11\%) e toranjas (5\%) (Ismail \& Zhang, 2004). A trajetória da laranja pelo mundo é conhecida apenas de forma aproximada. Segundo pesquisadores, ela foi levada da Ásia para o norte da África e de lá para o sul da Europa, onde teria chegado na Idade Média. Da Europa foi trazida para as Américas na época dos descobrimentos, por volta de 1500. A laranja espalhou-se pelo mundo sofrendo mutações e dando origem a novas variedades (ABECITRUS, 2002a).

Em 1540, já existiam laranjais no litoral norte e sul do Brasil introduzidos pelas expedições colonizadoras (Moreira, 1980). Nos arredores de Salvador, BA, antes de 1800, a laranja de umbigo (Baía) apareceu provavelmente por mutação da variedade Seleta. Daí espalhou-se por toda parte, atingindo a Califórnia, Estados Unidos, onde foi considerada mais tarde a "mais valiosa introdução de frutífera feita pelo Departamento de Agricultura" (Passos, 1988).

Na década de 60, a indústria brasileira de suco e outros subprodutos da laranja ganhou impulso. A motivação foi a grande geada que, em 1962, destruiu grande parte da citricultura dos Estados Unidos (ABECITRUS, 2002b). Na década de 80, o Brasil se tornou o maior produtor mundial de laranja, superando os Estados Unidos, posição que vem mantendo até hoje (Tabela 1).

Com o início da industrialização da matéria prima de citros, não houve maior atenção para a produção comercial de frutas in natura que sofre barreiras não-tarifárias dos países importadores, como técnicas e fitossanitárias, o que dificulta a comercialização da fruta (Neves \& Marino, 2002). Assim, o principal produto da cadeia citrícola brasileira é o suco de laranja concentrado congelado (SLCC). 
Tabela 1. Produção mundial de laranja (milhões de toneladas)

\begin{tabular}{cccccc}
\hline Países & 2003 & 2002 & 2001 & 2000 & 1999 \\
\hline Brasil & 17,2 & 18,4 & 17 & 21,3 & 22,9 \\
EUA & 10,5 & 11,2 & 11 & 11,8 & 8,9 \\
México & 4 & 3,8 & 4 & 3,8 & 3,5 \\
China & 3,8 & 3,7 & 3,6 & 2,8 & 3,2 \\
Espanha & 3 & 2,8 & 2,8 & 2,6 & 2,7 \\
Índia & 3 & 2.9 & 2,9 & 3 & 3 \\
Itália & 2 & 1,7 & 1,9 & 1,9 & 1,7 \\
Grécia & 1,2 & 1,2 & 1 & 1 & 1,1 \\
Mundo & 62,2 & 63,4 & 62,5 & 65,9 & 64 \\
\hline
\end{tabular}

Fonte: FAOSTAT, 2004

A indústria de suco concentrado produz diversos subprodutos da laranja como se visualiza na Figura 1. Eles possuem diferentes aplicações no mercado interno e externo, dentre as quais incluem-se a fabricação de produtos químicos, solventes, aromas, fragrâncias, tintas, cosméticos e complementos para ração animal (Boteon, 2002).

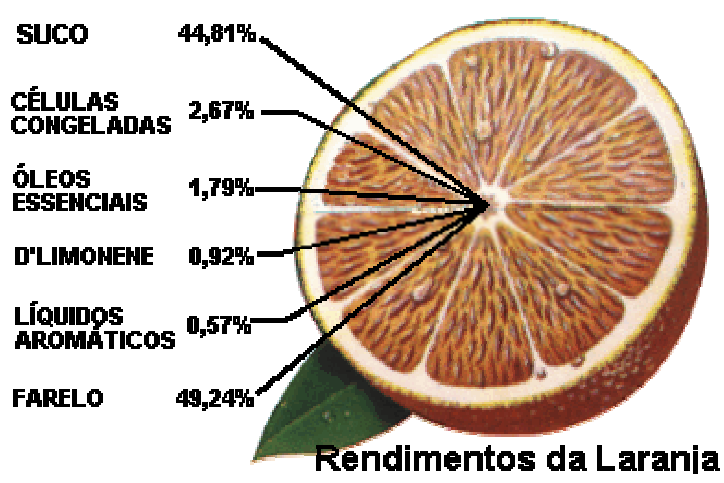

Figura 1 - Subprodutos da laranja 
Com uma das maiores coleções de citros, o Brasil possui um patrimônio representado por um parque de mais de 210 milhões de árvores de citros (Souza, 2001). Há cerca de 2 mil tipos de laranjas, tangerinas e limões - sendo as principais fontes os bancos de germoplasma. As variedades de laranja mais cultivadas são Pêra, Valência, Hamlim, Baía, Natal, Shamouti e Baianinha.

O agronegócio nacional dos citros é altamente competitivo no mercado internacional e alguns fatores contribuem para isso, como importantes instituições voltadas para a pesquisa, entre elas o Fundo de Defesa da Citricultura (Fundecitrus) e o Centro de Citricultura Sylvio Moreira, menor custo de produção comparativamente com os principais países produtores, clima favorável, oferta abundante da fruta in natura, proximidade do setor produtivo com o canal de escoamento, indústrias de grande porte, com boa penetração no mercado exterior.

O sistema agroindustrial citrícola representou $1,87 \%$ da pauta das exportações brasileiras e 4,47\% das exportações brasileiras de produtos do agribusiness em 2003. Movimentou US\$ 3,23 bilhões, sendo US\$ 1,33 bilhões referentes às exportações, e gerou 400 mil empregos diretos. O SLCC representa, em valor monetário, 72\% das exportações do setor. O Estado de São Paulo responde por $79 \%$ da produção brasileira de laranja e 95\% da exportação de suco de laranja (Neves \& Lopes, 2004), com 25 milhões de pés de laranja novos e 188 milhões pés de laranja em produção (IEA, 2004).

Nos últimos anos, o Brasil diminuiu sua área plantada com laranja, mas aumentou sua produtividade de 20,41t/ha em 2001 para 20,95 t/ha em 2004 (Tabela 2). A produtividade no Estado do Paraná, maior do Brasil, aumentou de 18,45 t/ha em 2001 para 25t/ha em 2004, superando o Estado de São Paulo que obteve uma produtividade média de 23,26 t/ha em 2004. 
Tabela 2. Área e produção de laranja no Brasil

\begin{tabular}{ccccc}
\hline & Safra 2004 & Safra 2003 & Safra 2002 & Safra 2001 \\
\hline Área (mil ha) & 810,5 & 822,7 & 831,1 & 825,2 \\
Produção (mil t) & $16.977,8$ & $16.902,6$ & $18.546,1$ & $16.843,6$ \\
\hline
\end{tabular}

Fonte: IBGE/CEPAGRO, 2005

A área e a produção encontram-se estabilizadas na maioria dos principais estados produtores de citros, com exceção de Minas Gerais, que vem diminuindo devido principalmente a problemas com pragas e doenças, e Paraná, que está aumentando (Tabela 3). O Estado de Sergipe detém a segunda maior área citrícola do país e a terceira maior produção, enquanto a Bahia possui a segunda maior produção e a terceira maior área, correspondendo estes dois Estados da região Nordeste por aproximadamente 12\% da área e 9\% da produção brasileira.

Tabela 3. Principais estados produtores de laranja no Brasil

\begin{tabular}{cccccc}
\hline Estado & & Safra 2004 & Safra 2003 & Safra 2002 & Safra 2001 \\
\hline \multirow{2}{*}{ São Paulo } & Área (mil ha) & 580,3 & 586 & 586,8 & 581,5 \\
& Produção (mil t) & 13.497 & 13.347 & 14.759 & 13.530 \\
Sergipe & Área (mil ha) & 51,9 & 51 & 50,4 & 49,9 \\
& Produção (mil t) & 710,4 & 690,6 & 701,4 & 581,3 \\
Bahia & Área (mil ha) & 48,6 & 48,3 & 50,8 & 49,5 \\
& Produção (mil t) & 771,6 & 770,3 & 923,4 & 865,4 \\
\multirow{2}{*}{ Minas Gerais } & Área (mil ha) & 38,9 & 41,6 & 43,6 & 43,8 \\
& Produção (mil t) & 596,3 & 666,2 & 698,2 & 551,8 \\
Rio Grande do Sul & Área (mil ha) & 27,1 & 27,2 & 27 & 26,9 \\
& Produção (mil t) & 342,6 & 354,7 & 345,6 & 345,3 \\
\multirow{2}{*}{ Paraná } & Área (mil ha) & 14,5 & 13,8 & 13 & 12,7 \\
& Produção (mil t) & 362,5 & 330,8 & 273 & 233,7 \\
Pará & Área (mil ha) & 12,4 & 12,4 & 12,7 & 12,7 \\
& Produção (mil t) & 205,5 & 205,2 & 210,2 & 200,2 \\
\hline
\end{tabular}

Fonte: IBGE/CEPAGRO, 2005 
A maior parte da produção brasileira de laranja (70\%) destina-se ao processamento industrial para transformação em suco concentrado e congelado, direcionado em sua quase totalidade (97\%) para o mercado externo. Dos 30\% restantes, pequena parcela destina-se à exportação, ficando a maior parte no mercado interno para ser consumida na forma de fruta fresca (Ghilardi et. al., 2002).

A União Européia é o principal mercado consumidor do SLCC brasileiro, compreendendo, nos últimos 3 anos, aproximadamente $70 \%$ do volume exportado.

O Acordo de Livre Comércio dos Países da América do Norte (NAFTA) diminuiu sua participação na importação de SLCC brasileiro nesta última década, principalmente devido à entrada do México neste bloco, que passou a ter maiores benefícios na comercialização (Neves \& Marino, 2002). Nos últimos anos, presenciou-se a participação de novos mercados, como a Rússia (Tabela 4).

Tabela 4. Exportações de suco de laranja concentrado e congelado (SLCC) pelo Porto de Santos (em toneladas)

\begin{tabular}{cccccc}
\hline $\begin{array}{c}\text { ANO } \\
\text { SAFRA }\end{array}$ & $\begin{array}{c}\text { UNIÃO } \\
\text { EUROPÉIA }\end{array}$ & NAFTA & ÁSIA & OUTROS & TOTAL \\
\hline $1993 / 94$ & 544.000 & 364.000 & 102.000 & 25.000 & 1.034 .000 \\
$1994 / 95$ & 631.000 & 216.000 & 146.000 & 31.000 & 1.024 .000 \\
$1995 / 96$ & 709.000 & 190.000 & 98.000 & 33.000 & 1.031 .000 \\
$1996 / 97$ & 789.000 & 193.000 & 125.000 & 30.000 & 1.138 .000 \\
$1997 / 98$ & 867.000 & 204.000 & 108.000 & 38.000 & 1.217 .000 \\
$1998 / 99$ & 756.000 & 210.000 & 93.000 & 37.000 & 1.096 .000 \\
$1999 / 00$ & 725.438 & 252.938 & 113.303 & 39.913 & 1.131 .592 \\
$2000 / 01$ & 872.210 & 199.897 & 129.849 & 49.984 & 1.251 .940 \\
$2001 / 02$ & 762.425 & 131.099 & 124.525 & 51.230 & 1.069 .279 \\
$2002 / 03$ & 867.226 & 231.257 & 126.151 & 60.227 & 1.284 .861 \\
\hline
\end{tabular}

Fonte: ABECITRUS/SECEX, 2004 


\subsection{Agricultura orgânica}

A agricultura orgânica é resultado de um movimento em que várias correntes estabeleceram formas diferentes de manejo do sistema solo/planta e da criação de animais (Neves, 2004). Segundo Ehlers (1999), esses movimentos podem ser agrupados em quatro grandes vertentes. Na Europa, surgem a agricultura biodinâmica, iniciada por Rudolf Steiner em 1924, a agricultura orgânica, cujos princípios foram estabelecidos entre os anos de 1925 e 1930 pelo pesquisador inglês Sir Albert Howard, e a agricultura biológica, inspirada nas idéias do suíço Hans Peter Müller. No Japão, surge a agricultura natural, a partir de 1935, baseada nas idéias de Mokiti Okada. O ponto comum entre as diferentes correntes que formam a base da agricultura orgânica é a busca de um sistema de produção sustentável no tempo e no espaço, mediante o manejo e a proteção dos recursos naturais, sem a utilização de produtos químicos agressivos à saúde humana e ao meio ambiente, mantendo a fertilidade e a vida dos solos, favorecendo a diversidade biológica e respeitando a integridade cultural dos agricultores (Darolt, 2003).

Segundo a definição do Codex Alimentarius (2004):

"A agricultura orgânica é um sistema de gerenciamento total da produção agrícola com vistas a promover e realçar a saúde do meio ambiente, preservar a biodiversidade, os ciclos e as atividades biológicas do solo. Nesse sentido, a agricultura orgânica enfatiza o uso de práticas de manejo em oposição ao uso de elementos estranhos ao meio rural. Isso abrange, sempre que possivel, a administração de conhecimentos agronômicos, biológicos e até mesmo mecânicos. Exclui a adoção de substâncias químicas ou outros materiais sintéticos que desempenhem no solo funções estranhas às desempenhadas pelo ecossistema."

Os princípios da agricultura orgânica baseiam-se em um sistema de produção sustentável, economicamente viável e socialmente justo. O sistema de manejo de produção 
orgânica apresenta particularidades do local tais como solo, clima, fauna, flora e recursos hídricos. Essas particularidades muitas vezes exigem soluções específicas para o tipo de cultivo e tratos culturais.

A agricultura orgânica já é praticada em mais de uma centena de países, ocupando área aproximada de 23 milhões de hectares. A Austrália possui a maior área certificada com orgânicos com 10,5 milhões de hectares, seguida da Argentina com 3,2 milhões de hectares, da Itália com 1,23 milhão de hectares e dos Estados Unidos com 950 mil hectares (IFOAM, 2003). O Brasil deteve a décima terceira maior área certificada com orgânicos, com cerca de 276 mil hectares em 2003. Atualmente, o Brasil detém a segunda maior área certificada com orgânicos, com cerca de 6,5 milhões de hectares (MAPA, 2005). O salto no ranking foi impulsionado pela inclusão do extrativismo sustentável no cálculo da área da agricultura orgânica brasileira.

Atendendo ao apelo de qualidade ambiental e do produto, o consumidor consciente e com maior poder aquisitivo opta por pagar mais por um produto orgânico. $\mathrm{O}$ mercado mundial de orgânicos foi estimado em US\$ 23 bilhões em 2002, dos quais o mercado norteamericano deteve 51\% e a Europa, 46\%. O mercado de alimentos e bebidas orgânicos da Alemanha é o maior da Europa, tendo movimentado em 2002 cerca de US\$ 3,06 bilhões, seguido do Reino Unido, com US\$ 1,5 bilhões,. Neste mesmo ano, o mercado latino americano movimentou US\$ 100 milhões e o asiático, US\$350 milhões (IFOAM, 2004).

\subsubsection{Certificação}

A certificação, em seu conceito amplo, é a definição de atributos de um produto, processo ou serviço e a garantia de que eles se enquadram em normas predefinidas (Nassar, 2003).

Existem normas para a certificação de empresas da agroindústria e produtores rurais que adotam a produção orgânica. Estas normas foram pioneiramente elaboradas na década 
de 80 por uma entidade européia, a IFOAM - International Federation of Organic Agriculture Movements. A partir das normas da IFOAM, vários países desenvolveram suas próprias normas de produção orgânica (Hoffmann, 2004).

No Brasil, a certificação teve origem informal, mediante o trabalho desenvolvido por organizações não-governamentais, que estabeleceram padrões e normas internas para produção e comercialização e criaram selos de garantia para seus produtos (selos de certificação), direcionados principalmente ao mercado interno (Ormond et. al., 2002). O crescimento das certificadoras no Brasil ocorreu principalmente no fim do século XX e início do século XXI, para atender à necessidade de exportação de produtos orgânicos que foi acompanhado por um considerável crescimento da produção orgânica nacional. Para normatizar o mercado de orgânicos no Brasil, foi criada a primeira norma de produção orgânica oficial, a Instrução Normativa n..$^{0}$ 007, de 17 de maio de 1999 (Apêndice 8), do Ministério da Agricultura e do Abastecimento - MAPA, que também instituiu o Órgão Colegiado Nacional e os Órgãos Colegiados Estaduais. Esses órgãos, compostos de entidades representativas do setor orgânico, são responsáveis pela sistematização e implantação das normas da produção orgânica nos estados e pela acreditação de entidades certificadoras.

O Instituto Biodinâmico (IBD), de Botucatu-SP, fundado em 1982, foi a primeira entidade certificadora orgânica nacional, reconhecida internacionalmente. Conquistou a acreditação IFOAM em 1995, a acreditação pelo Círculo de Credenciamento Alemão - DAR em 1999 e a acreditação do United States Department of Agriculture - USDA em 2002, além de possuir convênio com Japan Agriculture Standard - JAS (IBD, 2005). Atualmente, há mais de 15 certificadoras atuando no país.

As certificadoras verificam todos os procedimentos adotados no sistema de produção, tais como preparo do solo, adubação e controle biológico ou cultural das principais doenças. Todos os insumos utilizados devem ser permitidos pela Instrução 
Normativa 007 e pela certificadora. Além disso, são observadas as legislações ambientais e as relações trabalhistas. A verificação é realizada mediante auditorias externas periódicas e visitas para monitorar a implantação e a efetividade do sistema certificado. Com a conquista do selo, o produtor tem maior facilidade para vender sua safra tanto no mercado interno quanto no externo, no qual vem aumentando a demanda por produtos orgânicos.

\subsubsection{Citricultura orgânica}

A citricultura é a cultura que mais emprega acaricidas e utilizou o equivalente a 5\% do mercado de fertilizantes foliares em 2003 (PENSA, 2004). Como alternativa ao sistema de produção dependente de agroquímicos, a citricultura orgânica oferece um produto mais saudável sem utilização de agroquímicos danosos ao meio ambiente e à saúde humana.

A produção mundial de citros orgânicos foi estimada em 600 mil toneladas em 2001, o que representa menos de $1 \%$ da produção mundial. Aproximadamente 30 países produzem e exportam citros orgânicos certificados (Liu, 2004). Os maiores produtores são, em ordem decrescente, Itália, Estados Unidos, Brasil, Costa Rica, Grécia e Espanha. O Brasil é o maior produtor mundial de suco de laranja orgânico concentrado congelado (SLOCC) (FAO, 2003).

Segundo o Instituto Biodinâmico, há 4500 hectares certificados com citros orgânicos no Brasil (Vailati, 2003). Existem produtores de citros orgânicos em todas as regiões do Brasil (NO, SE, SU, NE, $\mathrm{CO}$ ), mas a produção está concentrada na região sudeste com

destaque para o Estado de São Paulo. É importante salientar que produtores e indústrias podem adquirir ou perder a certificação de acordo com o interesse de uma ou ambas as partes, o que significa que há constantes alterações nas lista de projetos certificados.

Mais de $85 \%$ da fruta cítrica orgânica produzida tem como destino a indústria processadora para a produção do SLOCC, que, em sua maior parte, é exportado. Atualmente, há seis indústrias certificadas que processam suco de laranja orgânico no Brasil: 
Citros Kiki, de Engenheiro Coelho, SP; Citrovita, de Catanduva, SP; Montecitrus, de Monte Azul Paulista, SP; Ecocitrus (processa tangerina orgânica), de Montenegro, RS; Usina Nova América, de Santa Cruz do Rio Pardo, SP e Hildebrand, de São Carlos, SP (IBD, 2003). Para a Citros Kiki, que atua há cerca de 40 anos no mercado de laranja e há 10 anos no de suco, a Europa paga cerca de US\$ 1800 pela tonelada de suco orgânico concentrado, o que corresponde a quase $\mathrm{o}$ triplo da cotação paga à bebida convencional (PLANETA ORGÂNICO, 2003). Segundo Turra \& Ghisi (2004), o produtor de citros orgânicos recebe melhor remuneração por seu produto, mas enfrenta dificuldades na produção, como o controle de pragas e doenças, necessidade de mão-de-obra especializada e, em alguns casos, dificuldades para comercializar sua produção.

\subsubsection{Calda sulfocálcica}

Considerada o melhor defensivo natural para frutíferas de clima temperado, a calda sulfocálcica é indicada principalmente para o tratamento de inverno de plantas que perdem as folhas (ácaro vermelho, cochonilha branca, oídio, sarna e podridão parda). Tem, ainda, proporcionado maior resistência e longevidade às frutas colhidas, especialmente aquelas transportadas a longas distâncias (AGROJURIS, 2005).

$\mathrm{Na}$ cultura da laranja em sistemas agroecológicos é bastante comum o uso da calda sulfocálcica (PLANETA ORGÂNICO, 2003). A calda sulfocálcica é considerada um acaricida, inseticida alternativo que tem como principal finalidade na citricultura o controle do ácaro Brevipalpus phoenicis (Geijskes), considerada uma das principais pragas na citricultura. Por apresentar baixo poder residual, a calda sulfocálcica é aplicada via foliar em média de 3 a 6 vezes no ano, em concentrações de 60L a 80L de calda em 2000L de água. É obtida num processo de reação da cal virgem com o enxofre, 
formando vários compostos, como polissulfetos de cálcio (Penteado, 2004). A calda sulfocálcica atua também como fertilizante, fornecendo cálcio e enxofre ao metabolismo das plantas com a finalidade de estimular as reações de fotossíntese e proteossíntese de forma que a planta se torne mais resistente às pragas (Bertoldo, 2003).

\subsection{Exigências nutricionais da laranjeira}

A absorção de elementos minerais pelos citros se dá durante o ano todo. Contudo, é maior no florescimento e quando se formam as folhas e ramos novos, período correspondente a março/abril e julho/setembro no Hemisfério Norte e a setembro/dezembro e março/abril no Hemisfério Sul (Kampfer \& Uexkull, 1966).

Os elementos químicos considerados essenciais para as plantas são $\mathrm{N}, \mathrm{P}, \mathrm{K}, \mathrm{Ca}, \mathrm{Mg}$, $\mathrm{S}$ (macronutrientes), $\mathrm{B}, \mathrm{Cl}, \mathrm{Co}, \mathrm{Cu}, \mathrm{Fe}, \mathrm{Mn}, \mathrm{Mo}, \mathrm{Zn}$ (micronutrientes) e $\mathrm{C}, \mathrm{H}, \mathrm{O}$. Nos frutos, os macronutrientes encontrados em maior quantidade são, em ordem decrescente, $\mathrm{N}, \mathrm{K}, \mathrm{Ca}$, $\mathrm{P}, \mathrm{S}$ e $\mathrm{Mg}$ (Tabela 5). O cálcio é o macronutriente encontrado em maior proporção nas plantas cítricas (Tabela 6). Normalmente, em citros, são aplicados os macronutrientes via solo e os micronutrientes via foliar .

Nos solos em geral, há uma quantidade considerável de nitrogênio, principalmente em formas orgânicas. As formas de nitrogênio mineral podem originar-se de condições aeróbicas da matéria orgânica e também de fertilizantes minerais e orgânicos adicionados ao solo (Raij, 1991). É absorvido pelas plantas na forma de $\mathrm{NO}^{3-}$ ou $\mathrm{NH}^{4+}$, conforme o $\mathrm{pH}$ do solo (Da Matta \& Loureiro, 2004).

As plantas absorvem o fósforo da solução do solo e o pH do solo tem grande

influência sobre a biodisponibilidade do elemento. É absorvido preferencialmente como $\mathrm{H}_{2} \mathrm{PO}_{4}{ }^{-}$, sendo rapidamente incorporado em compostos orgânicos (Raij, 1991). 
O potássio é absorvido pelas raízes na forma iônica $\mathrm{K}^{+}$, sendo o processo essencialmente ativo. O transporte a longa distância se faz pelo xilema e pelo floema e sua redistribuição ocorre de folhas e órgãos mais velhos para os mais novos ou para os frutos em crescimento (Malavolta et al., 1997).

O cálcio é absorvido como $\mathrm{Ca}^{2+}$, transportado na corrente transpiratória, sendo considerado um elemento imóvel no floema. As plantas necessitam de um suprimento constante de cálcio que possui um antagonismo muito forte com o potássio (Malavolta \& Violante Netto, 1989).

O magnésio é absorvido como $\mathrm{Mg}^{2+}$ da solução do solo (Malavolta \& Violante Netto, 1989). É móvel na planta e, em condições de deficiência, provoca clorose internerval.

O enxofre na planta encontra-se, em sua maior parte, nas proteínas. É normalmente fornecido às plantas indiretamente pelos tratamentos fitossanitários, bem como pelas fonte de $\mathrm{N}$ (sulfato de amônio) e de $\mathrm{P}_{2} \mathrm{O}_{5}$ (superfosfato simples) (Vitti \& Silva, 2000).

Tabela 5. Quantidade de macronutrientes e micronutrientes em 1 caixa de laranja contendo 40,8 $\mathrm{kg}$

\begin{tabular}{cccc}
\hline Macronutrientes & $(\mathrm{g})$ & Micronutrientes & $(\mathrm{mg})$ \\
\hline $\mathrm{N}$ & 76 & $\mathrm{~B}$ & 88 \\
$\mathrm{P}$ & 7 & $\mathrm{Cl}$ & 1000 \\
$\mathrm{~K}$ & 60 & $\mathrm{Cu}$ & 48 \\
$\mathrm{Ca}$ & 21 & $\mathrm{Fe}$ & 264 \\
$\mathrm{Mg}$ & 5 & $\mathrm{Mn}$ & 112 \\
$\mathrm{~S}$ & 6 & $\mathrm{Mo}$ & 0,32 \\
& & $\mathrm{Zn}$ & 36 \\
& & $\mathrm{Na}$ & 1740 \\
& & $\mathrm{Al}$ & 304 \\
\hline
\end{tabular}

Fonte: Malavolta \& Violante Netto (1989) 
Tabela 6. Concentrações médias $\left(\mathrm{mg} \cdot \mathrm{kg}^{-1}\right)$ de macronutrientes nas partes vegetativas da laranjeira (matéria seca)

\begin{tabular}{ccccccc}
\hline Órgão & $\mathrm{N}$ & $\mathrm{P}$ & $\mathrm{K}$ & $\mathrm{Ca}$ & $\mathrm{Mg}$ & $\mathrm{S}$ \\
\hline Folhas & 2,22 & 0,18 & 1,31 & 4,20 & 0,25 & 0,25 \\
Ramos & 1,02 & 0,17 & 0,15 & 1,82 & 0,28 & - \\
Troncos & 0,40 & 0,07 & 0,21 & 0,51 & 0,07 & - \\
Raízes & 0,82 & - & 0,28 & 0,10 & 0,05 & -
\end{tabular}

Fonte: Kampfer \& Uexkull (1966)

A disponibilidade dos micronutrientes é afetada principalmente pelo $\mathrm{pH}$, condições de oxi-redução, matéria orgânica e presença de outros íons (Malavolta et al., 1997). O boro, assim como o cálcio, é imóvel nas plantas sendo translocado por meio do xilema.

Normalmente, os micronutrientes mais deficientes na citricultura paulista são B, Mn e Zn (Grupo Paulista de Adubação, 1994). Segundo Quaggio \& Piza Júnior (2001) em condições tropicais, as deficiências de B e Zn são as mais freqüentes. O boro tem relação direta com o metabolismo e incorporação de cálcio na parede celular (Yamauchi et al., 1986). O manganês é absorvido pelas raízes das plantas na forma de $\mathrm{Mn}^{2+}$. A composição química do solo e da rizosfera exerce grande influência na absorção de manganês (Borkert et al., 2001). A deficiência de manganês em citros, embora generalizada, é freqüentemente de ocorrência transitória (Gupta, 2001). A forma predominantemente absorvida de zinco é a $\mathrm{Zn}^{2+}$, podendo ser também $\mathrm{Zn}^{-}$quelato. Alguns autores consideram o zinco altamente móvel, enquanto outros de mobilidade intermediária (Dechen et al., 1991).

A absorção de cobalto ocorre como $\mathrm{Co}^{2+}$. Quando absorvido por via foliar é praticamente imóvel, assim como Cu, Fe, Mn e Zn (Malavolta et al., 1997). 
O cloro é absorvido pelas raízes e folhas na forma de $\mathrm{Cl}^{-}$e tem grande mobilidade na planta. É fornecido às plantas por meio de diferentes fontes (reservas do solo, chuva, fertilizantes e poluição aérea), sendo mais freqüente a toxicidade do elemento em plantas do que a deficiência (Dechen et al., 1991). Uma das fontes de cloro mais utilizada na citricultura é o cloreto de potássio $(\mathrm{KCl})$.

O cobre não é prontamente móvel na planta, embora possa ser translocado das folhas velhas para as novas. Nos pomares em produção, doenças fúngicas são controladas com produtos à base de cobre que são suficientes para suprir a necessidade deste elemento na planta (Vitti, 1992).

O molibdênio é o micronutriente exigido em menor quantidade pelas plantas e também o que ocorre em menor concentração nos solos. É absorvido como molibdato $\left(\mathrm{MoO}_{4}{ }^{2+}\right)$ e sua absorção é proporcional à sua concentração no solo (Dechen et al., 1991).

O sódio é um elemento mineral benéfico às plantas (Furlani, 1999), sendo encontrado em maior quantidade nas laranjas (Tabela 5). A forma química que ocorre em minerais, na solução do solo e como cátion trocável, é a do íon $\mathrm{Na}^{+}$(Raij, 1991).

\subsection{Elementos terras raras em plantas}

Elementos terras raras estão presentes em todas as plantas, mas não são tidos como essenciais nem tóxicos (Wyttenbach et al., 1998). Podem ser absorvidos pela superfície das folhas depois de pulverizadas (Sun et al., 1994), mas a absorção normalmente ocorre pelas raízes das plantas (Wyttenbach et al., 1998). Markert \& Li (1991) determinaram elementos terras raras por espectrometria de emissão atômica com plasma induzido (ICP-AES) e ICPMS em várias espécies de plantas (Betula alba, Pinus sylvestris, Vaccinium vitis-idaea, Vaccinium myrtillus, Deschampsia flexuosa, Polytrichum sp. e Sphagnum sp.) do 
ecossistema natural de floresta da região nordeste da Alemanha. A concentração de lantanídeos acumulados em Sphagnum sp. é 3 vezes maior que a concentração média das outras plantas investigadas. França et al. (2002) estudaram na porção central da Mata de Santa Genebra, Estado de São Paulo, a distribuição de elementos terras raras em folhas de Pachystroma longifolium e Esenbeckia leiocarpa. A concentração desses elementos foi 32 vezes maior nas amostras de folhas de Pachystroma longifolium. A razão folha/solo para La foi 0,69 para Pachystroma longifolium e 0,21 para Sphagnum sp, conhecida como bioacumuladora de terras raras (Markert \& Li, 1991).

Embora pouco conhecidas, as interações entre solo, microrganismos e raízes das plantas podem influenciar a concentração de elementos terras raras nas plantas. A dissolução de fosfatos minerais é promovida por exudação de ácidos orgânicos de baixo peso molecular, por hifas de fungos e raízes de plantas, promovendo lixiviação e dissolução mineral por liberação de ácidos e compostos químicos para a rizosfera do solo (Tyler, 2004).

Foram determinados por Wutscher \& Perkins (1993) 14 elementos terras raras com espectrometria de emissão atômica com plasma induzido (ICP-AES) em amostras de folhas, cascas, troncos e raízes de plantas de citros em diferentes regiões dos Estados Unidos. Nas áreas experimentais foram realizados diferentes manejos, com fertilizante $(14 \% \mathrm{~N}, 1,7 \% \mathrm{P}$, 11,6\% K) e calcáreo dolomítico. A concentração de La nas folhas variou de 10 a 78 mg. $\mathrm{kg}^{-1}$. O solo com maior concentração de matéria orgânica e maior capacidade de troca catiônica (CTC), apresentou maior concentração de elementos terras raras. O fertilizante (NPK) mostrou baixas concentrações de lantanídeos, diferentemente do calcáreo dolomítico que apresentou 0,2 mg. $\mathrm{kg}^{-1} \mathrm{Sc} ; 7,5 \mathrm{mg} \cdot \mathrm{kg}^{-1} \mathrm{Y} ; 4,6 \mathrm{mg} \cdot \mathrm{kg}^{-1} \mathrm{La} ; 5,8 \mathrm{mg} \cdot \mathrm{kg}^{-1} \mathrm{Ce} ; 4,1$ de mg. $\mathrm{kg}^{-1}$ Nd; 2,7 de mg.kg-1 Eu; 1,7 mg.kg ${ }^{-1}$ Gd e 1,1 mg.kg ${ }^{-1}$ Dy.

Fernandes (1992) determinou a quantidade de solo no carregamento de cana-deaçúcar em dez diferentes tipos de solos no Estado de São Paulo, para a variedade SP701143. O elemento Sc mostrou ser um eficiente traçador de solo que entra na indústria com a 
cana-de-açúcar. Foi também verificada a correlação de escândio com ferro nas amostras de cana-de-açúcar industrializada, comprovando a presença de solo.

\section{5 $\mathrm{O}$ estado da arte analítica na citricultura}

Os sucos de laranjas comerciais são constituídos por diferentes variedades de citros, passam por processamentos tecnológicos distintos, podendo receber a adição de conservantes e açúcares para regularização de grau brix e ajuste de acidez. O suco de laranja concentrado congelado é pasteurizado, acondicionado sob vácuo e resfriado até $18{ }^{\circ} \mathrm{C}$ negativos, temperatura na qual será armazenado. O suco de laranja pasteurizado sofre tratamento térmico sendo resfriado até $20^{\circ} \mathrm{C}$ e envasado. $\mathrm{O}$ suco de laranja reconstituído é obtido a partir de adição de água potável ao suco concentrado congelado de forma a reduzir de $65^{\circ}$ Brix para aproximadamente $11^{\circ}$ Brix. A mistura é, então, pasteurizada e embalada (Tribess \& Tadini, 2002).

A concentração de elementos nutricionais e traços em sucos de laranja tem sido usada para monitorar a qualidade, investigar a autenticidade e caracterizar os países de origem. McHard et al. (1976) determinaram a concentração de oito elementos químicos (Ca, $\mathrm{Cu}, \mathrm{Fe}, \mathrm{Mg}, \mathrm{Na}, \mathrm{P}, \mathrm{K}, \mathrm{Zn}$ ) em sucos de laranja concentrados da Flórida por espectrometria de absorção atômica (AAS). Usando a técnica de reconhecimento de padrão, Bayer et al. (1980) determinaram a origem geográfica dos sucos de laranja concentrados congelados do Brasil e dos Estados Unidos (Flórida), pela discriminação por cinco elementos ( $\mathrm{Ba}, \mathrm{B}, \mathrm{Ga}, \mathrm{Mn}$ e $\mathrm{Rb}$ ). Posteriormente, a espectrometria de massas com plasma induzido em argônio (ICP-MS) permitiu determinar grande número de elementos químicos presentes nos sucos de laranja, usados para identificação de origem e detecção de adição de água de lavagem de polpa (Martin et al., 1997). 
Perfis de carotenóides por cromatografia líquida foram utilizados por Mouly et al. (1999) para identificar a origem geográfica de sucos de laranja de Belize e da Espanha. Simpkins et al. (2000) determinaram a concentração de 22 elementos traços (Al, Ba, B, Ca, Co, Fe, Li, Lu, Mg, Mn, Mo, Ni, P, K, Rb, Si, Na, Sr, Sn, Ti, V e Zn) em sucos de laranja concentrados do Brasil e da Austrália, utilizando espectrometria de emissão atômica com plasma induzido (ICP-AES) e ICP-MS. Também verificaram as diferenças regionais de sete variedades de laranja na Austrália.

Garcia-Wass et al. (2000) utilizaram a espectroscopia de massas por pirólise (PyMS) para comprovar autenticidade de sucos de laranja do Brasil, Israel, Chipre, África do Sul, Cuba, Espanha e Estados Unidos e detectar adulterações. Foram determinados os cátions $\mathrm{K}^{+}, \mathrm{Na}^{+}, \mathrm{Ca}^{2+}, \mathrm{Mg}^{2+}$, os açúcares glicose, frutose e sucrose e os ácidos orgânicos de amostras de sucos de laranja comerciais adquiridas no mercado tcheco de 1991-2001 para avaliar a autenticidade e a qualidade dos sucos, sendo observados casos de adulteração (Voldřich et al., 2002). Oito sucos de laranja integrais comerciais brasileiros foram analisados por Filli et al. (2003) para a determinação de $\mathrm{Ca}, \mathrm{Cu}, \mathrm{Fe}, \mathrm{K}, \mathrm{Mg}, \mathrm{Mn}, \mathrm{Na}, \mathrm{P}$ e Zn por espectrometria de emissão ótica com plasma indutivamente acoplado (ICP-OES).

\subsection{Análise por ativação neutrônica}

A análise por ativação neutrônica (NAA) é uma técnica analítica sensível utilizada para determinações multielementares em diferentes tipos de amostras (Glascock, 2004). Entre as modalidades de NAA, a análise por ativação neutrônica instrumental (INAA) é a mais difundida (Tagliaferro, 2002), pois permite determinação simultânea da maioria dos elementos contidos em uma amostra representativa com fidelidade e confiabilidade quando comparada a outras técnicas convencionais 
(Abugassa et al., 2004). A INAA é uma técnica de alto nível metrológico (Bode et al., 2000) que, por ser instrumental, não necessita de dissolução da amostra. No preparo das amostras, geralmente, utiliza-se de uma pequena quantidade de material, entre $100 \mathrm{mg}$ e $500 \mathrm{mg}$, para a obtenção de material fino, seco e homogêneo.

A NAA consiste na produção de radionuclídeos a partir da irradiação das amostras com nêutrons e posterior detecção da radioatividade induzida. Há diferentes tipos de reações que ocorrem pelo bombardeamento com nêutrons, sendo o mais comum a captura de um nêutron pelo nuclídeo alvo. A irradiação pode ocorrer em reatores nucleares de pesquisa ou mediante fonte de nêutrons, sendo o fluxo dos reatores mais elevado o que possibilita menores limites de detecção (Bacchi, 1993). A atividade produzida de um dado radionuclídeo depende do número de átomos do nuclídeo alvo presente na amostra, da intensidade do fluxo de nêutrons, do tempo de irradiação, da meia-vida do radionuclídeo formado e da probabilidade de ocorrência da reação (seção de choque).

Os radionuclídeos produzidos têm meias-vidas variando desde frações de segundos até vários anos, sendo a radioatividade medida por espectrometria de radiação gama, geralmente utilizando detectores semicondutores de germânio. Cada radionuclídeo emite raios gama com energias características, possibilitando a sua identificação. Os espectros produzidos são analisados por um software que localiza, identifica e calcula a área de cada pico (Bacchi \& Fernandes, 2003). A quantidade de eventos acumulados em um fotopico do radionuclídeo de interesse é utilizada para determinar a concentração do elemento na amostra. Existem diversas formas de padronização, sendo mais comum o uso de método comparativo, em que se irradia um padrão para cada elemento a ser determinado. Uma opção bastante empregada é o método $k_{0}$, que permite determinações multi-elementares pela irradiação de padrão para um único elemento. Esse método necessita de caracterização do fluxo de nêutrons e de calibração da eficiência de detecção. 


\section{MATERIAL E MÉTODOS}

\section{1 Área experimental}

O experimento foi realizado em duas propriedades que adotam distintamente o sistema de produção orgânico e o sistema de produção convencional de citros da região de Bebedouro, SP. A região de Bebedouro tem clima subtropical com uma temperatura média anual de 22,3 $3^{\circ}$ C. As propriedades distam aproximadamente $12 \mathrm{~km}$ entre si. Nas propriedades, tem-se a variedade de laranja Valência (Citrus sinensis L. Osbeck) enxertada sobre Limão Cravo (C. limonia Osbeck) com espaçamento de 7,0 m x 4,0 m. Os solos das duas áreas experimentais são de mesma classificação - Latossolo Vermelho Amarelo (LVA).

A propriedade que adota o sistema de produção orgânico é certificada desde 2003 pelo Instituto Biodinâmico - IBD e se localiza próximo da cidade de Monte Azul Paulista, SP. O IBD é acreditado pela IFOAM e com selo aceito nos mercados da Europa, Estados Unidos e Japão. O manejo desta propriedade é caracterizado pela adoção de adubos verdes, esterco de origem animal curtido e preparado com micronutrientes permitidos pela certificadora e legislação nacional, calda sulfocálcica para o controle de ácaros e outras pragas, roçadeira e carpa manual para o controle de plantas daninhas.

A propriedade convencional situada perto da cidade de Bebedouro utiliza, como manejo, fertilizantes sintéticos solúveis (NPK) e micronutrientes aplicados via foliar, agrotóxicos para o controle de pragas e doenças, roçadeira na entrelinha e herbicida na linha de cultivo. 


\subsection{Delineamento experimental e amostragem}

O delineamento experimental foi inteiramente ao acaso com 2 tratamentos (orgânico e convencional) e 30 repetições (plantas amostradas).

A coleta de amostras (solo, folha e fruto) na propriedade com citros orgânicos foi realizada no dia 15 de setembro de 2003 e 5 dias após na propriedade convencional.

Realizou-se a amostragem sistemática, isto é, amostrava-se uma planta ao acaso na primeira rua do talhão e andando em ziguezague pulavam-se 2 ruas amostrando-se outra planta. A coleta foi realizada em talhões homogêneos com relação à variedade, porta-enxerto, idade, declividade e textura do solo. Amostraram-se 30 plantas em cada sistema de cultivo (convencional e orgânico), sendo coletados folhas e frutos e também o solo sob a projeção das árvores.

\subsubsection{Solos}

Coletou-se 1 amostra composta de solo (1 sub-amostra a $50 \mathrm{~cm}$ para dentro da área de projeção da copa e 1 sub-amostra a 50 cm para fora da área de projeção da copa) por planta de 0 a $20 \mathrm{~cm}$ de profundidade.

As amostras foram acondicionadas em sacos plásticos identificados e encaminhadas ao Laboratório de Radioisótopos (CENA/USP), onde o solo foi seco em estufa a $80^{\circ} \mathrm{C}$ até atingir peso constante. A seguir, as amostras foram moídas em gral de porcelana, peneiradas $(1 \mathrm{~mm})$ e homogeneizadas.

Porções de $250 \mathrm{mg}$ das amostras foram transferidas para cápsulas de polietileno de alta pureza (6 $\mathrm{mm}$ de altura e $9 \mathrm{~mm}$ de diâmetro fabricadas pela Vrije Universiteit Amsterdam), apropriadas para a irradiação. Utilizaram-se dos materiais de referência certificados Soil-7 produzido pela International Atomic Energy Agency (IAEA) e Montana Soil (SRM-2711) produzido pelo National Institute of Standards and Techology (NIST) para controle da qualidade analítica. 


\subsubsection{Folhas}

Coletaram-se 25 folhas por planta, correspondendo a 5 folhas em cada quadrante na altura mediana e 5 folhas na parte interna da planta na altura mediana. Amostrou-se a terceira ou quarta folha do ramo com fruto (estágio de maturação).

As amostras foram acondicionadas em sacos plásticos identificados e encaminhadas ao Laboratório de Radioisótopos (CENA/USP), onde as folhas foram lavadas com água de torneira, secas em estufa a $60^{\circ} \mathrm{C}$ até atingir peso constante e moídas em moinho orbital de alumina.

Porções de $250 \mathrm{mg}$ das amostras foram transferidas para cápsulas de polietileno de alta pureza (12 mm de altura e $9 \mathrm{~mm}$ de diâmetro fabricadas pela Vrije Universiteit Amsterdam). Os materiais de referência certificados SRM-1515 (Apple Leaves), produzido

pelo NIST, Estados Unidos, e TL-1 (Tea Leaves) produzido pelo Institute of Nuclear Chemistry and Techology (INCT), Polônia. foram analisados juntamente com as amostras para controle da qualidade analítica.

\subsubsection{Sucos}

Coletaram-se 5 frutos por planta, sendo 1 fruto por quadrante (norte, sul, leste e oeste) e 1 fruto na parte interna da planta em uma altura mediana.

As amostras foram acondicionadas em sacos plásticos identificados e encaminhadas ao Laboratório de Radioisótopos (CENA/USP), onde os frutos foram lavados, o suco de laranja extraído com espremedor elétrico, acondicionado em ultra-freezer $\left(-80^{\circ} \mathrm{C}\right)$ e liofilizado (porções de $100 \mathrm{~mL}$ ) por $96 \mathrm{~h}$.

Porções de $150 \mathrm{mg}$ das amostras de suco de laranja liofilizado foram transferidas para cápsulas de polietileno (12 $\mathrm{mm}$ de altura e $9 \mathrm{~mm}$ de diâmetro fabricadas pela Vrije Universiteit Amsterdam). A amostra ocupou aproximadamente 50\% do volume da cápsula, como medida de segurança devido à temperatura atingida pelo material durante a 
irradiação. Para controle da qualidade analítica, foram analisados juntamente com as amostras os materiais de referência certificados V-10 (Hay Powder), produzido pela IAEA, Áustria, e TL-1 (Tea Leaves), produzido pelo Institute of Nuclear Chemistry and Techology (INCT), Polônia.

\subsection{Amostras oriundas do varejo}

Foram adquiridas amostras de sucos de laranja orgânicos e convencionais (Tabela 7) no mercado varejista do município de Piracicaba-SP, durante o mês de fevereiro de 2004. As amostras de suco de laranja orgânico concentrado congelado (SLOCC) da cooperativa COAGROSOL foram cedidas pela própria empresa. A amostragem constituiu de 11 amostras de sucos de laranja convencionais (integral, reconstituído e concentrado congelado) e 3 amostras de sucos de laranja orgânicos (reconstituído e concentrado congelado). As amostras foram armazenadas em geladeira ou freezer dependendo da necessidade de armazenamento do suco.

Tabela 7. Amostras de sucos de laranja comerciais adquiridas no varejo paulista

\begin{tabular}{ccccc}
\hline Marca & Categoria & Embalagem & Tipo & $\begin{array}{c}\text { Indústria } \\
\text { Processadora }\end{array}$ \\
\hline Native & Orgânico & Tetra Pak & Reconstituído & Usina Nova América \\
Maraú & Orgânico & Garrafa vidro & Reconstituído & Montecitrus \\
Coagrosol & Orgânico & Garrafa plástica & Concentrado congelado & Hildebrand \\
Lanjal & Convencional & Lata & Concentrado congelado & Global Bebidas \\
Yes & Convencional & Tetra Pak & Reconstituído & Cargill Agrícola S/A \\
Extra & Convencional & Tetra Pak & Integral e concentrado & Usina Nova América \\
Del Valle & Convencional & Tetra Pak & Reconstituído & Del Valle \\
Barateiro & Convencional & Tetra Pak & Reconstituído & Usina Nova América \\
Granja & Convencional & Tetra Pak & Integral e concentrado & Usina Nova América \\
Carrefour & Convencional & Tetra Pak & Integral & Cargill Agrícola S/A \\
Frutaki & Convencional & Tetra Pak & Reconstituído & Frugor \\
Santal & Convencional & Tetra Pak & Reconstituído & Parmalat \\
Danone & Convencional & Tetra Pak & Reconstituído & Usina Nova América \\
Salute & Convencional & Tetra Pak & Integral & Citrovita \\
\hline Obs: Os dato & & &
\end{tabular}

Obs: Os dados referentes ao tipo de suco e indústria processadora foram obtidos do rótulo do produto embalado. 
As amostras foram homogeneizadas e alíquotas de $100 \mathrm{~mL}$ (medidas em balão volumétrico) retiradas para a liofilização. A seguir, foram mantidas em congelador $\left(-18^{\circ} \mathrm{C}\right)$ e, posteriormente, levadas para um ultra-freezer $\left(-80^{\circ} \mathrm{C}\right)$, para atingir a temperatura adequada de liofilização. O tempo médio de liofilização de um lote de 6 amostras foi 96 horas e a temperatura do processo de liofilização variou de $-40^{\circ} \mathrm{C}$.

As primeiras amostras de SLCC liofilizadas não apresentaram resultados satisfatórios devido, principalmente, à formação de bolhas e derramamento de material. Dificuldade semelhante foi reportada por Kramer et al. (1988) que obteve bons resultados para o processo de liofilização quando adicionou-se o dobro da quantidade de água em relação à quantidade de suco concentrado. A temperatura do processo variou de $-40^{\circ} \mathrm{C}$ a $+20^{\circ} \mathrm{C}$ por 96 horas e 160 horas (bandejas com 12mm de suco). Pitombo (1999) obteve resultados satisfatórios para amostras de SLCC, utilizando porções de $5 \mathrm{~mL}$ de suco que foram congeladas e liofilizadas a $-40^{\circ} \mathrm{C}$ por 96 horas. Para o presente trabalho, adicionou-se $80 \mathrm{~mL}$ de água em $40 \mathrm{~mL}$ de suco de laranja concentrado congelado (orgânico e convencional).

\subsubsection{Calda sulfocálcica}

Foram adquiridas 3 amostras de calda sulfocálcica $(1 \mathrm{~L})$ da empresa Natural Rural de Araraquara-SP, produzidas pela Fertibom, Catanduva-SP, mesmo fornecedor da propriedade de citros orgânicos em estudo. Uma amostra de calda sulfocálcica em pó (1 kg) foi cedida por um produtor rural da região de Conchal-SP.

Foram retiradas alíquotas de $100 \mathrm{~mL}$, medidas em balão volumétrico, das amostras de calda sulfocálcica para determinação de sua densidade. A densidade média das 3 amostras de calda sulfocálcica foi 1,2333 $\pm 0,0003 \mathrm{~g} / \mathrm{mL}$.

As amostras foram homogeneizadas e alíquotas de $50 \mathrm{~mL}$ colocadas em pequenas bandejas plásticas e mantidas em estufa a $60^{\circ} \mathrm{C}-70^{\circ} \mathrm{C}$ por 28 horas. Um segundo procedimento adotado consistiu na retirada de três alíquotas de $50 \mathrm{~mL}$ de cada amostra, que foram colocadas em placa de petri e aquecidas com bico de bunsen por aproximadamente 1 hora para obtenção da calda sulfocálcica seca. 
Porções de 200 mg das amostras foram transferidas para cápsulas de polietileno de alta pureza (9 $\mathrm{mm}$ de altura e $9 \mathrm{~mm}$ de diâmetro fabricadas pela Vrije Universiteit Amsterdam), apropriadas para a irradiação. Foram utilizados os materiais de referência certificados Soil-7 da IAEA e Montana Soil (SRM-2711) do NIST para controle da qualidade analítica.

\subsection{Análise por ativação neutrônica}

As amostras foram enviadas ao Instituto de Pesquisas Energéticas e Nucleares (IPEN/CNEN), São Paulo, e irradiadas por 8 horas para folhas e sucos de laranja e 4 horas para solo e calda sulfocálcica, sob fluxo de nêutrons térmicos da ordem de $9 \times 10^{12} \mathrm{~cm}^{-2} \mathrm{~s}^{-1}$ no reator nuclear de pesquisa IEA-R1m. A radioatividade induzida foi medida no Laboratório de Radioisotópos do CENA/USP por espectrometria gama de alta resolução, empregando-se detectores de germânio hiperpuro da Ortec, modelos GEM45190 e GMX50220, com eficiências relativas de 45\% e 55\% no fotopico $1332 \mathrm{keV}$ do ${ }^{60}$ Co, além do modelo GWL22015, tipo poço com volume ativo de $249 \mathrm{~cm}^{3}$. Para melhor detecção de radionuclídeos com diferentes meias-vidas, foram realizadas quatro medições para cada amostra, com tempos de decaimento aproximados de 3, 7, 15 e 30 dias. As concentrações dos elementos químicos foram calculadas pelo método $k_{0}$, utilizando procedimento descrito por Bacchi et al. (2000). A avaliação dos espectros e todos os cálculos das concentrações foram realizados pelo programa de computador Quantu (Bacchi \& Fernandes, 2003).

Após testes iniciais com amostras de sucos de laranja liofilizados, observou-se que a faixa do fluxo de nêutrons térmicos mais adequada para a irradiação deste tipo de material foi da ordem de $7,5 \times 10^{12} \mathrm{~cm}^{-2} \mathrm{~s}^{-1}$ a $9,5 \times 10^{12} \mathrm{~cm}^{-2} \mathrm{~s}^{-1}$ por 8 horas.

\subsection{Análise estatística}

Empregaram-se as técnicas de análise estatística descritiva e estatísticas de análise de variância (ANOVA) de caráter univariado, considerada independentemente, para as amostras de sucos de laranja, folhas e solos. Foram testadas as hipóteses de igualdade de composição elementar entre as amostras de folhas e sucos oriundos de 
propriedades com o sistema de produção orgânico e convencional. Foram também realizadas análises de componentes principais - PCA de caráter multivariado (MANOVA). Para realização das análises estatísticas foi utilizado o pacote estatístico Statistical Analysis System (SAS Institute Inc., 1996). 


\section{RESULTADOS E DISCUSSÃO}

\subsection{Solo}

Pela análise univariada (teste F de Fisher) observou-se diferença significativa (em nível de confiança de 99\%) entre os solos Latossolo Vermelho Amarelo (LVA) dos dois sistemas de produção para As, Br, Co, Cr, Cs, Eu, Fe, K, La, Na, Nd, Sc, Sm, Ta, Tb e Th. As amostras de LVA sob sistema convencional apresentaram maiores concentrações de As, $\mathrm{Br}, \mathrm{Fe}, \mathrm{Sc}$, Ta e Th, enquanto as concentrações de Co, Cr, Cs, K, La, Na, Rb, Sm, Sr, Tb e Yb foram maiores para as amostras de solo LVA sob sistema orgânico (Tabela 8).

Tabela 8. Concentração e desvio padrão (mg.kg-1 $)$ dos elementos químicos determinados em 30 amostras de solos sob sistema de produção orgânico (1) e convencional (2)

\begin{tabular}{cccccccc}
\hline & $\mathbf{A s}$ & $\mathbf{B r}$ & $\mathbf{C e}$ & $\mathbf{C o}$ & $\mathbf{C r}$ & $\mathbf{C s}$ & $\mathbf{E u}$ \\
\hline $\mathbf{1}$ & 1,6 & 2,8 & 90 & 5,8 & 139 & 1,2 & 1,2 \\
& 0,2 & 0,4 & 14 & 0,8 & 21 & 0,2 & 0,2 \\
$\mathbf{2}$ & 3,6 & 4,0 & 87 & 3,2 & 115 & 0,71 & 0,64 \\
& 0,3 & 0,5 & 7 & 0,2 & 13 & 0,07 & 0,05 \\
\hline \multirow{2}{*}{$\mathbf{1}$} & $\mathbf{F e}$ & $\mathbf{H f}$ & $\mathbf{K}$ & $\mathbf{L a}$ & $\mathbf{N a}$ & $\mathbf{N d}$ & $\mathbf{S c}$ \\
& 23310 & 11 & 2421 & 41 & 171 & 35 & 7,2 \\
$\mathbf{2}$ & 2204 & 1,7 & 1299 & 6,8 & 84 & 6,5 & 1,2 \\
& 27942 & 12 & 289 & 24 & 44 & 19 & 9,0 \\
& 1694 & 1,4 & 82 & 2,6 & 6 & 2,7 & 0,7 \\
\hline \multirow{2}{*}{$\mathbf{1}$} & $\mathbf{S m}$ & $\mathbf{T a}$ & $\mathbf{T b}$ & $\mathbf{T h}$ & $\mathbf{U}$ & $\mathbf{Y b}$ & $\mathbf{Z n}$ \\
& 5,0 & 2,2 & 0,48 & 9,9 & 1,7 & 1,7 & 34 \\
$\mathbf{2}$ & 0,9 & 0,3 & 0,08 & 1,8 & 0,3 & 0,2 & 5,4 \\
& 2,6 & 2,9 & 0,28 & 12 & 1,8 & 1,5 & 32 \\
& 0,3 & 0,3 & 0,05 & 0,8 & 0,3 & 0,3 & 4,9 \\
\hline
\end{tabular}

Os valores mais discrepantes entre os solos sob cultivo orgânico e cultivo convencional ocorreram para K (aproximadamente 9 vezes, $2421 \pm 1299 \mathrm{mg} \cdot \mathrm{kg}^{-1}$ e $289 \pm$ $82 \mathrm{mg} . \mathrm{kg}^{-1}$ ) e para Na (aproximadamente 4 vezes, $171 \pm 84 \mathrm{mg} \cdot \mathrm{kg}^{-1}$ e $44 \pm 6 \mathrm{mg} \cdot \mathrm{kg}^{-1}$ ). 
A concentração de Cr de $139 \pm 3,5$ mg. $\mathrm{kg}^{-1}$ no solo conduzido sob sistema de produção orgânico foi maior que a concentração máxima de $100 \mathrm{mg} \cdot \mathrm{kg}^{-1}$ permitida pelo IBD (Tabela 9). Contudo, outros solos brasileiros, como o da Mata de Santa Genebra da região de Campinas, apresentaram concentrações entre 105 - $110 \mathrm{mg} \cdot \mathrm{kg}^{-1}$ na profundidade de 0-10 cm (França et al., 2003). Mesmo sendo um solo sob floresta nativa, sem interferência antropogênica, a concentração de cromo foi superior a $100 \mathrm{mg} \cdot \mathrm{kg}^{-1}$. Segundo o Relatório de Estabelecimento de Valores Orientados para Solos e Águas Subterrâneas no Estado de São Paulo da Companhia de Tecnologia de Saneamento Ambiental (CETESB, 2001), o valor máximo permitido para o Cr em solos agrícolas é $300 \mathrm{mg} \cdot \mathrm{kg}^{-1}$, sendo $75 \mathrm{mg} \cdot \mathrm{kg}^{-1}$ o valor de alerta, isto é, o limite a partir do qual a área deve ser monitorada. É importante considerar outros fatores (tipos de solo, teor de argila e $\mathrm{pH}$ ) para estabelecer limites de metais pesados no solo para a agricultura orgânica no Brasil.

Tabela 9. Concentrações máximas de metais pesados em solos, segundo o Instituto Biodinâmico (IBD, 2004)

\begin{tabular}{cc}
\hline Elemento & Concentração máxima $\left(\mathrm{mg}^{\mathrm{kg}} \mathrm{kg}^{-1}\right)$ \\
\hline Cádmio & 1,5 \\
Cobre & 60 \\
Níquel & 25 \\
Chumbo & 100 \\
Zinco & 200 \\
Mercúrio & 1 \\
Cromo & 100 \\
\hline
\end{tabular}




\subsection{Folhas}

As concentrações médias de 20 elementos determinados em 30 amostras de folhas para cada sistema de produção, orgânico e convencional, são apresentadas na Tabela 10.

Tabela 10. Concentração média e desvio padrão (mg. $\mathrm{kg}^{-1}$ ) dos elementos químicos determinados em 30 amostras de folhas de laranjeira dos sistemas de produção orgânico (Org.) e convencional (Conv.)

\begin{tabular}{lcccccccccc}
\hline & $\mathbf{B a}$ & $\mathbf{B r}$ & $\mathbf{C a}$ & $\mathbf{C e}$ & $\mathbf{C o}$ & $\mathbf{C s}$ & $\mathbf{E u}$ & $\mathbf{F e}$ & $\mathbf{K}$ & $\mathbf{L a}$ \\
\hline Org. & 235 & 13 & 35900 & 13 & 0,22 & 0,036 & 0,5 & 204 & 13500 & 27 \\
& 90 & 3,0 & 4500 & 6,0 & 0,05 & 0,011 & 0,2 & 60 & 2400 & 12 \\
Conv. & 70 & 6,8 & 32800 & 5,9 & 0,039 & 0,062 & 0,09 & 194 & 9700 & 8,3 \\
& 20 & 1,2 & 2300 & 1,4 & 0,008 & 0,015 & 0,02 & 50 & 1800 & 1,9 \\
\hline & $\mathbf{N a}$ & $\mathbf{N d}$ & $\mathbf{R b}$ & $\mathbf{S c}$ & $\mathbf{S m}$ & $\mathbf{S r}$ & $\mathbf{T b}$ & $\mathbf{T h}$ & $\mathbf{Y b}$ & $\mathbf{Z n}$ \\
\hline Org. & 70 & 21 & 11 & 0,05 & 2,1 & 260 & 0,20 & 0,036 & 0,26 & 26 \\
& 50 & 8,0 & 2,0 & 0,02 & 0,9 & 70 & 0,07 & 0,016 & 0,08 & 5,0 \\
Conv. & 59 & 4,6 & 4,0 & 0,05 & 0,40 & 137 & 0,036 & 0,039 & 0,05 & 38 \\
& 8,0 & 1,1 & 1,0 & 0,02 & 0,11 & 15 & 0,009 & 0,013 & 0,01 & 7,0 \\
\hline
\end{tabular}

As amostras de folhas oriundas do sistema de produção convencional apresentaram maiores concentrações de Cs e Zn, enquanto as concentrações de $\mathrm{Ba}, \mathrm{Br}$, Ce, Co, Eu, K, La, $\mathrm{Nd}, \mathrm{Rb}, \mathrm{Sm}, \mathrm{Sr}, \mathrm{Tb}$ e Yb foram maiores para as amostras de folhas do sistema de produção orgânico. Diferenças significativas (teste F de Fisher - em nível de confiança de 99\%) foram observadas entre as folhas dos dois sistemas de produção para $\mathrm{Ba}, \mathrm{Br}, \mathrm{Ce}, \mathrm{Co}, \mathrm{Cs}$, Eu, K, La, Nd, Rb, Sm, Sr, Tb, Yb e Zn. As maiores diferenças de concentração (acima de 5 vezes) entre o sistema de produção orgânico e o sistema de produção convencional foram verificadas para os elementos Co (0,22 mg. $\mathrm{kg}^{-1}-0,039$ mg. $\left.\mathrm{kg}^{-1}\right)$, Eu (0,5 mg.kg-1 - 0,09 mg.kg $\left.{ }^{-1}\right)$, Sm (2,1 mg.kg-1 $-0,4$ mg.kg-1 $)$, Tb (0,20 mg.kg-1 - 0,036 mg.kg $\left.{ }^{-1}\right)$ e Yb (0,26 mg.kg ${ }^{-1}-0,05$ mg.kg $\left.{ }^{-1}\right)$. 
Concentrações consideráveis de elementos terras raras foram encontradas nas amostras de folhas de citros, principalmente aquelas oriundas do sistema de produção orgânico (Tabela 11).

Tabela 11. Concentração média e desvio padrão (mg.kg-1) de elementos terras raras em folhas de laranjeira sob sistema de produção orgânico (org.) e convencional (conv.), de Pachystroma longifolium (França et al., 2002) e de Sphagnum sp (Markert \& Li ,1991). * limites de valores

\begin{tabular}{ccccc}
\hline & Citrus (org.) & Citrus (conv.) & $\begin{array}{c}\text { Pachystroma } \\
\text { longifolium }\end{array}$ & Sphagnum sp* \\
\hline $\mathrm{Ce}$ & $13 \pm 6$ & $5,9 \pm 1,4$ & $12,3 \pm 0,3$ & $0,25-0,55$ \\
$\mathrm{Eu}$ & $0,5 \pm 0,2$ & $0,09 \pm 0,02$ & $0,178 \pm 0,008$ & $0,005-0,015$ \\
$\mathrm{La}$ & $27 \pm 12$ & $8,3 \pm 1,9$ & $16,4 \pm 0,4$ & $0,15-0,25$ \\
$\mathrm{Nd}$ & $21 \pm 8,0$ & $4,6 \pm 1,1$ & $8,00 \pm 0,10$ & $0,1-0,25$ \\
$\mathrm{Sm}$ & $2,1 \pm 0,9$ & $0,40 \pm 0,11$ & $0,79 \pm 0,04$ & $0,02-0,04$ \\
$\mathrm{~Tb}$ & $0,20 \pm 0,07$ & $0,036 \pm 0,009$ & $0,087 \pm 0,008$ & $0,005-0,015$ \\
$\mathrm{Yb}$ & $0,26 \pm 0,08$ & $0,05 \pm 0,01$ & $0,140 \pm 0,005$ & $0,015-0,030$ \\
\hline
\end{tabular}

A concentração de elementos terras raras para Sphagnum sp foi 3 vezes maior que a concentração média das demais plantas investigadas (Markert \& Li, 1991). A razão folha/solo de La para Pachystroma longifolium foi 0,69 e para Sphagnum sp, considerada bioacumuladora de elementos terras raras, foi 0,21. A razão média folha/solo de La para amostras oriundas do sistema de produção orgânico foi 0,68 , valor próximo do obtido por França et al. (2002) para Pachystroma longifolium.

A média das razões folha/solo da propriedade com sistema de produção orgânico foram significativamente superiores (teste F de Fisher - em nível de confiança de 99\%), exceção para Sc, para todos os elementos em relação ao sistema de produção convencional (Tabela 12). Este fato sugere que outros fatores podem influenciar a concentração de elementos terras raras em citros. 
Tabela 12. Média das razões $(n=30)$ folha/solo dos elementos terras raras determinados nos sistemas de produção orgânico (Org) e convencional (Conv)

\begin{tabular}{cccccccc}
\hline & Ce & Eu & La & Nd & Sm & Tb & Yb \\
\hline Org & 0,15 & 0,45 & 0,68 & 0,63 & 0,44 & 0,44 & 0,15 \\
& 0,075 & 0,2 & 0,32 & 0,29 & 0,2 & 0,17 & 0,05 \\
Conv & 0,07 & 0,13 & 0,35 & 0,25 & 0,15 & 0,13 & 0,032 \\
& 0,02 & 0,05 & 0,09 & 0,09 & 0,05 & 0,05 & 0,011 \\
\hline
\end{tabular}

A concentração média de La de $27 \pm 12 \mathrm{mg} \cdot \mathrm{kg}^{-1}$ em folhas oriundas do sistema de produção orgânico situa-se na faixa de concentração (10 a 78 mg.kg-1) observada por Wutscher \& Perkins (1993). Normalmente, em matrizes geológicas, os elementos terras raras possuem correlação positiva com o Sc, um indicador da presença de terra em amostras de plantas (Fernandes, 1992). As concentrações de Sc nas folhas de citros foram semelhantes para ambos os sistemas de produção. No entanto, as concentrações dos elementos terras raras foram significativamente maiores nas folhas de citros sob sistema de produção orgânico. Para averiguar uma possível contaminação por solo em relação aos elementos terras raras presentes nas folhas de laranjeira orgânica, realizou-se uma matriz de correlação residual (Tabela 13). A correlação significativa $(\mathrm{p}<0,001)$ de Sc com Fe $(\mathrm{r}=0,97)$ e Th $(\mathrm{r}=0,98)$ sugerem que suas concentrações estejam relacionadas com partículas de solo aderidas às folhas (Fernandes 1988; 1992). Segundo Bacchi (1993), os elementos Hf, Fe e Th apresentaram alta correlação com Sc confirmando serem potenciais traçadores da presença de solo em amostras de cana-deaçúcar do processamento industrial para produção de açúcar e etanol. Não houve correlação dos elementos Ce, Eu, La, Nd, Sm, Tb e Yb com o Sc, nas amostras de folhas para o sistema de produção orgânico, o que indica que os elementos terras raras nas folhas podem ter sido absorvidos.

Uma observação de destaque é a correlação existente entre o Ca e os elementos terras raras, fato esse que leva a supor que tenham sido originados da calda sulfocálcica que é aplicada várias vezes nos laranjais orgânicos. 
Tabela 13. Coeficiente de correlação residual entre os 20 elementos químicos determinados nas 30 amostras de folhas de laranjeira orgânica analisadas. Valores entre parênteses indicam a probabilidade (p) com que a hipótese $r=0$ (que os dados não estão correlacionados) é rejeitada

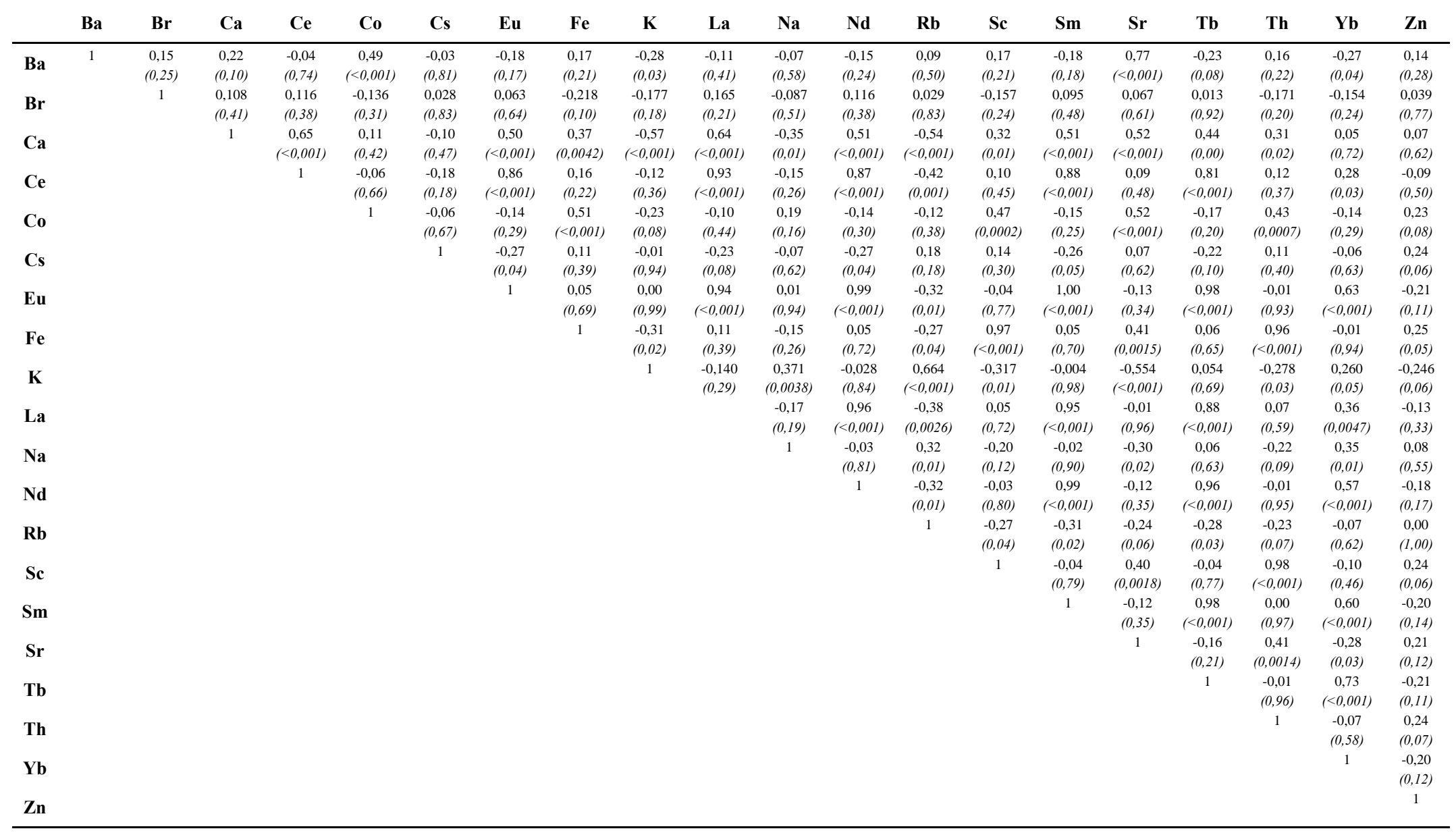


A análise dos componentes principais (PCA) permitiu a visualização da discriminação dos sistemas de produção. Foram consideradas todas as amostras de folhas do estudo, tendo-se como variáveis os sistemas de produção. A Figura 2 apresenta um gráfico de dispersão utilizando todos os elementos, com os dois primeiros componentes respondendo, respectivamente, por 55,4\% e 17,4\% da variação total. Os elementos $\mathrm{Ba}, \mathrm{Br}$, $\mathrm{Ca}, \mathrm{Ce}, \mathrm{Co}, \mathrm{Tb}$ e $\mathrm{Yb}$ foram os de maior contribuição no processo discriminatório.

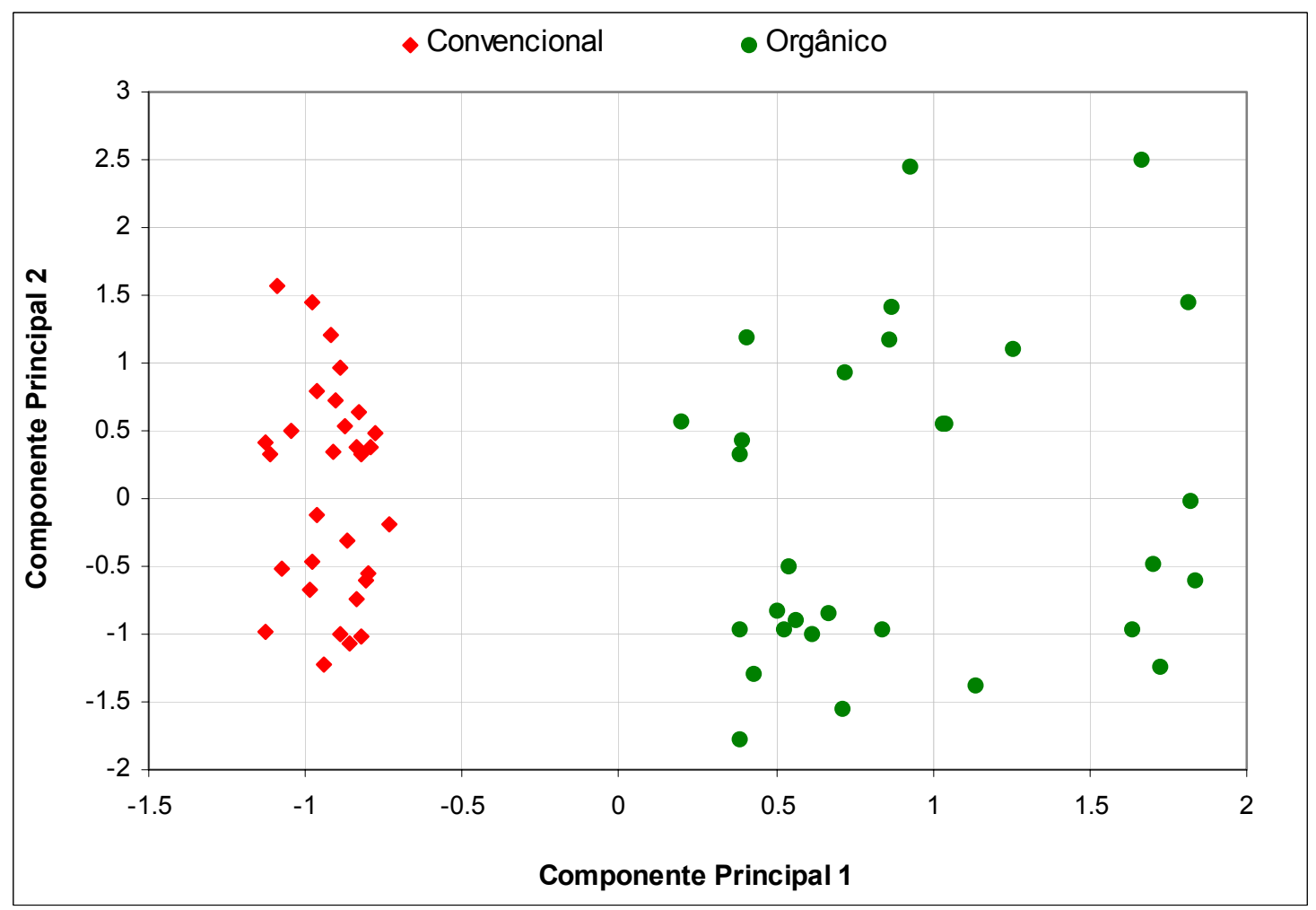

Figura 2 - Gráfico de dispersão com o primeiro e o segundo componentes principais (72,8 \% de informação total) para folhas 


\subsection{Sucos}

As concentrações médias de 10 elementos determinados em amostras de sucos para cada sistema de produção, orgânico e convencional, são apresentadas na Tabela 14.

Os valores de concentração obtidos nas amostras de sucos de laranja da variedade Valência (Tabela 14) ficaram próximos aos reportados por Simpkins et al. (2000) para Ca $\left(828 \pm 214 \mathrm{mg} \cdot \mathrm{kg}^{-1}\right), \mathrm{K}\left(16760 \pm 2930 \mathrm{mg} \cdot \mathrm{kg}^{-1}\right), \mathrm{Rb}\left(9,6 \pm 1,4 \mathrm{mg} \cdot \mathrm{kg}^{-1}\right)$ e $\mathrm{Zn}(3,3 \pm$ $\left.1,1 \mathrm{mg} \cdot \mathrm{kg}^{-1}\right)$.

Tabela 14. Concentração média e desvio padrão (mg.kg-1 matéria seca) dos elementos químicos determinados em amostras de suco de laranja dos sistemas de produção orgânico (Org. n=29) e convencional (Conv. n=30)

\begin{tabular}{|c|c|c|c|c|c|c|c|c|c|c|}
\hline & $\mathrm{Br}$ & $\mathbf{C a}$ & Co & Cs & $\mathbf{F e}$ & $\mathbf{K}$ & La & $\mathbf{N a}$ & $\mathbf{R b}$ & $\mathrm{Zn}$ \\
\hline Org & $\begin{array}{c}3,79 \\
1,32\end{array}$ & $\begin{array}{c}948 \\
217\end{array}$ & $\begin{array}{c}0,016 \\
0,006\end{array}$ & $\begin{array}{c}0,049 \\
0,026\end{array}$ & $\begin{array}{c}5,75 \\
1,11\end{array}$ & $\begin{array}{c}13865 \\
1529\end{array}$ & $\begin{array}{c}0,066 \\
0,034\end{array}$ & $\begin{array}{r}4,35 \\
1,57\end{array}$ & $\begin{array}{c}23,5 \\
4,9\end{array}$ & $\begin{array}{c}3,91 \\
1,69\end{array}$ \\
\hline Conv & $\begin{array}{c}0,54 \\
0,10\end{array}$ & $\begin{array}{r}532 \\
128\end{array}$ & $\begin{array}{c}0,005 \\
0,002\end{array}$ & $\begin{array}{c}0,12 \\
0,03\end{array}$ & $\begin{array}{c}6,16 \\
2,33\end{array}$ & $\begin{array}{c}13672 \\
1358\end{array}$ & $\begin{array}{c}0,03 \\
0,02\end{array}$ & $\begin{array}{r}5,54 \\
1,82\end{array}$ & $\begin{array}{c}13,1 \\
2,0\end{array}$ & $\begin{array}{r}4,40 \\
1,89\end{array}$ \\
\hline
\end{tabular}

As amostras de suco de laranja oriundas do sistema de produção convencional apresentaram maiores concentrações de Cs, Fe, Na e Zn, enquanto as concentrações de Br, Ca, Co, K, La e Rb foram maiores para as amostras de suco do sistema de produção orgânico. A concentração de bromo apresentou valores em torno de 7 vezes maiores no suco de laranja orgânico. Diferenças significativas (teste F de Fisher - em nível de confiança de 99\%) para $\mathrm{Br}$, Ca, Co, Cs, La e Rb foram observadas entre as amostras de suco de laranja dos dois sistemas de produção.

A análise de componentes principais permitiu a visualização da discriminação dos dois sistemas de produção. Foram consideradas 29 amostras de sucos de laranja para cada sistema de produção (variável). A Figura 3 apresenta um gráfico de dispersão com o primeiro e o segundo componentes, que respondem, respectivamente, por 40,3\% e 19,5\% da variação total. Os elementos $\mathrm{Br}$, Ca, Co, La, Rb e K foram os melhores discriminantes de sucos orgânicos de sucos convencionais. 


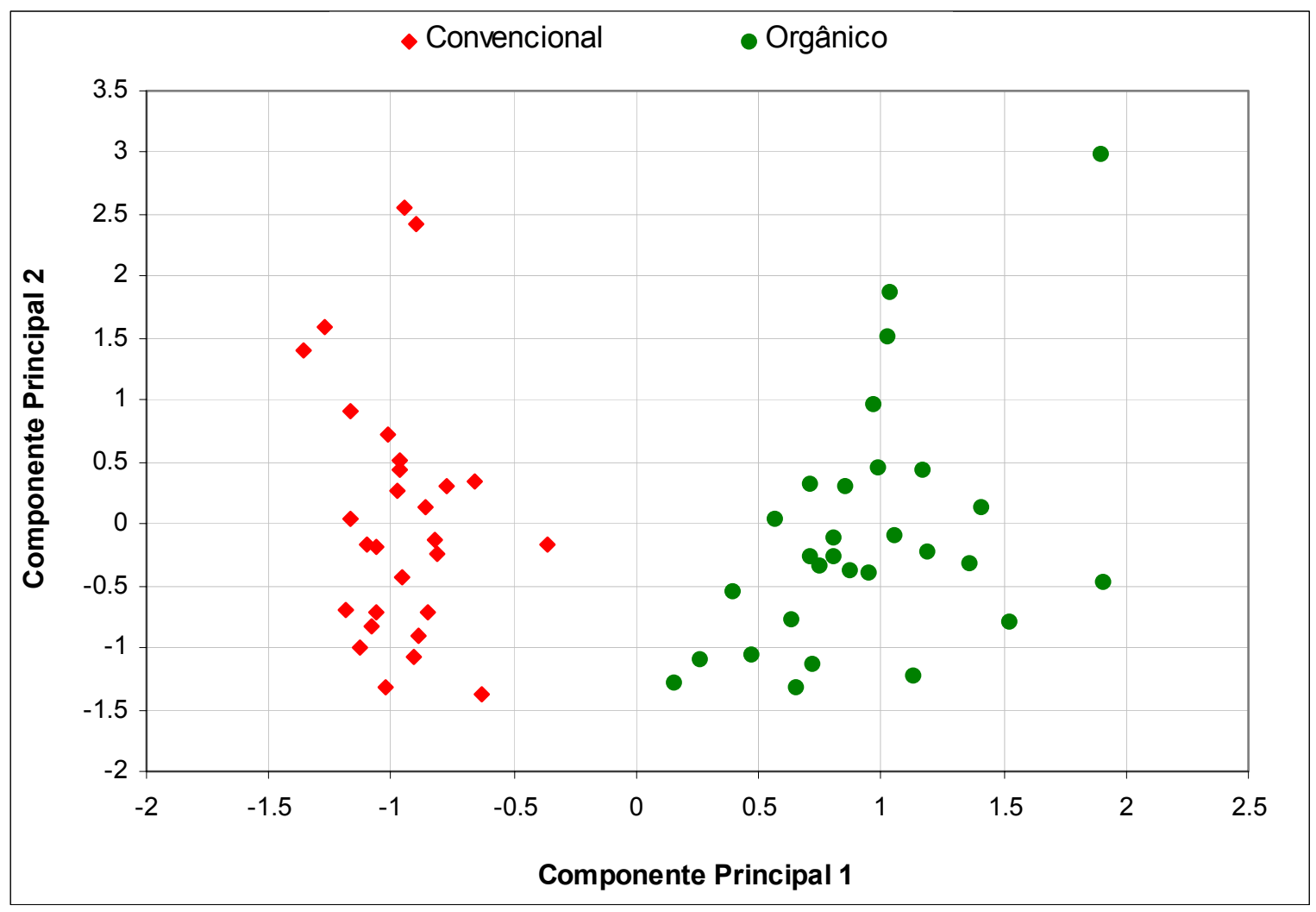

Figura 3 - Gráfico de dispersão para amostras de sucos de laranja provenientes dos sistemas de produção orgânico e convencional, com primeiro e segundo componentes principais (59,8 \% de informação total)

\subsection{Sucos comerciais}

As concentrações médias de 11 elementos determinados em amostras de sucos comerciais orgânicos (3 amostras) e convencionais (11 amostras) são apresentadas na Tabela 15.

Mediante análise estatística (teste F de Fisher), os sucos orgânicos (Coagrosol, Maraú e Native) diferiram significativamente (em nível de confiança de 99\%) dos sucos convencionais para $\mathrm{Br}$. 
Tabela 15. Concentração média $(\mathrm{n}=42)$ e desvio padrão $\left(\mathrm{mg} \cdot \mathrm{kg}^{-1}\right)$ dos elementos químicos determinados em amostras de sucos comerciais orgânico (o) e convencional (c). Valores com “<” indicam um valor abaixo do limite de detecção

\begin{tabular}{|c|c|c|c|c|c|c|c|c|c|c|c|}
\hline Marca & $\mathrm{Br}$ & $\mathbf{C a}$ & Co & Cs & $\mathrm{Fe}$ & $\mathbf{K}$ & La & $\mathbf{N a}$ & $\mathbf{R b}$ & Sc & $\mathbf{Z n}$ \\
\hline \multirow[t]{2}{*}{ Extra } & 1,03 & 542 & 0,008 & 0,15 & 8,8 & 15458 & 0,029 & 129 & 10,4 & $<0,00052$ & 3,73 \\
\hline & 0,31 & 213 & 0,003 & 0,045 & 3,0 & 4730 & 0,008 & 40 & 3,3 & 0,00007 & 1,16 \\
\hline \multirow[t]{2}{*}{ Granja } & 1,18 & 441 & 0,012 & 0,17 & 8,4 & 15889 & 0,027 & 119 & 12,8 & $<0,00049$ & 3,31 \\
\hline & 0,004 & 55 & 0,002 & 0,001 & 0,3 & 259 & 0,002 & 1 & 0,1 & 0,00013 & 0,29 \\
\hline \multirow[t]{2}{*}{ Carref. } & 1,44 & 559 & 0,011 & 0,06 & 5,3 & 14305 & 0,030 & 17 & 17,5 & $<0,00018$ & 2,80 \\
\hline & 0,03 & 28 & 0,0002 & 0,002 & 0,7 & 296 & 0,003 & 1 & 0,2 & 0,00001 & 0,21 \\
\hline \multirow[t]{2}{*}{ Salute } & 0,84 & 708 & 0,010 & 0,15 & 8,3 & 14969 & 0,031 & 113 & 10,8 & $<0,00047$ & 3,09 \\
\hline & 0,05 & 54 & 0,001 & 0,007 & 2,0 & 605 & 0,001 & 3 & 0,9 & 0,00013 & 0,13 \\
\hline \multirow[t]{2}{*}{ Barateiro } & 0,94 & 483 & 0,006 & 0,11 & 8,4 & 13032 & 0,024 & 113 & 10,6 & $<0,00066$ & 2,98 \\
\hline & 0,04 & 73 & 0,001 & 0,013 & 1,4 & 174 & 0,005 & 3 & 0,1 & 0,00000 & 0,25 \\
\hline \multirow[t]{2}{*}{ Frutaki } & 0,99 & 254 & 0,008 & 0,06 & 4,4 & 8481 & 0,019 & 97 & 8,1 & $<0,00042$ & 1,74 \\
\hline & 0,01 & 33 & 0,003 & 0,028 & 0,9 & 2830 & 0,002 & 12 & 0,3 & 0,00004 & 0,40 \\
\hline \multirow[t]{2}{*}{ Del Valle } & 0,73 & 42 & $<0,002$ & 0,08 & 6,1 & 7750 & 0,014 & 510 & 11,2 & $<0,00053$ & 3,47 \\
\hline & 0,03 & 28 & 0,000 & 0,001 & 0,6 & 155 & 0,005 & 3 & 0,1 & 0,00010 & 0,26 \\
\hline \multirow[t]{2}{*}{ Danone } & 1,11 & 319 & 0,013 & 0,09 & 5,9 & 11612 & 0,023 & 118 & 8,8 & $<0,00053$ & 2,24 \\
\hline & 0,04 & 87 & 0,006 & 0,036 & 1,2 & 3239 & 0,006 & 15 & 0,2 & 0,00012 & 0,48 \\
\hline \multirow[t]{2}{*}{ Yes } & 1,80 & 778 & 0,011 & 0,08 & 6,1 & 13687 & 0,037 & 94,9 & 17,1 & $<0,00025$ & 3,09 \\
\hline & 0,01 & 30 & 0,0066 & 0,004 & 1,04 & 158 & 0,006 & 0,2 & 0,4 & 0,00004 & 0,06 \\
\hline \multirow[t]{2}{*}{ Santal } & 0,96 & 677 & 0,0059 & 0,07 & 8,7 & 9906 & 0,011 & 81 & 9,8 & $<0,00036$ & 2,47 \\
\hline & 0,01 & 199 & 0,0011 & 0,002 & 1,96 & 62 & 0,002 & 0 & 0,1 & 0,00009 & 0,12 \\
\hline \multirow[t]{2}{*}{ Lanjal } & 0,90 & 447 & 0,015 & 0,04 & 22,8 & 6791 & 0,030 & 83 & 8,2 & 0,02413 & 1,75 \\
\hline & 0,009 & 76 & 0,002 & 0,001 & 0,3 & 12 & 0,007 & 2 & 0,1 & 0,00041 & 0,09 \\
\hline \multirow[t]{2}{*}{ Média (c) } & 1.08 & 511 & 0.009 & 0.10 & 8.5 & 11989 & 0.025 & 134 & 11 & 0.003 & 2.8 \\
\hline & 0.31 & 185 & 0.005 & 0.04 & 4.9 & 3676 & 0.009 & 123 & 3.3 & 0.007 & 0.8 \\
\hline \multirow[t]{2}{*}{ Coagrosol } & 2,73 & 508 & 0,007 & 0,06 & 10,7 & 13960 & 0,022 & 10 & 17,4 & $<0,00031$ & 3,0 \\
\hline & 0,07 & 15 & 0,0001 & 0,001 & 1,1 & 170 & 0,004 & 2 & 0,5 & 0,00007 & 0,12 \\
\hline \multirow[t]{2}{*}{ Maraú } & 2,70 & 588 & 0,014 & 0,08 & 11,0 & 15528 & 0,028 & 67 & 16,0 & $<0,00054$ & 3,12 \\
\hline & 0,27 & 54 & 0,007 & 0,001 & 1,9 & 474 & 0,001 & 28 & 0,4 & 0,00002 & 0,37 \\
\hline \multirow[t]{2}{*}{ Native } & 2,21 & 747 & 0,010 & 0,06 & 6,2 & 14443 & 0,019 & 146 & 7,1 & $<0,00032$ & 2,99 \\
\hline & 0,04 & 148 & 0,002 & 0,001 & 0,8 & 112 & 0,001 & 3 & 0,2 & 0,00007 & 0,44 \\
\hline \multirow[t]{2}{*}{ Média (o) } & 2.6 & 614 & 0.010 & 0.071 & 9.3 & 14644 & 0.023 & 74 & 14 & 0.00032 & 3.05 \\
\hline & 0.3 & 135 & 0.005 & 0.007 & 2.5 & 720 & 0.005 & 58 & 4.6 & 0.00015 & 0.31 \\
\hline
\end{tabular}


Os valores de concentração obtidos nas amostras de SLCC (Lanjal e Coagrosol) ficaram próximos aos reportados por Simpkins et al. (2000) para Ca (441 \pm 13 mg.kg $\left.{ }^{-1}\right), \mathrm{K}$ $\left(10569 \pm 936 \mathrm{mg} \cdot \mathrm{kg}^{-1}\right), \mathrm{Rb}\left(13,33 \pm 3,25 \mathrm{mg} \cdot \mathrm{kg}^{-1}\right)$ e $\mathrm{Zn}\left(1,76 \pm 0,59 \mathrm{mg} \cdot \mathrm{kg}^{-1}\right)$ para amostras de SLCC brasileiros. McHard et al. (1976) analisando SLCC da Flórida obteve os valores médios de Ca (923 mg.kg-1 com variação de 850-1050), Na (43 mg.kg ${ }^{-1}$ com variação de 21 a 90), K (18630 mg. $\mathrm{kg}^{-1}$ com variação 17750 a 19250), Zn (3,7 mg. $\mathrm{kg}^{-1}$ com variação 3,3 a 3,8) condizentes com os resultados obtidos (Tabela 15).

O suco da marca Del Valle apresentou a maior concentração média de sódio (510 mg.kg $\left.{ }^{-1}\right)$ e a menor concentração média de bromo $\left(0,73 \mathrm{mg} \cdot \mathrm{kg}^{-1}\right)$. Constituiu-se um outlier para sódio (mais de 5 vezes maior que a média dos sucos reconstituídos convencionais $\left.94 \mathrm{mg} \cdot \mathrm{kg}^{-1}\right)$.

O sódio apresentou concentrações variando desde $10 \mathrm{mg} \cdot \mathrm{kg}^{-1}$ (suco Coagrosol) a 510 mg. $\mathrm{kg}^{-1}$ (suco Del Valle). O suco de laranja Lanjal (SLCC) foi o único que apresentou uma concentração de escândio $\left(0,024 \mathrm{mg} \cdot \mathrm{kg}^{-1}\right)$ acima do limite de detecção para as 3 amostras e a maior de ferro (22,8 mg. $\left.\mathrm{kg}^{-1}\right)$, indicando que pode ter ocorrido contaminação por terra. O suco Yes apresentou as maiores concentrações de cálcio (778 mg. $\mathrm{kg}^{-1}$ ) e lantânio $\left(0,037 \mathrm{mg} \cdot \mathrm{kg}^{-1}\right)$.

O suco Coagrosol apresentou a menor concentração de sódio (10 mg. $\left.\mathrm{kg}^{-1}\right)$ e a maior de bromo (2,7 mg. $\left.\mathrm{kg}^{-1}\right)$.

É importante salientar que não há divulgação nos rótulos dos sucos de laranja a respeito da quantidade de potássio e zinco, macronutrientes importantes na alimentação humana.

A análise de componentes principais com os resultados de concentração de todos os elementos determinados nas amostras é representada pela Figura 4. Buscando-se os elementos que mais contribuíram para o processo discriminatório, realizou-se uma nova análise de componentes principais com Br, Ca, Co, Cs, K, La, Rb, Sc e Zn (Figura 5). O primeiro componente explica cerca de $32,7 \%$ da variação total enquanto o segundo explica $22,6 \%$. 


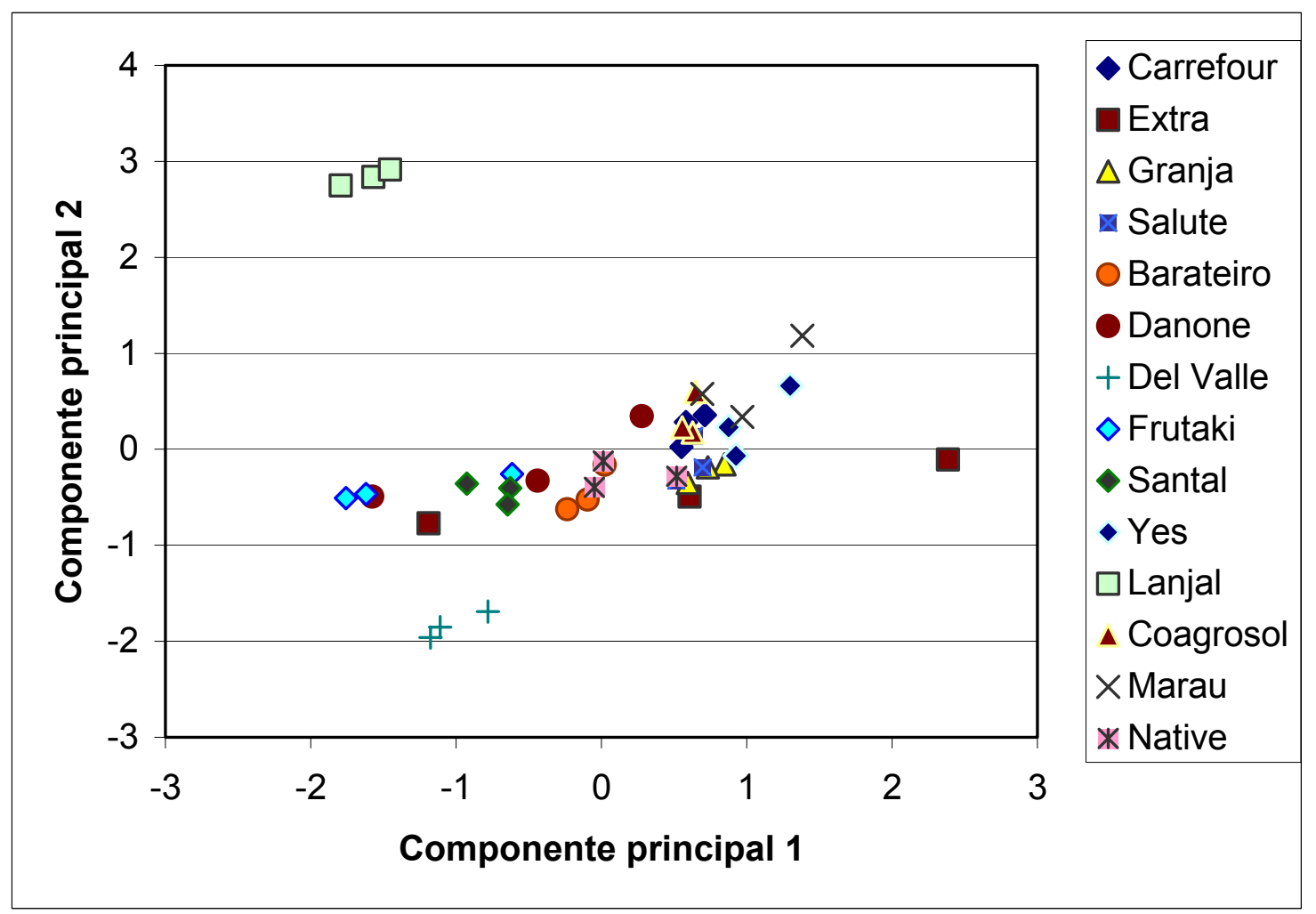

Figura 4 - Gráfico de dispersão com primeiro e segundo componentes principais com todos os elementos (55,3 \% de informação total) dos sucos comerciais

As 3 amostras de suco de cada marca (mesma data de fabricação) estão próximas entre si, com exceção das amostras dos sucos Extra e Danone (Figura 5). As amostras dos sucos Lanjal e Del Valle ficaram evidentemente separadas dos demais sucos. Os dados discrepantes de escândio e de sódio (Lanjal e Del Valle, respectivamente) em relação às demais amostras contribuíram para a separação dessas amostras. 


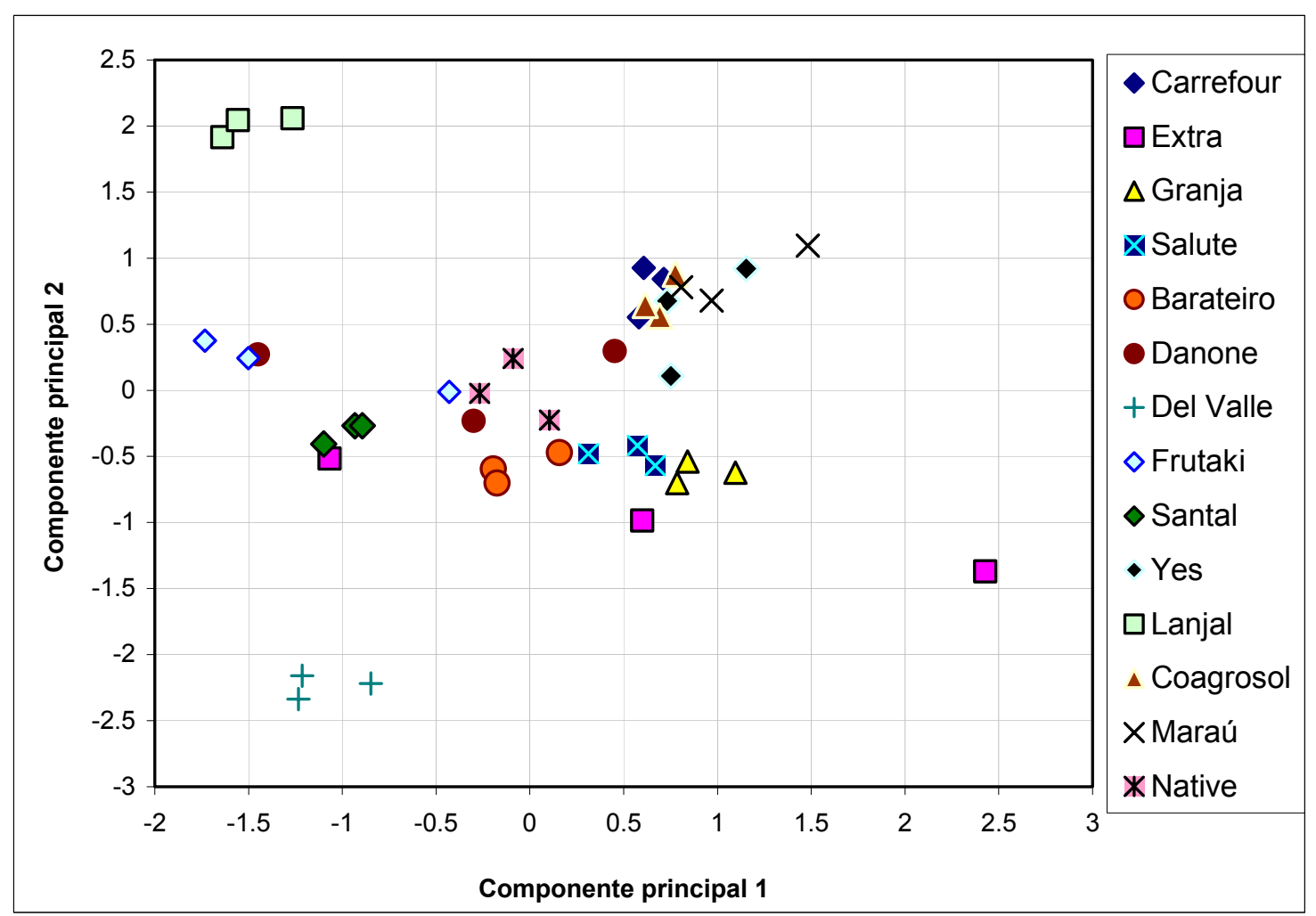

Figura 5 - Gráfico de dispersão com primeiro e segundo componentes principais excluindo se $\mathrm{Na}$ e Fe (54,2 \% de informação total)

Estes resultados sugerem que grande parte da variação da composição química observada nos sucos de marcas comerciais é decorrente das diferentes variedades, regiões de origem e etapas do processo de industrialização, fatores que dificultam sobremaneira o processo discriminatório de sucos orgânicos dos sucos convencionais.

\subsection{Calda sulfocálcica}

Nas condições analíticas empregadas, não foi possível determinar a concentração de elementos terras raras (Ce, Eu, La, Sc, Sm e Tb) nas amostras de calda sulfocálcica líquida (exceção - amostra número 3 para La, Sc e Sm). Os elementos terras raras foram encontrados predominantemente na amostra em pó. As amostras de calda sulfocálcica líquidas apresentaram 
maiores concentrações de Br, Ca e K. As concentrações de Fe e Na foram maiores para a calda sulfocálcica em pó (Tabela 16).

Apesar de a amostra número 3 ser do mesmo lote e data de fabricação que as amostras 1 e 2, ela apresentou diferentes coloração e concentração de As, Fe, La, Sc e Sm.

Tabela 16. Concentração média $(\mathrm{n}=3)$ e desvio padrão (mg.kg-1) dos elementos químicos determinados em amostras de calda sulfocálcica líquida (li) e calda sulfocálcica em pó (pó), *n=2

\begin{tabular}{|c|c|c|c|c|c|c|c|c|c|}
\hline & As & $\mathrm{Br}$ & $\mathbf{C a}$ & $\mathrm{Ce}$ & Co & $\mathbf{E u}$ & $\mathrm{Fe}$ & Hf & $\mathbf{K}$ \\
\hline \multirow[t]{2}{*}{$\overline{\mathbf{L i}}$} & 0.43 & 1.32 & 193000 & - & 0.22 & - & $42 *$ & - & 1014 \\
\hline & 0.03 & 0.03 & 2449 & - & 0.01 & - & 13 & - & 33 \\
\hline \multirow[t]{2}{*}{2 li } & 0.43 & 1.32 & 188333 & - & 0.22 & - & $52 *$ & - & 1021 \\
\hline & 0.02 & 0.02 & 1700 & - & 0.01 & - & 3 & - & 36 \\
\hline \multirow[t]{2}{*}{3 li } & 0.75 & 1.38 & 194000 & - & 0.27 & - & 106 & - & 1090 \\
\hline & 0.02 & 0.05 & 2828 & - & 0.01 & - & 21 & - & 41 \\
\hline \multirow[t]{3}{*}{4 pó } & - & 1.19 & 34800 & 233 & - & 2.50 & 695 & 0.43 & 631 \\
\hline & - & 0.04 & 497 & 0.82 & - & 0.02 & 18 & 0.05 & 16 \\
\hline & La & $\mathbf{N a}$ & $\mathbf{S b}$ & Sc & Sm & Ta & $\mathbf{T b}$ & Th & $\mathbf{Y b}$ \\
\hline \multirow[t]{2}{*}{$1 \mathrm{li}$} & - & 113 & 0.079 & - & - & - & - & - & - \\
\hline & - & 2.48 & 0.004 & - & - & - & - & - & - \\
\hline \multirow[t]{2}{*}{2 li } & - & 113 & 0.092 & - & - & - & - & - & - \\
\hline & - & 2.86 & 0.009 & - & - & - & - & - & - \\
\hline \multirow[t]{2}{*}{3 li } & 0.17 & 120 & 0.077 & 0.022 & 0.039 & - & - & - & - \\
\hline & 0.00 & 1.89 & 0.008 & 0.001 & 0.004 & - & - & - & - \\
\hline \multirow[t]{2}{*}{4 pó } & 96 & 1143 & - & 0.28 & 12 & 0.40 & 0.63 & 4.35 & 2,67 \\
\hline & 0.42 & 4.71 & - & 0.01 & 0.17 & 0.03 & 0.01 & 0.08 & 0.41 \\
\hline
\end{tabular}

\subsection{Considerações finais}

Diferenças significativas (teste F de Fisher - em nível de confiança de 99\%) para Br, $\mathrm{Co}$, Cs, La e $\mathrm{Rb}$ foram observadas entre as amostras de folhas e sucos de laranja dos dois sistemas de produção (Figura 6). A maioria dos elementos discriminantes apresentou maiores concentrações nas folhas das amostras do sistema de produção orgânico. As concentrações de Cs e $\mathrm{Rb}$ foram maiores nas amostras de suco para ambos os sistemas de produção. A concentração de Cs foi maior em folhas e frutos para o sistema de produção convencional.

Os elementos $\mathrm{Br}$, Ca, Co, Cs e Rb discriminaram o sistema de produção orgânico do convencional. Vale ressaltar que esses elementos são comuns para discriminação de 
cultivo orgânico e convencional de café e batata (Fernandes et al., 2004). As concentrações de $\mathrm{Br}$ e $\mathrm{Co}$ sob sistema de cultivo convencional foram maiores tanto para café quanto para batata (Figura 6). As concentrações de Ca e Rb foram maiores para café, laranja e batata cultivados organicamente. A concentração de Cs foi maior no sistema de produção convencional para todas as culturas (Tabela 17).

Na Tabela 17, os resultados de concentração correspondem a 25 amostras de grão de café, 30 amostras de suco de laranja e 4 amostras de batata.

Tabela 17. Concentração média e desvio padrão (mg. $\mathrm{kg}^{-1}$ ) dos elementos químicos determinados em amostras de grãos de café, sucos de laranja e polpa de batata cultivados sob sistemas de produção orgânico (Org.) e convencional (Conv.)

\begin{tabular}{|c|c|c|c|c|c|c|}
\hline & \multicolumn{2}{|c|}{ Café } & \multicolumn{2}{|c|}{ Laranja } & \multicolumn{2}{|c|}{ Batata } \\
\hline & Org. & Conv. & Org. & Conv. & Org. & Conv. \\
\hline \multirow[t]{2}{*}{$\mathrm{Br}$} & 0,22 & 0,45 & 3,79 & 0,54 & 1,10 & 1,73 \\
\hline & 0,009 & 0,05 & 1,32 & 0,10 & 0,07 & 0,10 \\
\hline \multirow[t]{2}{*}{ Ca } & 1480 & 1120 & 948 & 532 & $<230$ & $<230$ \\
\hline & 60 & 60 & 217 & 128 & - & - \\
\hline \multirow[t]{2}{*}{ Co } & 0,14 & 0,21 & 0,016 & 0,005 & 21,8 & 19,4 \\
\hline & 0,006 & 0,04 & 0,006 & 0,002 & 1,1 & 1,1 \\
\hline \multirow[t]{2}{*}{ Cs } & 0,049 & 0,102 & 0,049 & 23,5 & 0,007 & 0,013 \\
\hline & 0,003 & 0,008 & 0,026 & 4,9 & 0,002 & 0,001 \\
\hline \multirow[t]{2}{*}{$\mathbf{R b}$} & 23,0 & 33 & 23,5 & 13,1 & 15,9 & 12,1 \\
\hline & 0,7 & 4 & 4,9 & 2 & 0,9 & 0,7 \\
\hline
\end{tabular}



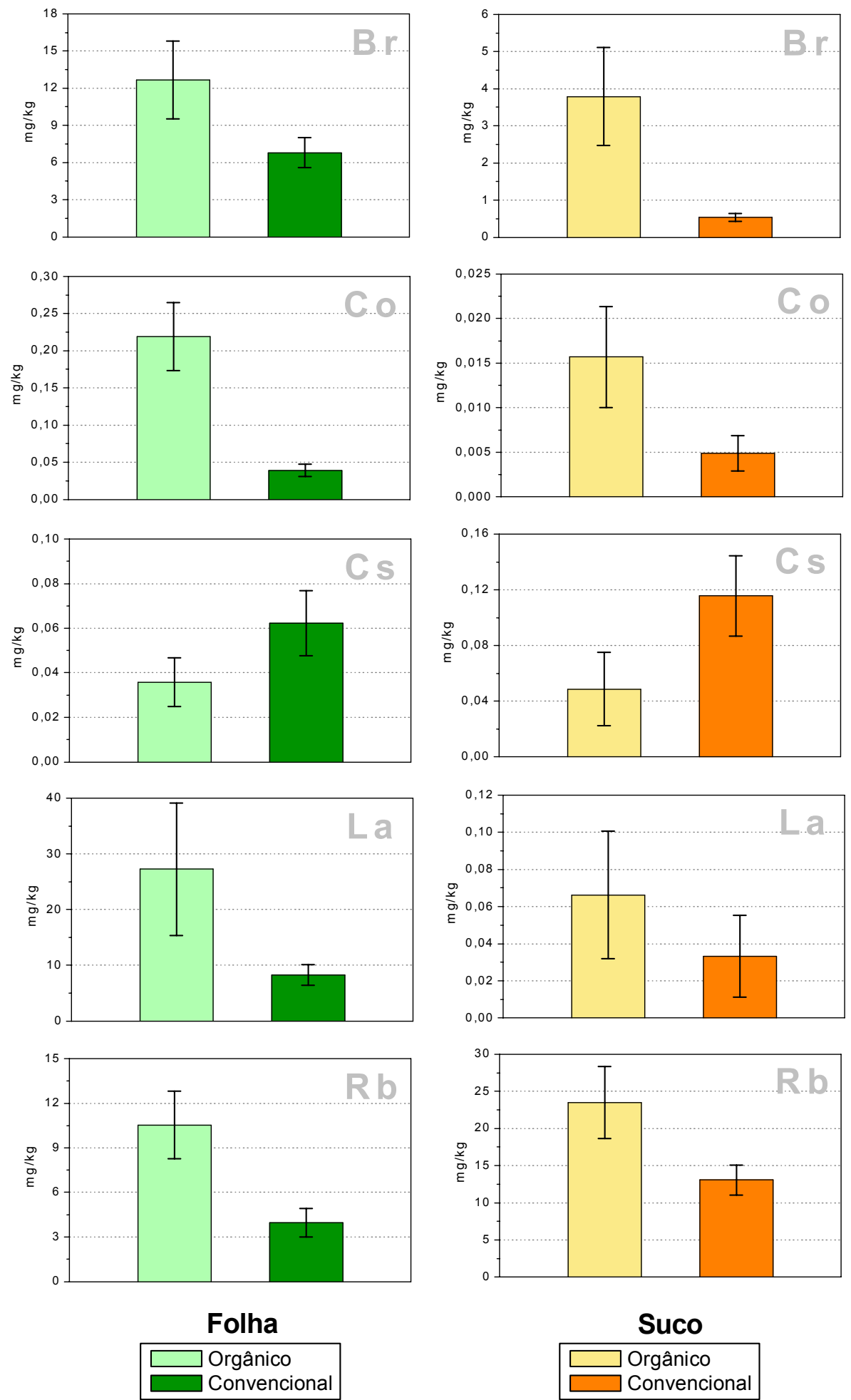

Figura 6 - Gráficos de composição elementar (mg. $\mathrm{kg}^{-1}$ ) de amostras de folhas e sucos de laranja do sistema orgânico e convencional 
Br, Ca e Co foram elementos encontrados nas amostras de calda sulfocálcica líquida que discriminaram os sistemas de produção para amostras de sucos de laranja. A matriz de coeficiente de correlação residual para folhas de laranjeira orgânica apresentou correlações significativas $(\mathrm{p}<0,001)$ para Ca (elemento em maior concentração na calda sulfocácica) com Ce $(r=0,65)$, Eu $(r=0,50), K(r=-0,57)$, La $(r=0,64)$, Nd $(r=0,51)$, Rb $(r=-0,54)$, Sm $(r=51)$ e Sr $(r=0,52)$. Alguns desses elementos, como K e La presentes em ambas as caldas sulfocálcicas e Ce, Eu e Sr presentes na calda sulfocálcica em pó, sugerem que a calda sulfocácica pode influenciar no processo de discriminação dos sistemas de produção. 


\section{CONCLUSÕES}

Nas condições que o experimento foi conduzido, permite-se chegar às seguintes conclusões:

Os solos das duas propriedades de mesma classificação textural Latossolo Vermelho Amarelo, apresentam diferenças de composição química. Apesar de estar presente em ambos os solos, o Cr não foi detectado nas folhas e sucos, o que sugere que sua concentração no solo pode não estar relacionada com o manejo.

Pelos resultados da matriz de correlação residual) e pelas altas razões folha/solo para os elementos terras raras, semelhantes a plantas consideradas bioacumuladoras de elementos terras raras, supõe-se que os elementos terras raras podem ser absorvidos pelas plantas de laranjeira Valência.

Nas amostras de folhas oriundas do sistema de produção orgânico, o Ca (elemento presente em maior concentração na calda sulfocálcica) apresentou correlações significativas $(\mathrm{p}<0,001)$ com K, La, Ce, Eu e Sm, elementos também encontrados na calda sulfocálcica. $\mathrm{Br}$ e Co, encontrados em maior quantidade nas folhas e sucos de laranja da propriedade que adota o sistema de produção orgânico, também estão presentes na calda sulfocálcica. Estes resultados indicam que a calda sulfocálcica pode influenciar no processo discriminatório dos sistemas de produção em citros. Seriam necessários trabalhos de campo que verifiquem a influência na planta da calda sulfocálcica e outros insumos utilizados na agricultura orgânica, o que facilitaria o processo de discriminação e de autenticidade do produto orgânico.

O sucos comerciais não proporcionaram boa discriminação devido ao grande número de váriáveis que influenciam os valores de concentração dos elementos químicos de interesse. 
O suco de laranja concentrado congelado da marca Lanjal foi o único a apresentar diferença significativa na concentração de Sc e a maior concentração de Fe, sendo um indício de contaminação por terra.

As análises estatísticas multivariadas (componentes principais) evidenciaram a separação das amostras de folhas e sucos oriundas de propriedades com sistemas de produção orgânico e convencional de laranja. Br, Co, Cs, La e Rb foram elementos que discriminaram o sistema de produção orgânico e convencional para amostras oriundas do campo.

As concentrações de $\mathrm{Br}$ foram significativamente superiores para todas as amostras orgânicas, isto é, sucos comerciais orgânicos, folhas e sucos orgânicos da propriedade em estudo, sendo este elemento o melhor discriminante para as amostras estudadas. 


\section{REFERÊNCIAS BIBLIOGRÁFICAS}

ASSOCIAÇÃO BRASILEIRA DOS EXPORTADORES DE CÍTRICOS. A história da laranja. http://www.abecitrus.com.br/historia.html (26 set. 2002a).

ASSOCIAÇÃO BRASILEIRA DOS EXPORTADORES DE CÍTRICOS. A industrialização da laranja. http://www.abecitrus.com.br/indus.html (21 set. 2002b).

ASSOCIAÇÃO BRASILEIRA DOS EXPORTADORES DE CÍTRICOS. Produção de Laranja. http://www.abecitrus.com.br/safrano.html (17 abr. 2004).

ABUGASSA, I.O.; SARMANI S.; El-GHAWI, U. Instrumental neutron activation analysis based on $k_{0}$-standardization method as compared with other methods in the analysis of the IAEA inter-comparison test. Journal of Radioanalytical and Nuclear Chemistry, v.259, n.3, p.381, 2004.

AGROJURIS. Notas sobre a produção e uso de caldas caseiras alternativas na agricultura.http://www.agrojuris.eng.br/Minicurso/Producaocaldascaseiras/1.08Caldade enxofre(sulfocalcica).htm (17 fev. 2005).

BACCHI, M.A. Avaliação de impurezas minerais e desgaste na indústria sucroalcooleira através de análise por ativação neutrônica. Piracicaba, 1993. 80p. Dissertação (Mestrado) Centro de Energia Nuclear na Agricultura, Universidade de São Paulo. 
BACCHI, M.A.; FERNANDES, E.A.N. Quantu - design and development of a software package dedicated to $\mathrm{k}_{0}$-standardized INAA. Journal of Radioanalytical and Nuclear Chemistry, v.257, n.3, p.577-582, 2003.

BACCHI, M.A.; FERNANDES, E.A.N.; OLIVEIRA, H. A Brazilian experience on $k_{0}$ standardized neutron activation analysis. Journal of Radioanalytical and Nuclear Chemistry, v.245, n.1, p.217-222, 2000.

BAYER, S.; McHARD, J.A.; WINEFORDNER, J.D. Determination of the geographical origins of frozen concentrated orange juice via pattern recognition. Journal of Agricultural and Food Chemistry, v.28, p.1306-1307, 1980.

BERTOLDO, A.A. Desenvolvimento de metodologia para determinação dos componentes e especiação de polissulfetos em amostras de calda sulfocálcica. São Carlos, 2003. 87p. Dissertação (Mestrado) Instituto de Química de São Carlos, Universidade de São Paulo.

BODE, P.; FERNANDES, E.A.N.; GREENBERG, R.R. Metrology for chemical measurements and the position of INAA. Journal of Radioanalytical and Nuclear Chemistry, v.245, n.1, p.109-114, 2000.

BORKERT, C.M.; PAVAN, M.A.; BATAGLIA, O.C. Disponibilidade e avaliação de elementos catiônicos: ferro e manganês. In: FERREIRA, M.E.; CRUZ, M.C.P.; RAIJ, B.V.; ABREU, C.A. (Ed.) Micronutrientes e elementos tóxicos na agricultura. Jaboticabal: 2001 p.173.

BOTEON, M. Cadeia agroindustrial de citros. http://cepea.esalq.usp.br/indic/zip/ Cadeia\%20Citros.pdf (22 ago. 2002).

CODEX ALIMENTARIUS. Alimentos produzidos organicamente http://www. codexalimentarius.net/web/archives.jsp?year=01 (10 jul. 2004) 
COMPANHIA DE TECNOLOGIA DE SANEAMENTO AMBIENTAL. Relatório de estabelecimento de valores orientados para solos e águas subterrâneas no Estado de São Paulo 2001 http://www.cetesb.sp.gov.br/Solo/solo_geral.asp (08 jan. 2005).

DA MATTA, F.M.; LOUREIRO M.E. Nutrição mineral de plantas. http://www.ufv.br/DBV/PGFVG/Bve\%20270/pdf/Nutricaomin1.pdf (18 ago. 2004).

DAROLT, M.R. As principais correntes do movimento orgânico e suas particularidades. http://www.planetaorganico.com.br/trabdurolt.htm (20 jul. 2003).

DAVIES, F.S.; ALBRIGO, L.G. Cítricos. Zaragoza: Editora Acribia, 1994. 4p.

DECHEN, A.R.; HAAG, H.P.; CARMELLO, Q.A.C. Funções dos micronutrientes nas plantas. In: FERREIRA, M.E.; PESSÔA DA CRUZ, M. (Ed.) . Micronutrientes na agricultura. Piracicaba: Associação Brasileira para Pesquisa da Potassa e do Fosfato 1991, p.69.

EHLERS, E. Agricultura sustentável - Origens e perspectivas de um novo paradigma. 2.ed. São Paulo: Livros da Terra, 1999. p.47

FAOSTAT. Estatistical Databases. http://apps.fao.org/faostat/collections?version= ext\&hasbulk=0\&subset=agriculture (11 Nov. 2004).

FAO. World markets for organic citrus and citrus juices. http://www.fao.org/es/ESC/esce/escr/orghorticulture/PDF/organic\%20citrus\%20markets .pdf (8 Jun. 2003).

FERNANDES, E.A.N. Scandium as tracer in the sugar and alcohol agroindustry. Journal of Radioanalytical and Nuclear Chemistry, v.168, n.1, p.41-46, 1992. 
FERNANDES, E.A.N.; TAGLIAFERRO, F.S.; BACCHI, M.A.; BODE, P.; TURRA, C.; SANTOS, L.G. INAA as a tool to identify organically grown food. Washington DC : 2004 American Nuclear Society, p. $847-848$.

FILLI, S.P.; OLIVEIRA, E.; OLIVEIRA, P.V. On-line digestion in a focused microwaveassisted oven for elements determination in orange juice by inductively coupled plasma optical emission spectrometry. Journal Chemistry Society, v.14, n.3, p.435-441, 2003.

FRANÇA, E.J.; BACCHI, M.A.; DE NADAI FERNANDES, E.A.; GANDOLFI, S. Mata de Santa Genebra, SP, Brazil: can mineral cycling in urban forestry fragment reveal anthropogenic activities? In: BIOMONITORING OF ATMOSPHERIC POLLUTION. Lisboa : S. Ed. 2003. Proceedings

FRANÇA, E.J.; DE NADAI FERNANDES, E.A.; BACCHI, M.A.; TAGLIAFERRO, F. S. Pathway of rare-earth elements in a Brazil forestry fragment. Journal of Alloys and Compounds v.344, p.21-26, 2002.

FURLANI, P.R.; BOLONHEZI, D.; SILVEIRA, L.C.P.; FAQUIN, V. Nutrição mineral de hortaliças, preparo e manejo de soluções nutritivas. Cultivo protegido de hortaliças em solo e hidroponia. Informe Agropecuário, v.20, n.200/201, p.90-98, 1999.

GARCIA-WASS, F.; HAMMOND, D.; MOTTRAM, D.S.; GUTTERIDGE, C.S. Detection of fruit juice authenticity using pyrolysis mass spectroscopy. Food Chemistry, v.69, p.215-220, 2000.

GLASCOCK, M.D. An overview of neutron activation analysis. University of Missouri Research Reactor (MURR) 2003. http://www.missouri.edu/ glascock/naa_over.htm (30 out. 2004). 
GHILARDI, A.A.; MAIA, M.L.; AMARO, A.A.; De NEGRI, J.D. Citricultura paulista: exigência física de fatores de produção, estimativa de custo e evolução das técnicas agrícolas. Informações Econômicas, v.32, n.9, set. 2002.

GRUPO PAULISTA DE ADUBAÇÃO E CALAGEM PARA CITROS. Recomendação de adubação e calagem para citros no Estado de São Paulo. Laranja, n.3, p.10, 1994 (Edição especial).

GUPTA, U.C. Micronutrientes e elementos tóxicos em plantas e animais. In: FERREIRA, M.E.; CRUZ, M.C.P.; RAIJ, B.V.; ABREU, C.A. (Ed.) Micronutrientes e elementos tóxicos na agricultura. Jaboticabal SP : 2001. 18p.

HOFFMANN H. Alimento orgânico e produto artesanal. http://www.saude.sc.gov.br/temp/forumIntersetorial/textos/Feinvisa/Feinvisa/Oficina $\% 2$ 001\%20-\%20Texto\%201\%20-\%20Alimento\%20Org\%C3\%A2nico\%20e\%20Produto\% 20Artezanal.doc. (14 de out. 2004)

IBD. Projetos certificados. http://www.ibd.com.br/default.asp (14 out. 2003)

IBD. Diretrizes para o padrão de qualidade orgânico Instituto Biodinâmico. http://www.ibd.com.br/publicacoes/DiretrizesIBD200412ed.pdf (10 fev. 2005)

INSTITUTO BRASILEIRO DE GEOGRAFIA E ESTATÍSTICA. http://www.ibge.gov.br (07 fev. 2005).

INSTITUTO DE ECONOMIA AGRÍCOLA. Previsões e estimativas das safras agrícolas, por região administrativa (RA), Estado de São Paulo, ano agrícola 2002/03, levantamento final, setembro de 2003. http://www.iea.sp.gov.br/out/producao/ps0903-11-t12.htm (14 out. 2004). 
INTERNATIONAL FEDERATION OF ORGANIC AGRICULTURE MOVEMENTS. The world of organic agriculture 2003 - statistics and future prospects. http://www.ifoam.org/statistic/statistics_studie.pdf(12 dez. 2003).

INTERNATIONAL FEDERATION OF ORGANIC AGRICULTURE MOVEMENTS. The world of organic agriculture 2004 - statistics and emerging trends. http://www.ifoam.org (18 set. 2004).

ISMAIL M.; ZHANG, J. Post-harvest citrus disease control. Outlooks on pest of management. http://www.researchinformation.co.uk/pest/sample/15-1/13-Ismail.pdf (24 out. 2004).

KAMPFER, M.; UEXKULL, H.R. von. Nuevos conocimientos sobre la fertilización de los cítricos. 3ed. Hanover : Verlag Gesselschaft fur Ackerbau, 1966. 104p.

KRAMER, G.N.; DE ANGELIS, L.; PAUWELS, J.; OOGHE, W.; BELLIARDO, J.J. The freeze-drying of orange juice for the preparation of reference materials. Fresenius $\mathbf{Z}$ Analytical Chemistry, n.332, p.694-697, 1988.

LIU, P. World markets for organic citrus and citrus juice. FAO. http://www.fao.org/es/ESC/common/ecg/28303_en_CitrusorganicEN.pdf (17 jun. 2004)

MALAVOLTA, E; VIOLANTE NETTO, A. Nutrição mineral, calagem, gessagem e adubação dos citros. Associação Brasileira para Pesquisa da Potassa e do Fosfato Piracicaba: Potafos, 1989. 21p.

MALAVOLTA E.; VITTI, G.C.; OLIVEIRA, S.A. Associação Brasileira para Pesquisa da Potassa e do Fosfato. Piracicaba: Avaliação do estado nutricional das plantas. 1997. 90p. 
McHARD, J.A.; WINEFORDNER, J.D., ATTAWAY, J.A. A new hydrolysis procedure for preparation of orange juice for trace element analysis by atomic absorption spectrometry. Journal Agricultural Food Chemistry, v.24, p.41-45, 1976.

MARKERT, B.; LI, Z.D. Natural background concentrations of rare-earth elements in a forest ecosystem. Science of the Total Environment, v.1, p.37-45, 1991.

MARTIN, G.J.; FOURNIER, J.B.; ALLAIN, P.; MAURAS, Y.; AGUILE, L. Optimization of analytical methods for origin assessment of orange juices, II. ICP-MS determination of trace and ultra-trace elements. Analusis, v.25, p.7-13, 1997.

MINISTÉRIO DA AGRICULTURA PECUÁRIA E ABASTECIMENTO. A agricultura orgânica brasileira tem a segunda maior área do mundo. http://www.agricultura.gov.br/ (24 fev. 2005).

MOREIRA, S.A. História da citricultura no Brasil. In: Fundação Cargill. Citricultura Brasileira. Campinas, 1980. p.1-28.

MOULY, P.P.; GAYDOU, E.M.; CORSETTI, J. Determination of the geographical origin of Valencia orange juice using carotenoid liquid chromatographic profiles. Journal Chromatograph Science, v. 844, p.149-159, 1999.

NASSAR, A.M. Certificação no Agribusiness. In: ZYLBERZTAJN, D.; SCARE, R.F. (Ed.). Gestão da qualidade no agribusiness. São Paulo: Atlas, 2003. cap.3, p.30-39.

NEVES, M.F.; MARINO, M.K. Estudos da competitividade de cadeias integradas no Brasil: impactos da zona de livre comércio - Cadeia: citros. Universidade de Campinas (UNICAMP), Instituto de Economia (IE), Núcleo de Economia Industrial e da Tecnologia (NEIT), Campinas, jul. de 2002. 1v. 
NEVES, M.C.P. Harmonização e equivalência no comércio mundial de produtos orgânicos. http://www.cnpab.embrapa.br/servicos/artigos/artigo_reuniao_onu_ao.html (17 out. 2004).

NEVES, M.F.; LOPES, F.F. Mapeamento e quantificação do sistema agroindustrial citrícola. Revista Fundecitrus, ed.122, mai./jun. 2004. p.8-9.

ORMOND, J.G.P.; De PAULA, S.R.L.; FILHO, P.F.; Da ROCHA, L.T.M. Agricultura orgânica: quando o passado é futuro, Rio de Janeiro: Banco Nacional de Desenvolvimento Econômico e Social (BNDES), Setorial 2002.

PASSOS, O.S. A Citricultura no Estado da Bahia de 1960 ao ano 2000. Cruz das Almas: EMBRAPA - CNPMF, 1988.

PENTEADO, S.R. Uso da calda sulfocálcica no controle alternativo de ácaros na citricultura. http://www.agrorganica.com.br/ (3 set. 2004).

PITOMBO, R.N.M. Suco de laranja liofilizado: influência da atividade de água e temperatura sobre o teor de vitamina C. Revista de Farmácia e Química, v.37, 1999, n. 4, p. $45-47$.

PLANETA ORGÂNICO. Citricultura Orgânica - I http://www.planetaorganico.com.br /citricult1.htm (14 jan. 2003).

PROGRAMA DE ESTUDOS DOS NEGÓCIOS DO SISTEMA AGROINDUSTRIAL. Novo Mapeamento do Sistema Agroindustrial Citrícola. 2004. http://www.abecitrus.com.br/informa.html\#nota_pensa (18 out. 2004).

QUAGGIO, J.A.; PIZA JÚNIOR, C.T. Micronutrientes para frutíferas tropicais. In: FERREIRA, M.E.; CRUZ, M.C.P.; RAIJ, B. van; ABREU, C.A. (Ed.). 
Micronutrientes tóxicos e metais pesados na agricultura. Jaboticabal: CNPq/Fapesp/Potafos, 2001. p.459-491.

RAIJ, B. van Fertilidade do solo e adubação. São Paulo: Agronomia Ceres, 1991. p.164$165,1991$.

REUTHER, W. Climate and citrus behavior. In: REUTHER, W. (Ed.). The citrus industry. Berkeley: University of California, 1973, v.3, cap. 4, p.280-337.

SAS INSTITUTE INC. SAS/STAT Guide for personal computers. 6.ed. Cary: SAS Institute, 1996. $1028 \mathrm{p}$.

SIMPKINS, W.A.; LOUIE, H.; WU, M.; HARRISON, M.; GOLDBERG, D. Trace elements in Australian orange juice and other products. Food Chemistry, v.71, p.423433, 2000.

SMITH, P.F. Leaf analysis of citrus. In: CHILDERS, N.F. (Ed.). Fruit nutrition. News Brunswick: Horticultural Publications Rutgers, 1966, cap.2, p.208-228.

SOUZA, A.C. Frutas cítricas: singularidades do mercado. Preços Agrícolas, p.8-10, maio/junho 2001 .

SUN, J.; ZHAO, H.; WANG, Y. Study of the contents of trace rare earth elements and their distribution in wheat and rice samples. Journal of Radioanalytical and Nuclear Chemistry, v.179, p.377-383, 1994.

SWINGLE, W.T, REECE, P.C. The botany of citrus and its wild relativies. In: REUTHER, W., BATCHELOR, L.D., WEBBER, H.J. (Ed). The citrus industry. Berkeley : University of California, 1967, p.190-430. 
TAGLIAFERRO, F.S. Metrologia em química: estudo da qualidade de cafés brasileiros. Piracicaba, 2002. 134p. Tese (Doutorado) - Centro de Energia Nuclear na Agricultura, Universidade de São Paulo.

TRIBESS, T.B.; TADINI, C.C. Suco de laranja natural minimamente processado: uma alternativa para ampliar o mercado de suco de laranja no Brasil. http://www.fearp.usp.br/egna/resumos/CarmenTadini.pdf(18 set. 2002).

TURRA, C.; GHISI, F.A. Produção de laranja orgânica no Brasil: produção, mercado e tendências. Anais: Congresso da Sociedade Brasileira de Economia e Sociologia Rural, Cuiabá 2004.

TYLER, G. Rare earth elements in soil and plant systems. A review Plant and Soil v.267, p.191-206, 2004.

VAILATI, J. Do Brasil para o mundo. http://www.centrodecitricultura.br/palestras /vailati.PDF (28 mai. 2003).

VITTI, G.C.; SILVA, M.M. Fertilizantes alternativos na cultura dos citros In: Simpósio sobre fisiologia, nutrição, adubação e manejo para produção sustentável de citros Piracicaba, 2000 Potafos.

VITTI, G.C. Nutrition and growth of citrus plants. In: DONADIO, L. C. (Ed.). In: INTERNATIONAL SEMINAR ON CITRUS PHYSIOLOGY, Jaboticabal : FUNEP 1992. Proceedings.

VOLDŘICH, M.; SKÀlOVA, P.; KVASNIČKA, F.; CUHRA, P.; KUBÍK, M. Authenticity of 100\% orange juice in the Czech market in 1996-2001. Czech Journal Food Science, v.20, n.2, p.83-88, 2002. 
WUTSCHER, H.K.; PERKINS, R.E. Acid extractable rare earth elements in Florida citrus soils and trees. Community Soil Science Plant Analytical, v.24, p.2059-2068, 1993.

WYTTENBACH, A.; FURRER, V.; SCHLEPPI, P.; TOBLER, L. Rare earth elements in soil and in soil-grown plants. Plant and Soil, v.199, p.267-273, 1998.

YAMAUCHI, T.; HARA, T.; SONODA, Y. Effects of boron deficiencies and calcium supply on the calcium metabolism in tomato plant. Plant and Soil, v.93, p.223-231, 1986. 
APÊNDICES 
APÊNDICE 1. Concentração de elementos químicos $\left(m g \cdot \mathrm{kg}^{-1}\right)$ e incertezas relativas $(k=2)$ em amostras de solo sob cultivo orgânico

\begin{tabular}{|c|c|c|c|c|c|c|c|c|c|c|}
\hline & $\begin{array}{c}\text { Planta } \\
1 \\
\end{array}$ & $\begin{array}{c}\text { Planta } \\
2 \\
\end{array}$ & $\begin{array}{c}\text { Planta } \\
3 \\
\end{array}$ & $\begin{array}{c}\text { Planta } \\
4\end{array}$ & $\begin{array}{c}\text { Planta } \\
5\end{array}$ & $\begin{array}{c}\text { Planta } \\
6 \\
\end{array}$ & $\begin{array}{c}\text { Planta } \\
7 \\
\end{array}$ & $\begin{array}{c}\text { Planta } \\
8 \\
\end{array}$ & $\begin{array}{c}\text { Planta } \\
9 \\
\end{array}$ & $\begin{array}{c}\text { Planta } \\
10 \\
\end{array}$ \\
\hline As & $\begin{array}{c}1,33 \\
12,2\end{array}$ & $\begin{array}{c}1,64 \\
8,6\end{array}$ & $\begin{array}{c}1,46 \\
8,8\end{array}$ & $\begin{array}{c}1,70 \\
8,6\end{array}$ & $\begin{array}{c}1,57 \\
8,6\end{array}$ & $\begin{array}{c}1,92 \\
8,0\end{array}$ & $\begin{array}{c}1,94 \\
7,8\end{array}$ & $\begin{array}{c}1,67 \\
7,4\end{array}$ & $\begin{array}{c}1,82 \\
8,0\end{array}$ & $\begin{array}{c}1,83 \\
11,4\end{array}$ \\
\hline $\mathrm{Br}$ & $\begin{array}{c}2,19 \\
7,3\end{array}$ & $\begin{array}{c}2,61 \\
6,9\end{array}$ & $\begin{array}{c}2,61 \\
6,7\end{array}$ & $\begin{array}{c}3,35 \\
6,8\end{array}$ & $\begin{array}{c}2,68 \\
6,6\end{array}$ & $\begin{array}{c}2,65 \\
7,3\end{array}$ & $\begin{array}{c}2,51 \\
7,3\end{array}$ & $\begin{array}{c}2,48 \\
6,5\end{array}$ & $\begin{array}{c}2,76 \\
6,4\end{array}$ & $\begin{array}{c}3 \\
7,0\end{array}$ \\
\hline Ce & $\begin{array}{c}77,6 \\
4,0\end{array}$ & $\begin{array}{c}96,6 \\
4,6\end{array}$ & $\begin{array}{c}87,8 \\
4,6\end{array}$ & $\begin{array}{c}99,2 \\
4,0\end{array}$ & $\begin{array}{c}80,4 \\
4,2\end{array}$ & $\begin{array}{c}82,4 \\
4,0\end{array}$ & $\begin{array}{l}84 \\
4,2\end{array}$ & $\begin{array}{c}71,3 \\
4,0\end{array}$ & $\begin{array}{c}90,8 \\
4,0\end{array}$ & $\begin{array}{c}87,4 \\
4,4\end{array}$ \\
\hline Co & $\begin{array}{c}5,22 \\
3,0\end{array}$ & $\begin{array}{c}6,54 \\
2,8\end{array}$ & $\begin{array}{c}6,35 \\
2,8\end{array}$ & $\begin{array}{c}6,17 \\
3,0\end{array}$ & $\begin{array}{c}5,71 \\
3,0\end{array}$ & $\begin{array}{c}4,9 \\
3,0\end{array}$ & $\begin{array}{c}5,12 \\
3,0\end{array}$ & $\begin{array}{c}4,81 \\
2,8\end{array}$ & $\begin{array}{c}5,12 \\
3,0\end{array}$ & $\begin{array}{c}5,28 \\
2,8\end{array}$ \\
\hline $\mathrm{Cr}$ & $\begin{array}{c}137 \\
3,2\end{array}$ & $\begin{array}{c}163 \\
3,2\end{array}$ & $\begin{array}{c}175 \\
3,6\end{array}$ & $\begin{array}{c}154 \\
3,4\end{array}$ & $\begin{array}{c}154 \\
3,2\end{array}$ & $\begin{array}{c}148 \\
3,6\end{array}$ & $\begin{array}{c}159 \\
3,4\end{array}$ & $\begin{array}{c}135 \\
3,8\end{array}$ & $\begin{array}{c}123 \\
3,6\end{array}$ & $\begin{array}{c}143 \\
3,2\end{array}$ \\
\hline Cs & $\begin{array}{c}0,99 \\
10,2\end{array}$ & $\begin{array}{c}1,27 \\
9\end{array}$ & $\begin{array}{c}1,02 \\
8,6\end{array}$ & $\begin{array}{c}1,24 \\
8,4\end{array}$ & $\begin{array}{c}1,14 \\
9,4\end{array}$ & $\begin{array}{c}1,15 \\
8,0\end{array}$ & $\begin{array}{c}1,18 \\
9,6\end{array}$ & $\begin{array}{c}1,16 \\
7,8\end{array}$ & $\begin{array}{c}1,37 \\
8,0\end{array}$ & $\begin{array}{c}1,27 \\
8,2\end{array}$ \\
\hline $\mathrm{Eu}$ & $\begin{array}{c}1,13 \\
5\end{array}$ & $\begin{array}{c}1,35 \\
4,8\end{array}$ & $\begin{array}{c}1,17 \\
4,8\end{array}$ & $\begin{array}{c}1,34 \\
5,2\end{array}$ & $\begin{array}{c}1,19 \\
5\end{array}$ & $\begin{array}{c}1,16 \\
6,2\end{array}$ & $\begin{array}{c}1,13 \\
5\end{array}$ & $\begin{array}{c}0,99 \\
4,8\end{array}$ & $\begin{array}{c}1,13 \\
4,8\end{array}$ & $\begin{array}{c}1,17 \\
5,6\end{array}$ \\
\hline $\mathrm{Fe}$ & $\begin{array}{c}21823 \\
2,8\end{array}$ & $\begin{array}{c}24856 \\
2,8\end{array}$ & $\begin{array}{c}24509 \\
2,8\end{array}$ & $\begin{array}{c}26418 \\
2,8\end{array}$ & $\begin{array}{c}24113 \\
2,8\end{array}$ & $\begin{array}{c}22851 \\
2,6\end{array}$ & $\begin{array}{c}24173 \\
2,8\end{array}$ & $\begin{array}{c}22726 \\
2,8\end{array}$ & $\begin{array}{c}25020 \\
2,8\end{array}$ & $\begin{array}{c}25028 \\
2,8\end{array}$ \\
\hline Hf & $\begin{array}{c}10,71 \\
3,8\end{array}$ & $\begin{array}{c}11,02 \\
3,8\end{array}$ & $\begin{array}{c}10,20 \\
4\end{array}$ & $\begin{array}{c}10,41 \\
3,8\end{array}$ & $\begin{array}{c}9,66 \\
4\end{array}$ & $\begin{array}{c}7,79 \\
3,8\end{array}$ & $\begin{array}{c}10,03 \\
3,8\end{array}$ & $\begin{array}{c}8,57 \\
3,8\end{array}$ & $\begin{array}{c}10,01 \\
3,8\end{array}$ & $\begin{array}{c}11,21 \\
3,6\end{array}$ \\
\hline K & $\begin{array}{c}2242 \\
5,4\end{array}$ & $\begin{array}{c}3468 \\
3,4\end{array}$ & $\begin{array}{c}1451 \\
8,2\end{array}$ & $\begin{array}{c}1211 \\
4,6\end{array}$ & $\begin{array}{c}1231 \\
6,4\end{array}$ & $\begin{array}{c}1965 \\
4\end{array}$ & $\begin{array}{c}1976 \\
4,2\end{array}$ & $\begin{array}{c}1241 \\
4,4\end{array}$ & $\begin{array}{c}990 \\
7,2\end{array}$ & $\begin{array}{c}945 \\
8,2\end{array}$ \\
\hline La & $\begin{array}{c}35,2 \\
2,4\end{array}$ & $\begin{array}{c}43,5 \\
2,6\end{array}$ & $\begin{array}{c}40,8 \\
2,6\end{array}$ & $\begin{array}{c}46,3 \\
2,4\end{array}$ & $\begin{array}{c}37,3 \\
2,6\end{array}$ & $\begin{array}{c}40,8 \\
2,6\end{array}$ & $\begin{array}{c}40,4 \\
2,6\end{array}$ & $\begin{array}{c}34,4 \\
2,6\end{array}$ & $\begin{array}{c}41,4 \\
2,6\end{array}$ & $\begin{array}{c}39,1 \\
2,4\end{array}$ \\
\hline $\mathrm{Na}$ & $\begin{array}{c}136,7 \\
5,2\end{array}$ & $\begin{array}{c}200 \\
3,8\end{array}$ & $\begin{array}{c}100,6 \\
4,4\end{array}$ & $\begin{array}{c}97,4 \\
5,4\end{array}$ & $\begin{array}{c}95,7 \\
5,8\end{array}$ & $\begin{array}{c}125,8 \\
4,2\end{array}$ & $\begin{array}{c}140 \\
3,4\end{array}$ & $\begin{array}{c}91,6 \\
3,4\end{array}$ & $\begin{array}{c}72,4 \\
4,4\end{array}$ & $\begin{array}{c}75,8 \\
4,4\end{array}$ \\
\hline $\mathrm{Nd}$ & $\begin{array}{c}31,1 \\
11,8\end{array}$ & $\begin{array}{c}39,9 \\
11,6\end{array}$ & $\begin{array}{c}33,8 \\
10,2\end{array}$ & $\begin{array}{c}38,3 \\
10,6\end{array}$ & $\begin{array}{c}35,8 \\
10,2\end{array}$ & $\begin{array}{c}36,9 \\
9,6\end{array}$ & $\begin{array}{c}37,2 \\
9,2\end{array}$ & $\begin{array}{c}28 \\
14,2\end{array}$ & $\begin{array}{r}32,7 \\
10,6\end{array}$ & $\begin{array}{c}32,3 \\
10,4\end{array}$ \\
\hline Sc & $\begin{array}{c}7,64 \\
2,8\end{array}$ & $\begin{array}{c}9,1 \\
3\end{array}$ & $\begin{array}{c}8,42 \\
2,8\end{array}$ & $\begin{array}{c}9,65 \\
3\end{array}$ & $\begin{array}{c}8,11 \\
3\end{array}$ & $\begin{array}{c}7,52 \\
3\end{array}$ & $\begin{array}{c}7,37 \\
2,8\end{array}$ & $\begin{array}{c}6,97 \\
3\end{array}$ & $\begin{array}{c}8,4 \\
3\end{array}$ & $\begin{array}{c}8,18 \\
2,8\end{array}$ \\
\hline $\mathrm{Sm}$ & $\begin{array}{c}4,32 \\
9,8\end{array}$ & $\begin{array}{c}5,09 \\
7,4\end{array}$ & $\begin{array}{c}4,79 \\
7,2\end{array}$ & $\begin{array}{c}5,43 \\
6,4\end{array}$ & $\begin{array}{c}4,31 \\
7,2\end{array}$ & $\begin{array}{c}4,60 \\
7,2\end{array}$ & $\begin{array}{c}4,64 \\
6,8\end{array}$ & $\begin{array}{c}3,72 \\
6,2\end{array}$ & $\begin{array}{c}4,44 \\
8\end{array}$ & $\begin{array}{c}4,56 \\
7,6\end{array}$ \\
\hline $\mathrm{Ta}$ & $\begin{array}{c}1,81 \\
7,8\end{array}$ & $\begin{array}{c}1,97 \\
7,8\end{array}$ & $\begin{array}{c}2,26 \\
7,6\end{array}$ & $\begin{array}{c}2,17 \\
8\end{array}$ & $\begin{array}{c}2,17 \\
7,8\end{array}$ & $\begin{array}{c}1,77 \\
8,2\end{array}$ & $\begin{array}{c}1,90 \\
8\end{array}$ & $\begin{array}{c}1,82 \\
8,2\end{array}$ & $\begin{array}{c}1,95 \\
8\end{array}$ & $\begin{array}{c}2,02 \\
7,8\end{array}$ \\
\hline $\mathrm{Tb}$ & $\begin{array}{c}0,48 \\
9,8\end{array}$ & $\begin{array}{c}0,48 \\
10,4\end{array}$ & $\begin{array}{c}0,46 \\
10,2\end{array}$ & $\begin{array}{c}0,51 \\
10,8\end{array}$ & $\begin{array}{c}0,44 \\
10,4\end{array}$ & $\begin{array}{c}0,39 \\
11,2\end{array}$ & $\begin{array}{c}0,45 \\
10,6\end{array}$ & $\begin{array}{c}0,36 \\
13,2\end{array}$ & $\begin{array}{c}0,44 \\
11,4\end{array}$ & $\begin{array}{c}0,51 \\
10,2\end{array}$ \\
\hline Th & $\begin{array}{c}7,30 \\
4,6\end{array}$ & $\begin{array}{c}8,91 \\
4,2\end{array}$ & $\begin{array}{c}8,91 \\
4,4\end{array}$ & $\begin{array}{c}10,61 \\
4\end{array}$ & $\begin{array}{c}8,16 \\
4,6\end{array}$ & $\begin{array}{c}8,70 \\
4,2\end{array}$ & $\begin{array}{c}8,89 \\
4,2\end{array}$ & $\begin{array}{c}7,73 \\
4,6\end{array}$ & $\begin{array}{c}9,90 \\
4,2\end{array}$ & $\begin{array}{c}9,46 \\
4,2\end{array}$ \\
\hline $\mathrm{U}$ & $\begin{array}{c}1,46 \\
25,2\end{array}$ & $\begin{array}{c}1,20 \\
28,8\end{array}$ & $\begin{array}{l}1,70 \\
21,0\end{array}$ & $\begin{array}{c}1,64 \\
26,6\end{array}$ & $\begin{array}{c}1,41 \\
25,8\end{array}$ & $\begin{array}{c}1,59 \\
26,4\end{array}$ & $\begin{array}{c}1,13 \\
31,4\end{array}$ & $\begin{array}{c}1,27 \\
25,8\end{array}$ & $\begin{array}{c}1,55 \\
24\end{array}$ & $\begin{array}{c}1,52 \\
27,6\end{array}$ \\
\hline $\mathrm{Yb}$ & $\begin{array}{c}1,84 \\
4,4\end{array}$ & $\begin{array}{c}1,94 \\
4,2\end{array}$ & $\begin{array}{c}1,80 \\
4\end{array}$ & $\begin{array}{c}1,70 \\
4,6\end{array}$ & $\begin{array}{c}1,65 \\
4,4\end{array}$ & $\begin{array}{c}1,43 \\
4,4\end{array}$ & $\begin{array}{c}1,31 \\
4,6\end{array}$ & $\begin{array}{c}1,25 \\
5,4\end{array}$ & $\begin{array}{c}1,54 \\
4,4\end{array}$ & $\begin{array}{c}1,81 \\
4,2\end{array}$ \\
\hline $\mathrm{Zn}$ & $\begin{array}{l}41 \\
24\end{array}$ & $\begin{array}{c}44 \\
19,5\end{array}$ & $\begin{array}{l}39 \\
23\end{array}$ & $\begin{array}{c}41 \\
25,4\end{array}$ & $\begin{array}{c}33 \\
23,2\end{array}$ & $\begin{array}{c}32 \\
33,7\end{array}$ & $\begin{array}{c}38 \\
17,9\end{array}$ & $\begin{array}{c}27 \\
22,1\end{array}$ & $\begin{array}{c}44 \\
15,2\end{array}$ & $\begin{array}{l}35 \\
24\end{array}$ \\
\hline
\end{tabular}


APÊNDICE 1. Concentração de elementos químicos (mg.kg-1) e incertezas relativas $(k=2)$ em amostras de solo sob cultivo orgânico

\begin{tabular}{|c|c|c|c|c|c|c|c|c|c|c|}
\hline & $\begin{array}{c}\text { Planta } \\
11 \\
\end{array}$ & $\begin{array}{c}\text { Planta } \\
12 \\
\end{array}$ & $\begin{array}{c}\text { Planta } \\
13 \\
\end{array}$ & $\begin{array}{c}\text { Planta } \\
14 \\
\end{array}$ & $\begin{array}{c}\text { Planta } \\
15 \\
\end{array}$ & $\begin{array}{c}\text { Planta } \\
16 \\
\end{array}$ & $\begin{array}{c}\text { Planta } \\
17 \\
\end{array}$ & $\begin{array}{c}\text { Planta } \\
18 \\
\end{array}$ & $\begin{array}{c}\text { Planta } \\
19 \\
\end{array}$ & $\begin{array}{c}\text { Planta } \\
20 \\
\end{array}$ \\
\hline As & $\begin{array}{c}1,2 \\
11\end{array}$ & $\begin{array}{c}1,6 \\
9,2\end{array}$ & $\begin{array}{c}1,9 \\
8\end{array}$ & $\begin{array}{l}1,4 \\
8,4\end{array}$ & $\begin{array}{c}1,4 \\
11\end{array}$ & $\begin{array}{l}1,7 \\
9,2\end{array}$ & $\begin{array}{c}1,6 \\
8\end{array}$ & $\begin{array}{l}1,6 \\
10,6\end{array}$ & $\begin{array}{l}1,6 \\
8,6\end{array}$ & $\begin{array}{c}1,6 \\
11\end{array}$ \\
\hline $\mathrm{Br}$ & $\begin{array}{c}2,56 \\
8,3\end{array}$ & $\begin{array}{c}3,64 \\
6,8\end{array}$ & $\begin{array}{c}4,19 \\
5,6\end{array}$ & $\begin{array}{c}2,51 \\
5,8\end{array}$ & $\begin{array}{c}2,66 \\
7,7\end{array}$ & $\begin{array}{c}3,22 \\
6,2\end{array}$ & $\begin{array}{c}2,96 \\
5,8\end{array}$ & $\begin{array}{c}2,80 \\
6,6\end{array}$ & $\begin{array}{c}2,60 \\
6,4\end{array}$ & $\begin{array}{c}2,46 \\
6,2\end{array}$ \\
\hline $\mathrm{Ce}$ & $\begin{array}{c}87,9 \\
4,4\end{array}$ & $\begin{array}{c}133,1 \\
4,4\end{array}$ & $\begin{array}{c}124,1 \\
4,0\end{array}$ & $\begin{array}{c}64,9 \\
4,4\end{array}$ & $\begin{array}{c}86,7 \\
4,2\end{array}$ & $\begin{array}{c}95,6 \\
4,0\end{array}$ & $\begin{array}{c}72,3 \\
3,8\end{array}$ & $\begin{array}{c}81,7 \\
7,8\end{array}$ & $\begin{array}{c}88,1 \\
8\end{array}$ & $\begin{array}{c}74,1 \\
8,2\end{array}$ \\
\hline Co & $\begin{array}{c}4,3 \\
3,0\end{array}$ & $\begin{array}{l}5,9 \\
2,8\end{array}$ & $\begin{array}{l}6,1 \\
2,8\end{array}$ & $\begin{array}{c}4,4 \\
3,0\end{array}$ & $\begin{array}{l}5,3 \\
2,8\end{array}$ & $\begin{array}{c}5,7 \\
4\end{array}$ & $\begin{array}{c}4,9 \\
4,6\end{array}$ & $\begin{array}{r}5,5 \\
4,4\end{array}$ & $\begin{array}{c}5,7 \\
4\end{array}$ & $\begin{array}{c}5,5 \\
4\end{array}$ \\
\hline $\mathrm{Cr}$ & $\begin{array}{c}156 \\
3,2\end{array}$ & $\begin{array}{c}153 \\
3,6\end{array}$ & $\begin{array}{c}160 \\
3,6\end{array}$ & $\begin{array}{c}108 \\
3,5\end{array}$ & $\begin{array}{c}129 \\
3,2\end{array}$ & $\begin{array}{c}118 \\
3,5\end{array}$ & $\begin{array}{c}114 \\
4,1\end{array}$ & $\begin{array}{c}114 \\
3,7\end{array}$ & $\begin{array}{c}104 \\
3,7\end{array}$ & $\begin{array}{c}148 \\
3,4\end{array}$ \\
\hline Cs & $\begin{array}{c}0,98 \\
8,4\end{array}$ & $\begin{array}{c}1,43 \\
7,2\end{array}$ & $\begin{array}{c}1,79 \\
8,2\end{array}$ & $\begin{array}{c}1,04 \\
10,2\end{array}$ & $\begin{array}{c}1,41 \\
7,4\end{array}$ & $\begin{array}{c}1,56 \\
7,8\end{array}$ & $\begin{array}{c}1,26 \\
7,6\end{array}$ & $\begin{array}{c}1,2 \\
8\end{array}$ & $\begin{array}{l}1,1 \\
8,4\end{array}$ & $\begin{array}{c}1 \\
8,4\end{array}$ \\
\hline $\mathrm{Eu}$ & $\begin{array}{c}1,18 \\
5\end{array}$ & $\begin{array}{c}1,83 \\
4,6\end{array}$ & $\begin{array}{c}1,57 \\
4,6\end{array}$ & $\begin{array}{c}0,87 \\
5,8\end{array}$ & $\begin{array}{c}1,17 \\
5\end{array}$ & $\begin{array}{c}1,11 \\
4,4\end{array}$ & $\begin{array}{c}0,94 \\
4,8\end{array}$ & $\begin{array}{c}0,93 \\
5\end{array}$ & $\begin{array}{c}1,03 \\
5,2\end{array}$ & $\begin{array}{c}0,87 \\
4,4\end{array}$ \\
\hline $\mathrm{Fe}$ & $\begin{array}{c}17421 \\
2,8\end{array}$ & $\begin{array}{c}24912 \\
2,6\end{array}$ & $\begin{array}{c}27322 \\
2,8\end{array}$ & $\begin{array}{c}19328 \\
2,8\end{array}$ & $\begin{array}{c}22819 \\
2,6\end{array}$ & $\begin{array}{c}25274 \\
4,0\end{array}$ & $\begin{array}{c}21040 \\
3,8\end{array}$ & $\begin{array}{c}23048 \\
3,8\end{array}$ & $\begin{array}{c}22866 \\
4,2\end{array}$ & $\begin{array}{c}22114 \\
4,2\end{array}$ \\
\hline Hf & $\begin{array}{c}12,3 \\
4,0\end{array}$ & $\begin{array}{c}14,0 \\
3,8\end{array}$ & $\begin{array}{c}14,9 \\
4,0\end{array}$ & $\begin{array}{c}12,2 \\
3,8\end{array}$ & $\begin{array}{c}11,4 \\
3,8\end{array}$ & $\begin{array}{c}11,9 \\
4,6\end{array}$ & $\begin{array}{r}9,5 \\
5,2\end{array}$ & $\begin{array}{r}8,7 \\
5,4\end{array}$ & $\begin{array}{c}10,6 \\
4,4\end{array}$ & $\begin{array}{c}11,7 \\
4,4\end{array}$ \\
\hline $\mathrm{K}$ & $\begin{array}{c}4215 \\
3,4\end{array}$ & $\begin{array}{c}3862 \\
3,2\end{array}$ & $\begin{array}{c}2302 \\
4,0\end{array}$ & $\begin{array}{c}1622 \\
5,2\end{array}$ & $\begin{array}{c}1721 \\
4,4\end{array}$ & $\begin{array}{c}1665 \\
5,2\end{array}$ & $\begin{array}{c}1493 \\
5,0\end{array}$ & $\begin{array}{c}1173 \\
9,2\end{array}$ & $\begin{array}{c}1073 \\
9,2\end{array}$ & $\begin{array}{c}1131 \\
7,0\end{array}$ \\
\hline $\mathrm{La}$ & $\begin{array}{c}43,4 \\
2,6\end{array}$ & $\begin{array}{c}65,7 \\
2,8\end{array}$ & $\begin{array}{c}54,9 \\
2,6\end{array}$ & $\begin{array}{c}31,0 \\
2,6\end{array}$ & $\begin{array}{c}40,3 \\
2,4\end{array}$ & $\begin{array}{c}44,2 \\
2,6\end{array}$ & $\begin{array}{c}31,5 \\
2,6\end{array}$ & $\begin{array}{c}35,6 \\
2,4\end{array}$ & $\begin{array}{c}39,1 \\
2,6\end{array}$ & $\begin{array}{c}31,3 \\
2,6\end{array}$ \\
\hline $\mathrm{Na}$ & $\begin{array}{c}372 \\
3,6\end{array}$ & $\begin{array}{c}308 \\
4,2\end{array}$ & $\begin{array}{c}180 \\
3,8\end{array}$ & $\begin{array}{c}174 \\
4,2\end{array}$ & $\begin{array}{c}143 \\
3,4\end{array}$ & $\begin{array}{l}144 \\
10,7\end{array}$ & $\begin{array}{c}117 \\
7,1\end{array}$ & $\begin{array}{l}85 \\
7,3\end{array}$ & $\begin{array}{l}90 \\
7,7\end{array}$ & $\begin{array}{l}92 \\
7,3\end{array}$ \\
\hline $\mathrm{Nd}$ & $\begin{array}{c}36,6 \\
11,0\end{array}$ & $\begin{array}{c}53,6 \\
7,2\end{array}$ & $\begin{array}{c}46,6 \\
8,0\end{array}$ & $\begin{array}{c}22,8 \\
11,4\end{array}$ & $\begin{array}{c}35,4 \\
10,4\end{array}$ & $\begin{array}{c}38,5 \\
78,4\end{array}$ & $\begin{array}{c}27,4 \\
60,2\end{array}$ & $\begin{array}{c}24,3 \\
50,2\end{array}$ & $\begin{array}{c}30,1 \\
58,8\end{array}$ & $\begin{array}{c}22,8 \\
45,0\end{array}$ \\
\hline Sc & $\begin{array}{c}4,46 \\
2,8\end{array}$ & $\begin{array}{c}6,78 \\
2,8\end{array}$ & $\begin{array}{c}7,85 \\
2,8\end{array}$ & $\begin{array}{c}4,82 \\
2,8\end{array}$ & $\begin{array}{c}6,17 \\
2,8\end{array}$ & $\begin{array}{c}6,89 \\
3,6\end{array}$ & $\begin{array}{c}5,94 \\
3,6\end{array}$ & $\begin{array}{c}6,87 \\
3,6\end{array}$ & $\begin{array}{c}6,48 \\
3,6\end{array}$ & $\begin{array}{c}6,44 \\
3,8\end{array}$ \\
\hline $\mathrm{Sm}$ & $\begin{array}{c}5,14 \\
7,4\end{array}$ & $\begin{array}{c}7,81 \\
8,8\end{array}$ & $\begin{array}{c}6,69 \\
9,8\end{array}$ & $\begin{array}{c}3,59 \\
11,8\end{array}$ & $\begin{array}{c}4,73 \\
7,6\end{array}$ & $\begin{array}{c}5,30 \\
5,8\end{array}$ & $\begin{array}{c}3,91 \\
5,8\end{array}$ & $\begin{array}{c}4,05 \\
5,4\end{array}$ & $\begin{array}{c}4,90 \\
5,8\end{array}$ & $\begin{array}{c}3,88 \\
5,6\end{array}$ \\
\hline Та & $\begin{array}{c}2,19 \\
7,8\end{array}$ & $\begin{array}{c}2,95 \\
7,6\end{array}$ & $\begin{array}{c}3,36 \\
7,6\end{array}$ & $\begin{array}{c}1,98 \\
7,8\end{array}$ & $\begin{array}{c}2,34 \\
8,2\end{array}$ & $\begin{array}{c}2,50 \\
8,4\end{array}$ & $\begin{array}{c}1,90 \\
8,2\end{array}$ & $\begin{array}{c}2,14 \\
8,0\end{array}$ & $\begin{array}{c}2,06 \\
8,6\end{array}$ & $\begin{array}{c}1,99 \\
7,8\end{array}$ \\
\hline $\mathrm{Tb}$ & $\begin{array}{c}0,44 \\
9,2\end{array}$ & $\begin{array}{c}0,76 \\
7,6\end{array}$ & $\begin{array}{c}0,66 \\
8,4\end{array}$ & $\begin{array}{c}0,35 \\
10,6\end{array}$ & $\begin{array}{r}0,47 \\
10,4\end{array}$ & $\begin{array}{c}0,49 \\
10,5\end{array}$ & $\begin{array}{c}0,38 \\
10,4\end{array}$ & $\begin{array}{c}0,45 \\
13,6\end{array}$ & $\begin{array}{c}0,47 \\
9,3\end{array}$ & $\begin{array}{r}0,37 \\
12,6\end{array}$ \\
\hline Th & $\begin{array}{r}9,2 \\
4,4\end{array}$ & $\begin{array}{c}12,9 \\
4,0\end{array}$ & $\begin{array}{c}13,1 \\
4,2\end{array}$ & $\begin{array}{l}7,2 \\
4,2\end{array}$ & $\begin{array}{l}10 \\
4,2\end{array}$ & $\begin{array}{c}12,1 \\
4,2\end{array}$ & $\begin{array}{r}7,4 \\
4,4\end{array}$ & $\begin{array}{c}8,6 \\
4,8\end{array}$ & $\begin{array}{c}11,3 \\
5,6\end{array}$ & $\begin{array}{c}8,3 \\
5,4\end{array}$ \\
\hline $\mathrm{U}$ & $\begin{array}{c}1,78 \\
30,0\end{array}$ & $\begin{array}{r}2,22 \\
22,2\end{array}$ & $\begin{array}{r}2,27 \\
21,0\end{array}$ & $\begin{array}{c}1,65 \\
32,4\end{array}$ & $\begin{array}{c}1,53 \\
27,6\end{array}$ & $\begin{array}{c}1,65 \\
31,2\end{array}$ & $\begin{array}{r}1,42 \\
32,8\end{array}$ & $\begin{array}{c}1,56 \\
20,4\end{array}$ & $\begin{array}{c}1,94 \\
23,6\end{array}$ & $\begin{array}{c}1,88 \\
24,6\end{array}$ \\
\hline $\mathrm{Yb}$ & $\begin{array}{c}1,23 \\
4,8\end{array}$ & $\begin{array}{c}1,91 \\
5,4\end{array}$ & $\begin{array}{c}2,09 \\
4,2\end{array}$ & $\begin{array}{c}1,29 \\
4,4\end{array}$ & $\begin{array}{c}1,62 \\
4,4\end{array}$ & $\begin{array}{c}1,59 \\
4,0\end{array}$ & $\begin{array}{c}1,71 \\
4,0\end{array}$ & $\begin{array}{c}1,81 \\
5,4\end{array}$ & $\begin{array}{c}1,65 \\
4,4\end{array}$ & $\begin{array}{c}1,81 \\
4,0\end{array}$ \\
\hline $\mathrm{Zn}$ & $\begin{array}{c}32 \\
15,7\end{array}$ & $\begin{array}{c}44 \\
12,4\end{array}$ & $\begin{array}{c}45 \\
16,4\end{array}$ & $\begin{array}{c}32 \\
16,3\end{array}$ & $\begin{array}{c}37 \\
18,3\end{array}$ & $\begin{array}{c}32 \\
25,0\end{array}$ & $\begin{array}{c}32 \\
21,3\end{array}$ & $\begin{array}{c}33 \\
24,2\end{array}$ & $\begin{array}{c}28 \\
31,0\end{array}$ & $\begin{array}{c}31 \\
25,2\end{array}$ \\
\hline
\end{tabular}


APÊNDICE 1. Concentração de elementos químicos (mg.kg-1) e incertezas relativas $(k=2)$ em amostras de solo sob cultivo orgânico

\begin{tabular}{|c|c|c|c|c|c|c|c|c|c|c|}
\hline & $\begin{array}{c}\text { Planta } \\
21 \\
\end{array}$ & $\begin{array}{c}\text { Planta } \\
22 \\
\end{array}$ & $\begin{array}{c}\text { Planta } \\
23 \\
\end{array}$ & $\begin{array}{c}\text { Planta } \\
24 \\
\end{array}$ & $\begin{array}{c}\text { Planta } \\
25 \\
\end{array}$ & $\begin{array}{c}\text { Planta } \\
26 \\
\end{array}$ & $\begin{array}{c}\text { Planta } \\
27 \\
\end{array}$ & $\begin{array}{c}\text { Planta } \\
28 \\
\end{array}$ & $\begin{array}{c}\text { Planta } \\
29 \\
\end{array}$ & $\begin{array}{c}\text { Planta } \\
30 \\
\end{array}$ \\
\hline As & $\begin{array}{c}1,79 \\
9,0\end{array}$ & $\begin{array}{c}1,78 \\
14,0\end{array}$ & $\begin{array}{c}1,60 \\
9,0\end{array}$ & $\begin{array}{c}1,43 \\
11,4\end{array}$ & $\begin{array}{c}1,26 \\
9,0\end{array}$ & $\begin{array}{c}1,60 \\
9,2\end{array}$ & $\begin{array}{c}1,38 \\
10,8\end{array}$ & $\begin{array}{c}1,33 \\
15,6\end{array}$ & $\begin{array}{r}1,41 \\
11,4\end{array}$ & $\begin{array}{c}1,42 \\
15,8\end{array}$ \\
\hline $\mathrm{Br}$ & $\begin{array}{c}2,89 \\
6,4\end{array}$ & $\begin{array}{c}3,37 \\
6,6\end{array}$ & $\begin{array}{c}2,98 \\
6,0\end{array}$ & $\begin{array}{c}2,63 \\
6,4\end{array}$ & $\begin{array}{c}2,34 \\
6,2\end{array}$ & $\begin{array}{c}3,08 \\
6,2\end{array}$ & $\begin{array}{c}2,63 \\
6,6\end{array}$ & $\begin{array}{c}2,58 \\
7,6\end{array}$ & $\begin{array}{c}2,71 \\
7,2\end{array}$ & $\begin{array}{c}2,78 \\
7,0\end{array}$ \\
\hline $\mathrm{Ce}$ & $\begin{array}{l}98 \\
4,2\end{array}$ & $\begin{array}{c}103 \\
4,2\end{array}$ & $\begin{array}{l}85 \\
8,4\end{array}$ & $\begin{array}{c}103 \\
7,6\end{array}$ & $\begin{array}{c}75 \\
11,2\end{array}$ & $\begin{array}{c}100 \\
3,8\end{array}$ & $\begin{array}{l}87 \\
6,8\end{array}$ & $\begin{array}{l}96 \\
8,2\end{array}$ & $\begin{array}{l}98 \\
6,6\end{array}$ & $\begin{array}{l}94 \\
4,0\end{array}$ \\
\hline Co & $\begin{array}{c}6,25 \\
4,0\end{array}$ & $\begin{array}{c}6,15 \\
3,8\end{array}$ & $\begin{array}{c}6,61 \\
4,0\end{array}$ & $\begin{array}{c}7,20 \\
3,8\end{array}$ & $\begin{array}{c}5,31 \\
4,0\end{array}$ & $\begin{array}{c}6,14 \\
4,2\end{array}$ & $\begin{array}{c}6,22 \\
4,6\end{array}$ & $\begin{array}{c}6,70 \\
4,2\end{array}$ & $\begin{array}{c}7,57 \\
4,0\end{array}$ & $\begin{array}{l}6,6 \\
4,2\end{array}$ \\
\hline $\mathrm{Cr}$ & $\begin{array}{c}129 \\
3,8\end{array}$ & $\begin{array}{c}119 \\
3,9\end{array}$ & $\begin{array}{c}135 \\
3,6\end{array}$ & $\begin{array}{c}145 \\
3,6\end{array}$ & $\begin{array}{c}121 \\
3,5\end{array}$ & $\begin{array}{c}144 \\
3,4\end{array}$ & $\begin{array}{c}122 \\
3,7\end{array}$ & $\begin{array}{c}139 \\
3,4\end{array}$ & $\begin{array}{c}198 \\
3,2\end{array}$ & $\begin{array}{c}142 \\
3,4\end{array}$ \\
\hline Cs & $\begin{array}{c}1,24 \\
9,2\end{array}$ & $\begin{array}{c}1,34 \\
10,4\end{array}$ & $\begin{array}{c}1,24 \\
10,0\end{array}$ & $\begin{array}{c}1,36 \\
8,0\end{array}$ & $\begin{array}{c}0,94 \\
9,6\end{array}$ & $\begin{array}{c}1,15 \\
8,6\end{array}$ & $\begin{array}{c}1,16 \\
8,2\end{array}$ & $\begin{array}{c}1,10 \\
8,4\end{array}$ & $\begin{array}{c}1,20 \\
8,2\end{array}$ & $\begin{array}{c}1,13 \\
8,6\end{array}$ \\
\hline $\mathrm{Eu}$ & $\begin{array}{c}1,05 \\
4,2\end{array}$ & $\begin{array}{c}1,13 \\
4,4\end{array}$ & $\begin{array}{c}1,09 \\
4,2\end{array}$ & $\begin{array}{c}1,32 \\
4,0\end{array}$ & $\begin{array}{c}0,97 \\
4,4\end{array}$ & $\begin{array}{c}1,16 \\
4,8\end{array}$ & $\begin{array}{c}1,08 \\
4,2\end{array}$ & $\begin{array}{c}1,05 \\
4,2\end{array}$ & $\begin{array}{c}1,21 \\
4,4\end{array}$ & $\begin{array}{c}1,21 \\
4,2\end{array}$ \\
\hline $\mathrm{Fe}$ & $\begin{array}{c}25936 \\
3,8\end{array}$ & $\begin{array}{c}25002 \\
3,8\end{array}$ & $\begin{array}{c}24213 \\
3,8\end{array}$ & $\begin{array}{c}26203 \\
3,6\end{array}$ & $\begin{array}{c}19731 \\
4,0\end{array}$ & $\begin{array}{c}22834 \\
4,0\end{array}$ & $\begin{array}{c}22414 \\
3,8\end{array}$ & $\begin{array}{c}20929 \\
4,0\end{array}$ & $\begin{array}{c}22942 \\
3,8\end{array}$ & $\begin{array}{c}21435 \\
4,2\end{array}$ \\
\hline $\mathrm{Hf}$ & $\begin{array}{c}12,9 \\
5,4\end{array}$ & $\begin{array}{c}10,6 \\
4,6\end{array}$ & $\begin{array}{c}13,2 \\
4,4\end{array}$ & $\begin{array}{c}11,9 \\
4,8\end{array}$ & $\begin{array}{r}9,9 \\
4,4\end{array}$ & $\begin{array}{c}11,7 \\
4,6\end{array}$ & $\begin{array}{c}9,6 \\
4,6\end{array}$ & $\begin{array}{c}10,6 \\
4,6\end{array}$ & $\begin{array}{c}14,8 \\
4,2\end{array}$ & $\begin{array}{c}10,9 \\
4,6\end{array}$ \\
\hline $\mathrm{K}$ & $\begin{array}{c}1472 \\
9,2\end{array}$ & $\begin{array}{c}2229 \\
7,4\end{array}$ & $\begin{array}{c}3012 \\
6,2\end{array}$ & $\begin{array}{c}3261 \\
6,2\end{array}$ & $\begin{array}{c}3015 \\
4,4\end{array}$ & $\begin{array}{c}3626 \\
5,2\end{array}$ & $\begin{array}{c}4173 \\
6,0\end{array}$ & $\begin{array}{c}4357 \\
5,6\end{array}$ & $\begin{array}{c}5010 \\
12,4\end{array}$ & $\begin{array}{c}5490 \\
7,0\end{array}$ \\
\hline $\mathrm{La}$ & $\begin{array}{c}40,2 \\
2,6\end{array}$ & $\begin{array}{c}42,6 \\
2,6\end{array}$ & $\begin{array}{c}39,9 \\
2,6\end{array}$ & $\begin{array}{c}48,9 \\
2,6\end{array}$ & $\begin{array}{c}37,4 \\
2,6\end{array}$ & $\begin{array}{c}43,5 \\
2,6\end{array}$ & $\begin{array}{c}39,7 \\
2,6\end{array}$ & $\begin{array}{c}44,0 \\
2,6\end{array}$ & $\begin{array}{c}45,2 \\
2,4\end{array}$ & $\begin{array}{c}42,0 \\
2,6\end{array}$ \\
\hline $\mathrm{Na}$ & $\begin{array}{c}113 \\
5,1\end{array}$ & $\begin{array}{c}146 \\
7,5\end{array}$ & $\begin{array}{c}183 \\
7,9\end{array}$ & $\begin{array}{c}198 \\
8,1\end{array}$ & $\begin{array}{c}200 \\
5,0\end{array}$ & $\begin{array}{c}234 \\
6,6\end{array}$ & $\begin{array}{c}255 \\
8,0\end{array}$ & $\begin{array}{l}286 \\
11,0\end{array}$ & $\begin{array}{c}308 \\
8,4\end{array}$ & $\begin{array}{l}357 \\
12,0\end{array}$ \\
\hline $\mathrm{Nd}$ & $\begin{array}{c}39,1 \\
82,8\end{array}$ & $\begin{array}{c}36,9 \\
73,8\end{array}$ & $\begin{array}{c}32,1 \\
64,2\end{array}$ & $\begin{array}{c}37,7 \\
85,0\end{array}$ & $\begin{array}{c}25,4 \\
50,8\end{array}$ & $\begin{array}{c}39,3 \\
82,8\end{array}$ & $\begin{array}{c}31,9 \\
70,4\end{array}$ & $\begin{array}{c}36,4 \\
70,4\end{array}$ & $\begin{array}{c}37,6 \\
76,0\end{array}$ & $\begin{array}{c}35,6 \\
70,4\end{array}$ \\
\hline Sc & $\begin{array}{c}7,70 \\
3,6\end{array}$ & $\begin{array}{c}7,73 \\
3,6\end{array}$ & $\begin{array}{c}6,92 \\
3,6\end{array}$ & $\begin{array}{c}7,96 \\
3,8\end{array}$ & $\begin{array}{c}5,70 \\
3,6\end{array}$ & $\begin{array}{c}6,81 \\
3,6\end{array}$ & $\begin{array}{c}6,65 \\
3,6\end{array}$ & $\begin{array}{c}6,13 \\
3,6\end{array}$ & $\begin{array}{c}7,00 \\
3,6\end{array}$ & $\begin{array}{c}6,80 \\
3,6\end{array}$ \\
\hline Sm & $\begin{array}{c}5,05 \\
5,8\end{array}$ & $\begin{array}{c}5,32 \\
5,8\end{array}$ & $\begin{array}{c}5,02 \\
5,8\end{array}$ & $\begin{array}{c}6,20 \\
6,0\end{array}$ & $\begin{array}{c}4,42 \\
6,4\end{array}$ & $\begin{array}{c}6,00 \\
5,8\end{array}$ & $\begin{array}{c}4,91 \\
5,6\end{array}$ & $\begin{array}{c}5,41 \\
5,6\end{array}$ & $\begin{array}{c}5,79 \\
5,6\end{array}$ & $\begin{array}{c}5,21 \\
5,4\end{array}$ \\
\hline Та & $\begin{array}{c}2,35 \\
8,0\end{array}$ & $\begin{array}{c}2,39 \\
8,2\end{array}$ & $\begin{array}{c}2,27 \\
8,0\end{array}$ & $\begin{array}{c}2,51 \\
7,8\end{array}$ & $\begin{array}{c}1,86 \\
7,8\end{array}$ & $\begin{array}{c}2,20 \\
8,0\end{array}$ & $\begin{array}{c}2,09 \\
8,2\end{array}$ & $\begin{array}{c}2,02 \\
7,8\end{array}$ & $\begin{array}{c}2,25 \\
8,0\end{array}$ & $\begin{array}{c}2,23 \\
8,0\end{array}$ \\
\hline $\mathrm{Tb}$ & $\begin{array}{c}0,53 \\
9,2\end{array}$ & $\begin{array}{c}0,49 \\
11,3\end{array}$ & $\begin{array}{c}0,49 \\
9,7\end{array}$ & $\begin{array}{c}0,57 \\
8,4\end{array}$ & $\begin{array}{c}0,38 \\
10,4\end{array}$ & $\begin{array}{c}0,55 \\
9,0\end{array}$ & $\begin{array}{c}0,46 \\
10,4\end{array}$ & $\begin{array}{c}0,51 \\
11,0\end{array}$ & $\begin{array}{c}0,54 \\
9,6\end{array}$ & $\begin{array}{c}0,49 \\
13,6\end{array}$ \\
\hline Th & $\begin{array}{c}12,5 \\
4,4\end{array}$ & $\begin{array}{c}11,3 \\
4,2\end{array}$ & $\begin{array}{c}10,4 \\
6,0\end{array}$ & $\begin{array}{c}11,5 \\
5,0\end{array}$ & $\begin{array}{l}8,2 \\
4,6\end{array}$ & $\begin{array}{c}12,5 \\
4,2\end{array}$ & $\begin{array}{c}9,6 \\
5,4\end{array}$ & $\begin{array}{c}12,7 \\
5,8\end{array}$ & $\begin{array}{c}10,8 \\
5,8\end{array}$ & $\begin{array}{l}9,7 \\
4,2\end{array}$ \\
\hline $\mathrm{U}$ & $\begin{array}{l}1,9 \\
21\end{array}$ & $\begin{array}{l}1,9 \\
22,2\end{array}$ & $\begin{array}{l}1,5 \\
34,6\end{array}$ & $\begin{array}{c}2 \\
33\end{array}$ & $\begin{array}{c}1,8 \\
19\end{array}$ & $\begin{array}{l}1,6 \\
25,4\end{array}$ & $\begin{array}{l}1,3 \\
21,8\end{array}$ & $\begin{array}{c}2 \\
22,2\end{array}$ & $\begin{array}{l}2,6 \\
16,4\end{array}$ & $\begin{array}{c}1,2 \\
40\end{array}$ \\
\hline $\mathrm{Yb}$ & $\begin{array}{c}2,16 \\
3,6\end{array}$ & $\begin{array}{c}1,88 \\
3,8\end{array}$ & $\begin{array}{c}1,85 \\
4,4\end{array}$ & $\begin{array}{c}2,00 \\
4,0\end{array}$ & $\begin{array}{c}1,43 \\
4,4\end{array}$ & $\begin{array}{c}1,71 \\
3,8\end{array}$ & $\begin{array}{c}1,55 \\
4,6\end{array}$ & $\begin{array}{c}1,63 \\
4,4\end{array}$ & $\begin{array}{c}2,07 \\
4,0\end{array}$ & $\begin{array}{c}1,79 \\
3,8\end{array}$ \\
\hline Zn & $\begin{array}{c}33 \\
44,7\end{array}$ & $\begin{array}{c}34 \\
26,0\end{array}$ & $\begin{array}{c}29 \\
38,9\end{array}$ & $\begin{array}{c}36 \\
40,8\end{array}$ & $\begin{array}{c}24 \\
63,4\end{array}$ & $\begin{array}{c}32 \\
24,2\end{array}$ & $\begin{array}{c}30 \\
31,5\end{array}$ & $\begin{array}{c}35 \\
32,7\end{array}$ & $\begin{array}{c}29 \\
35,9\end{array}$ & $\begin{array}{c}32 \\
19,5\end{array}$ \\
\hline
\end{tabular}


APÊNDICE 2. Concentração de elementos químicos $\left(m g \cdot \mathrm{kg}^{-1}\right)$ e incertezas relativas $(k=2)$ em amostras de solo sob cultivo convencional

\begin{tabular}{|c|c|c|c|c|c|c|c|c|c|c|}
\hline & $\begin{array}{c}\text { Planta } \\
1\end{array}$ & $\begin{array}{c}\text { Planta } \\
2 \\
\end{array}$ & $\begin{array}{c}\text { Planta } \\
3\end{array}$ & $\begin{array}{c}\text { Planta } \\
4\end{array}$ & $\begin{array}{c}\text { Planta } \\
5\end{array}$ & $\begin{array}{c}\text { Planta } \\
6\end{array}$ & $\begin{array}{c}\text { Planta } \\
7\end{array}$ & $\begin{array}{c}\text { Planta } \\
8\end{array}$ & $\begin{array}{c}\text { Planta } \\
9\end{array}$ & $\begin{array}{c}\text { Planta } \\
10\end{array}$ \\
\hline As & $\begin{array}{c}3,54 \\
5,4\end{array}$ & $\begin{array}{c}3,40 \\
5,8\end{array}$ & $\begin{array}{c}3,70 \\
5,6\end{array}$ & $\begin{array}{c}3,77 \\
5,0\end{array}$ & $\begin{array}{c}3,30 \\
5,6\end{array}$ & $\begin{array}{c}3,62 \\
6,8\end{array}$ & $\begin{array}{c}4,91 \\
5,4\end{array}$ & $\begin{array}{c}3,46 \\
6,4\end{array}$ & $\begin{array}{c}3,27 \\
5,8\end{array}$ & $\begin{array}{c}3,53 \\
5,2\end{array}$ \\
\hline $\mathrm{Br}$ & $\begin{array}{c}4,68 \\
5,2\end{array}$ & $\begin{array}{c}4,81 \\
5,6\end{array}$ & $\begin{array}{c}4,88 \\
5,8\end{array}$ & $\begin{array}{c}3,99 \\
5,2\end{array}$ & $\begin{array}{c}5,11 \\
5,6\end{array}$ & $\begin{array}{c}4,12 \\
5,4\end{array}$ & $\begin{array}{c}3,83 \\
5,8\end{array}$ & $\begin{array}{c}3,64 \\
6,4\end{array}$ & $\begin{array}{c}3,36 \\
5,8\end{array}$ & $\begin{array}{c}3,35 \\
5,8\end{array}$ \\
\hline $\mathrm{Ce}$ & $\begin{array}{l}76 \\
4,2\end{array}$ & $\begin{array}{l}81 \\
4,4\end{array}$ & $\begin{array}{l}89 \\
4,2\end{array}$ & $\begin{array}{l}89 \\
4,4\end{array}$ & $\begin{array}{l}86 \\
4,0\end{array}$ & $\begin{array}{l}97 \\
4,4\end{array}$ & $\begin{array}{l}91 \\
4,4\end{array}$ & $\begin{array}{l}81 \\
4,0\end{array}$ & $\begin{array}{l}83 \\
4,2\end{array}$ & $\begin{array}{l}90 \\
4,6\end{array}$ \\
\hline Co & $\begin{array}{c}3,12 \\
3,2\end{array}$ & $\begin{array}{c}3,12 \\
3,2\end{array}$ & $\begin{array}{c}3,33 \\
3,4\end{array}$ & $\begin{array}{c}3,40 \\
3,4\end{array}$ & $\begin{array}{c}3,23 \\
3,2\end{array}$ & $\begin{array}{c}3,35 \\
3,4\end{array}$ & $\begin{array}{c}3,23 \\
3,4\end{array}$ & $\begin{array}{c}3,15 \\
3,4\end{array}$ & $\begin{array}{c}3,36 \\
3,6\end{array}$ & $\begin{array}{r}3,3 \\
3,4\end{array}$ \\
\hline $\mathrm{Cr}$ & $\begin{array}{c}117 \\
3,2\end{array}$ & $\begin{array}{c}123 \\
3,6\end{array}$ & $\begin{array}{c}138 \\
3,2\end{array}$ & $\begin{array}{c}137 \\
3,6\end{array}$ & $\begin{array}{c}122 \\
4,0\end{array}$ & $\begin{array}{c}123 \\
3,2\end{array}$ & $\begin{array}{c}121 \\
3,9\end{array}$ & $\begin{array}{c}126 \\
3,0\end{array}$ & $\begin{array}{c}116 \\
3,2\end{array}$ & $\begin{array}{c}134 \\
3,6\end{array}$ \\
\hline Cs & $\begin{array}{c}0,85 \\
12,2\end{array}$ & $\begin{array}{c}0,71 \\
16,2\end{array}$ & $\begin{array}{r}0,72 \\
13,6\end{array}$ & $\begin{array}{c}0,78 \\
12,8\end{array}$ & $\begin{array}{r}0,77 \\
16,6\end{array}$ & $\begin{array}{c}0,74 \\
12,6\end{array}$ & $\begin{array}{c}0,69 \\
11,2\end{array}$ & $\begin{array}{c}0,63 \\
19,8\end{array}$ & $\begin{array}{r}0,87 \\
10,6\end{array}$ & $\begin{array}{r}0,74 \\
15,4\end{array}$ \\
\hline $\mathrm{Eu}$ & $\begin{array}{c}0,65 \\
7,0\end{array}$ & $\begin{array}{c}0,64 \\
7,2\end{array}$ & $\begin{array}{c}0,66 \\
6,6\end{array}$ & $\begin{array}{c}0,67 \\
4,8\end{array}$ & $\begin{array}{c}0,67 \\
5,8\end{array}$ & $\begin{array}{c}0,71 \\
5,6\end{array}$ & $\begin{array}{c}0,61 \\
6,0\end{array}$ & $\begin{array}{c}0,56 \\
7,0\end{array}$ & $\begin{array}{c}0,62 \\
6,6\end{array}$ & $\begin{array}{c}0,67 \\
5,8\end{array}$ \\
\hline $\mathrm{Fe}$ & $\begin{array}{c}26082 \\
2,8\end{array}$ & $\begin{array}{c}28263 \\
2,8\end{array}$ & $\begin{array}{c}29508 \\
2,6\end{array}$ & $\begin{array}{c}28480 \\
2,8\end{array}$ & $\begin{array}{c}27882 \\
2,8\end{array}$ & $\begin{array}{c}29545 \\
2,8\end{array}$ & $\begin{array}{c}28177 \\
3,0\end{array}$ & $\begin{array}{c}27647 \\
2,8\end{array}$ & $\begin{array}{c}27663 \\
2,8\end{array}$ & $\begin{array}{c}28509 \\
2,8\end{array}$ \\
\hline Hf & $\begin{array}{c}13,6 \\
3,6\end{array}$ & $\begin{array}{c}12,4 \\
3,6\end{array}$ & $\begin{array}{c}12,5 \\
3,6\end{array}$ & $\begin{array}{c}12,8 \\
4,0\end{array}$ & $\begin{array}{c}13,5 \\
3,4\end{array}$ & $\begin{array}{c}13,2 \\
4,0\end{array}$ & $\begin{array}{c}11,4 \\
3,8\end{array}$ & $\begin{array}{c}10,8 \\
3,6\end{array}$ & $\begin{array}{c}12,7 \\
3,6\end{array}$ & $\begin{array}{c}15,0 \\
3,6\end{array}$ \\
\hline $\mathrm{K}$ & $\begin{array}{c}281 \\
8,8\end{array}$ & $\begin{array}{l}275 \\
10,2\end{array}$ & $\begin{array}{l}292 \\
10,0\end{array}$ & $\begin{array}{c}250 \\
8,8\end{array}$ & $\begin{array}{c}682 \\
7,8\end{array}$ & $\begin{array}{l}375 \\
11,0\end{array}$ & $\begin{array}{l}282 \\
15,8\end{array}$ & $\begin{array}{l}286 \\
16,6\end{array}$ & $\begin{array}{l}325 \\
14,0\end{array}$ & $\begin{array}{l}241 \\
11,4\end{array}$ \\
\hline $\mathrm{La}$ & $\begin{array}{c}24,9 \\
2,6\end{array}$ & $\begin{array}{c}23,8 \\
2,6\end{array}$ & $\begin{array}{c}25,3 \\
2,6\end{array}$ & $\begin{array}{c}26,1 \\
2,6\end{array}$ & $\begin{array}{c}26,0 \\
2,6\end{array}$ & $\begin{array}{c}28,1 \\
2,6\end{array}$ & $\begin{array}{c}24,1 \\
2,6\end{array}$ & $\begin{array}{c}22,9 \\
2,6\end{array}$ & $\begin{array}{c}22,6 \\
2,6\end{array}$ & $\begin{array}{c}23,4 \\
2,4\end{array}$ \\
\hline $\mathrm{Na}$ & $\begin{array}{c}45,0 \\
4,2\end{array}$ & $\begin{array}{c}40,4 \\
5,1\end{array}$ & $\begin{array}{c}44,1 \\
5,9\end{array}$ & $\begin{array}{c}38,7 \\
4,0\end{array}$ & $\begin{array}{c}60,2 \\
4,0\end{array}$ & $\begin{array}{c}50,2 \\
4,8\end{array}$ & $\begin{array}{c}50,4 \\
5,4\end{array}$ & $\begin{array}{c}43,7 \\
6,3\end{array}$ & $\begin{array}{c}47,8 \\
5,4\end{array}$ & $\begin{array}{c}41,4 \\
4,5\end{array}$ \\
\hline $\mathrm{Nd}$ & $\begin{array}{c}21 \\
15,6\end{array}$ & $\begin{array}{c}21 \\
20,8\end{array}$ & $\begin{array}{c}18 \\
19,8\end{array}$ & $\begin{array}{c}18 \\
21,8\end{array}$ & $\begin{array}{c}22 \\
15,4\end{array}$ & $\begin{array}{c}24 \\
12,4\end{array}$ & $\begin{array}{c}23 \\
12,6\end{array}$ & $\begin{array}{c}22 \\
17,4\end{array}$ & $\begin{array}{c}17 \\
20,0\end{array}$ & $\begin{array}{c}17 \\
26,6\end{array}$ \\
\hline Sc & $\begin{array}{c}9,54 \\
3,0\end{array}$ & $\begin{array}{c}9,80 \\
2,8\end{array}$ & $\begin{array}{c}9,82 \\
3,0\end{array}$ & $\begin{array}{c}9,05 \\
3,0\end{array}$ & $\begin{array}{c}8,44 \\
3,0\end{array}$ & $\begin{array}{c}9,22 \\
3,0\end{array}$ & $\begin{array}{c}8,69 \\
3,0\end{array}$ & $\begin{array}{c}8,65 \\
2,8\end{array}$ & $\begin{array}{c}8,57 \\
3,0\end{array}$ & $\begin{array}{r}9,0 \\
3,0\end{array}$ \\
\hline $\mathrm{Sm}$ & $\begin{array}{c}3 \\
7,0\end{array}$ & $\begin{array}{c}2 \\
9,4\end{array}$ & $\begin{array}{c}3 \\
10,6\end{array}$ & $\begin{array}{c}3 \\
6,8\end{array}$ & $\begin{array}{c}3 \\
5,8\end{array}$ & $\begin{array}{c}3 \\
6,4\end{array}$ & $\begin{array}{c}2 \\
5,4\end{array}$ & $\begin{array}{c}2 \\
5,4\end{array}$ & $\begin{array}{c}2 \\
5,6\end{array}$ & $\begin{array}{c}3 \\
5,8\end{array}$ \\
\hline Та & $\begin{array}{c}3,07 \\
7,6\end{array}$ & $\begin{array}{c}3,20 \\
7,6\end{array}$ & $\begin{array}{c}3,15 \\
7,6\end{array}$ & $\begin{array}{c}2,99 \\
7,6\end{array}$ & $\begin{array}{c}2,76 \\
7,8\end{array}$ & $\begin{array}{c}3,16 \\
7,6\end{array}$ & $\begin{array}{c}2,81 \\
7,8\end{array}$ & $\begin{array}{c}3,25 \\
9,0\end{array}$ & $\begin{array}{c}2,80 \\
7,6\end{array}$ & $\begin{array}{c}2,87 \\
7,8\end{array}$ \\
\hline $\mathrm{Tb}$ & $\begin{array}{c}0,30 \\
15,2\end{array}$ & $\begin{array}{c}0,28 \\
15,8\end{array}$ & $\begin{array}{c}0,28 \\
15,2\end{array}$ & $\begin{array}{c}0,30 \\
12,2\end{array}$ & $\begin{array}{r}0,27 \\
14,2\end{array}$ & $\begin{array}{c}0,33 \\
16,0\end{array}$ & $\begin{array}{r}0,25 \\
16,6\end{array}$ & $\begin{array}{r}0,30 \\
16,6\end{array}$ & $\begin{array}{c}0,26 \\
17,6\end{array}$ & $\begin{array}{r}0,37 \\
12,4\end{array}$ \\
\hline Th & $\begin{array}{l}13 \\
4,0\end{array}$ & $\begin{array}{l}12 \\
4,4\end{array}$ & $\begin{array}{l}13 \\
4,2\end{array}$ & $\begin{array}{l}12 \\
4,2\end{array}$ & $\begin{array}{l}11 \\
4,0\end{array}$ & $\begin{array}{l}12 \\
4,2\end{array}$ & $\begin{array}{l}11 \\
4,4\end{array}$ & $\begin{array}{l}11 \\
4,4\end{array}$ & $\begin{array}{l}12 \\
4,0\end{array}$ & $\begin{array}{l}12 \\
4,6\end{array}$ \\
\hline $\mathrm{U}$ & $\begin{array}{l}2,1 \\
20,4\end{array}$ & $\begin{array}{l}1,3 \\
52,4\end{array}$ & $\begin{array}{l}2,0 \\
30,6\end{array}$ & $\begin{array}{l}1,5 \\
21,6\end{array}$ & $\begin{array}{l}1,7 \\
24,8\end{array}$ & $\begin{array}{l}1,5 \\
33,8\end{array}$ & $\begin{array}{l}2,1 \\
25,0\end{array}$ & $\begin{array}{l}1,7 \\
38,2\end{array}$ & $\begin{array}{l}1,7 \\
18,6\end{array}$ & $\begin{array}{l}2,3 \\
18,0\end{array}$ \\
\hline $\mathrm{Yb}$ & $\begin{array}{c}1,46 \\
4,4\end{array}$ & $\begin{array}{c}1,32 \\
5,8\end{array}$ & $\begin{array}{c}1,35 \\
4,8\end{array}$ & $\begin{array}{c}1,37 \\
5,0\end{array}$ & $\begin{array}{c}1,31 \\
5,0\end{array}$ & $\begin{array}{c}1,58 \\
4,0\end{array}$ & $\begin{array}{c}1,28 \\
4,6\end{array}$ & $\begin{array}{c}1,30 \\
5,2\end{array}$ & $\begin{array}{c}1,34 \\
4,2\end{array}$ & $\begin{array}{c}2,05 \\
3,8\end{array}$ \\
\hline $\mathrm{Zn}$ & $\begin{array}{c}32,6 \\
20,8\end{array}$ & $\begin{array}{r}32,7 \\
23,7\end{array}$ & $\begin{array}{c}30,9 \\
48,9\end{array}$ & $\begin{array}{c}35,6 \\
19,3\end{array}$ & $\begin{array}{c}43,3 \\
17,6\end{array}$ & $\begin{array}{c}35,0 \\
20,2\end{array}$ & $\begin{array}{c}29,8 \\
26,4\end{array}$ & $\begin{array}{r}33,2 \\
26,4\end{array}$ & $\begin{array}{c}30,1 \\
33,7\end{array}$ & $\begin{array}{c}32,9 \\
21,2\end{array}$ \\
\hline
\end{tabular}


APÊNDICE 2. Concentração de elementos químicos (mg.kg-1) e incertezas relativas (k=2) em amostras de solo sob cultivo convencional

\begin{tabular}{|c|c|c|c|c|c|c|c|c|c|c|}
\hline & $\begin{array}{c}\text { Planta } \\
11\end{array}$ & $\begin{array}{c}\text { Planta } \\
12\end{array}$ & $\begin{array}{c}\text { Planta } \\
13\end{array}$ & $\begin{array}{c}\text { Planta } \\
14\end{array}$ & $\begin{array}{c}\text { Planta } \\
15\end{array}$ & $\begin{array}{c}\text { Planta } \\
16\end{array}$ & $\begin{array}{c}\text { Planta } \\
17\end{array}$ & $\begin{array}{c}\text { Planta } \\
18\end{array}$ & $\begin{array}{c}\text { Planta } \\
19\end{array}$ & $\begin{array}{c}\text { Planta } \\
20\end{array}$ \\
\hline As & $\begin{array}{c}3,57 \\
6,2\end{array}$ & $\begin{array}{c}3,46 \\
6,8\end{array}$ & $\begin{array}{c}3,66 \\
5,4\end{array}$ & $\begin{array}{c}3,67 \\
5,6\end{array}$ & $\begin{array}{c}3,29 \\
5,6\end{array}$ & $\begin{array}{c}3,83 \\
5,6\end{array}$ & $\begin{array}{c}3,57 \\
5,6\end{array}$ & $\begin{array}{c}3,51 \\
5,8\end{array}$ & $\begin{array}{c}4,17 \\
9,6\end{array}$ & $\begin{array}{c}3,64 \\
5,8\end{array}$ \\
\hline $\mathrm{Br}$ & $\begin{array}{c}3,9 \\
6,0\end{array}$ & $\begin{array}{c}4,0 \\
5,8\end{array}$ & $\begin{array}{c}3,3 \\
5,6\end{array}$ & $\begin{array}{c}3,3 \\
6,0\end{array}$ & $\begin{array}{c}3,3 \\
6,0\end{array}$ & $\begin{array}{r}3,7 \\
5,4\end{array}$ & $\begin{array}{c}3,9 \\
5,0\end{array}$ & $\begin{array}{r}4,0 \\
5,2\end{array}$ & $\begin{array}{c}5,0 \\
5,8\end{array}$ & $\begin{array}{r}4,0 \\
5,6\end{array}$ \\
\hline $\mathrm{Ce}$ & $\begin{array}{l}89 \\
4,2\end{array}$ & $\begin{array}{l}83 \\
3,8\end{array}$ & $\begin{array}{l}86 \\
4,0\end{array}$ & $\begin{array}{l}87 \\
4,4\end{array}$ & $\begin{array}{l}81 \\
4,4\end{array}$ & $\begin{array}{l}91 \\
8,8\end{array}$ & $\begin{array}{l}99 \\
6,0\end{array}$ & $\begin{array}{l}83 \\
5,8\end{array}$ & $\begin{array}{c}102 \\
8,8\end{array}$ & $\begin{array}{l}87 \\
3,8\end{array}$ \\
\hline Co & $\begin{array}{c}3,44 \\
3,2\end{array}$ & $\begin{array}{c}3,17 \\
3,4\end{array}$ & $\begin{array}{c}3,29 \\
3,4\end{array}$ & $\begin{array}{c}3,42 \\
3,2\end{array}$ & $\begin{array}{c}2,98 \\
3,4\end{array}$ & $\begin{array}{c}3,50 \\
4,6\end{array}$ & $\begin{array}{c}3,35 \\
4,2\end{array}$ & $\begin{array}{c}2,99 \\
4,2\end{array}$ & $\begin{array}{c}3,74 \\
4,8\end{array}$ & $\begin{array}{c}3,0 \\
5,0\end{array}$ \\
\hline $\mathrm{Cr}$ & $\begin{array}{c}108 \\
3,2\end{array}$ & $\begin{array}{c}117 \\
3,3\end{array}$ & $\begin{array}{c}107 \\
3,5\end{array}$ & $\begin{array}{c}111 \\
3,2\end{array}$ & $\begin{array}{c}135 \\
3,4\end{array}$ & $\begin{array}{c}102 \\
3,7\end{array}$ & $\begin{array}{l}99 \\
3,7\end{array}$ & $\begin{array}{l}98 \\
3,7\end{array}$ & $\begin{array}{c}117 \\
3,7\end{array}$ & $\begin{array}{c}102 \\
3,5\end{array}$ \\
\hline Cs & $\begin{array}{r}0,70 \\
14,4\end{array}$ & $\begin{array}{c}0,65 \\
18,0\end{array}$ & $\begin{array}{c}0,74 \\
14,8\end{array}$ & $\begin{array}{c}0,67 \\
13,8\end{array}$ & $\begin{array}{c}0,69 \\
12,4\end{array}$ & $\begin{array}{c}0,68 \\
11,6\end{array}$ & $\begin{array}{c}0,63 \\
12,6\end{array}$ & $\begin{array}{c}0,59 \\
13,4\end{array}$ & $\begin{array}{c}0,80 \\
10,8\end{array}$ & $\begin{array}{c}0,71 \\
12,6\end{array}$ \\
\hline $\mathrm{Eu}$ & $\begin{array}{c}0,64 \\
6,4\end{array}$ & $\begin{array}{c}0,60 \\
6,0\end{array}$ & $\begin{array}{c}0,61 \\
5,2\end{array}$ & $\begin{array}{c}0,63 \\
8,4\end{array}$ & $\begin{array}{c}0,61 \\
6,6\end{array}$ & $\begin{array}{c}0,61 \\
5,6\end{array}$ & $\begin{array}{c}0,61 \\
4,6\end{array}$ & $\begin{array}{c}0,58 \\
7,8\end{array}$ & $\begin{array}{c}0,71 \\
5,0\end{array}$ & $\begin{array}{c}0,62 \\
4,8\end{array}$ \\
\hline $\mathrm{Fe}$ & $\begin{array}{c}29335 \\
2,8\end{array}$ & $\begin{array}{c}27724 \\
2,8\end{array}$ & $\begin{array}{c}28526 \\
2,8\end{array}$ & $\begin{array}{c}28224 \\
3,0\end{array}$ & $\begin{array}{c}26348 \\
2,8\end{array}$ & $\begin{array}{c}29502 \\
3,8\end{array}$ & $\begin{array}{c}28284 \\
4,2\end{array}$ & $\begin{array}{c}26149 \\
3,8\end{array}$ & $\begin{array}{c}31698 \\
4,0\end{array}$ & $\begin{array}{c}26871 \\
4,0\end{array}$ \\
\hline Hf & $\begin{array}{c}12,4 \\
3,6\end{array}$ & $\begin{array}{c}12,3 \\
3,4\end{array}$ & $\begin{array}{c}13,4 \\
3,8\end{array}$ & $\begin{array}{c}11,5 \\
3,6\end{array}$ & $\begin{array}{c}12,0 \\
3,8\end{array}$ & $\begin{array}{c}11,5 \\
5,8\end{array}$ & $\begin{array}{l}9,7 \\
4,6\end{array}$ & $\begin{array}{c}10,4 \\
4,6\end{array}$ & $\begin{array}{c}13,3 \\
4,4\end{array}$ & $\begin{array}{c}10,3 \\
4,8\end{array}$ \\
\hline $\mathrm{K}$ & $\begin{array}{l}271 \\
13,8\end{array}$ & $\begin{array}{l}291 \\
20,0\end{array}$ & $\begin{array}{l}324 \\
17,8\end{array}$ & $\begin{array}{l}202 \\
23,4\end{array}$ & $\begin{array}{c}282 \\
9,8\end{array}$ & $\begin{array}{l}267 \\
10,2\end{array}$ & $\begin{array}{l}303 \\
16,0\end{array}$ & $\begin{array}{c}317 \\
9,8\end{array}$ & $\begin{array}{l}264 \\
28,6\end{array}$ & $\begin{array}{l}252 \\
12,2\end{array}$ \\
\hline $\mathrm{La}$ & $\begin{array}{c}21,9 \\
2,6\end{array}$ & $\begin{array}{c}19,9 \\
2,6\end{array}$ & $\begin{array}{c}21,3 \\
2,6\end{array}$ & $\begin{array}{c}21,0 \\
2,6\end{array}$ & $\begin{array}{c}19,7 \\
2,6\end{array}$ & $\begin{array}{c}22,4 \\
2,6\end{array}$ & $\begin{array}{c}21,5 \\
2,4\end{array}$ & $\begin{array}{c}20,1 \\
2,6\end{array}$ & $\begin{array}{c}25,2 \\
2,6\end{array}$ & $\begin{array}{c}23,1 \\
2,6\end{array}$ \\
\hline $\mathrm{Na}$ & $\begin{array}{l}49 \\
5,0\end{array}$ & $\begin{array}{l}42 \\
6,3\end{array}$ & $\begin{array}{l}46 \\
6,1\end{array}$ & $\begin{array}{l}47 \\
6,5\end{array}$ & $\begin{array}{l}50 \\
4,2\end{array}$ & $\begin{array}{l}58 \\
8,0\end{array}$ & $\begin{array}{l}40 \\
8,5\end{array}$ & $\begin{array}{l}38 \\
7,7\end{array}$ & $\begin{array}{l}41 \\
5,0\end{array}$ & $\begin{array}{l}36 \\
7,3\end{array}$ \\
\hline $\mathrm{Nd}$ & $\begin{array}{c}17,3 \\
17,8\end{array}$ & $\begin{array}{r}19,7 \\
16,6\end{array}$ & $\begin{array}{c}17,5 \\
19,8\end{array}$ & $\begin{array}{c}22,2 \\
23,8\end{array}$ & $\begin{array}{c}13,4 \\
24,8\end{array}$ & $\begin{array}{c}15,8 \\
32,0\end{array}$ & $\begin{array}{c}17,1 \\
34,4\end{array}$ & $\begin{array}{c}14,1 \\
28,2\end{array}$ & $\begin{array}{c}18,4 \\
34,8\end{array}$ & $\begin{array}{c}20,3 \\
41,4\end{array}$ \\
\hline Sc & $\begin{array}{c}9,12 \\
3,0\end{array}$ & $\begin{array}{c}8,65 \\
3,0\end{array}$ & $\begin{array}{c}8,82 \\
3,0\end{array}$ & $\begin{array}{c}8,84 \\
3,0\end{array}$ & $\begin{array}{c}8,31 \\
3,0\end{array}$ & $\begin{array}{c}9,28 \\
4,0\end{array}$ & $\begin{array}{c}9,01 \\
3,6\end{array}$ & $\begin{array}{c}8,69 \\
3,6\end{array}$ & $\begin{array}{c}10,63 \\
3,6\end{array}$ & $\begin{array}{c}8,77 \\
3,6\end{array}$ \\
\hline $\mathrm{Sm}$ & $\begin{array}{c}2,49 \\
9,8\end{array}$ & $\begin{array}{c}2,22 \\
6,2\end{array}$ & $\begin{array}{r}2,31 \\
11,0\end{array}$ & $\begin{array}{c}2,40 \\
6,4\end{array}$ & $\begin{array}{c}2,27 \\
5,4\end{array}$ & $\begin{array}{c}2,66 \\
5,4\end{array}$ & $\begin{array}{c}2,65 \\
5,4\end{array}$ & $\begin{array}{c}2,37 \\
5,8\end{array}$ & $\begin{array}{c}3,08 \\
5,6\end{array}$ & $\begin{array}{c}2,60 \\
5,4\end{array}$ \\
\hline Та & $\begin{array}{c}2,76 \\
7,6\end{array}$ & $\begin{array}{c}2,66 \\
8,0\end{array}$ & $\begin{array}{c}2,73 \\
8,0\end{array}$ & $\begin{array}{c}2,81 \\
7,6\end{array}$ & $\begin{array}{c}2,52 \\
7,6\end{array}$ & $\begin{array}{c}2,74 \\
8,0\end{array}$ & $\begin{array}{c}2,76 \\
7,8\end{array}$ & $\begin{array}{c}2,54 \\
8,4\end{array}$ & $\begin{array}{c}3,12 \\
8,0\end{array}$ & $\begin{array}{c}2,60 \\
8,0\end{array}$ \\
\hline $\mathrm{Tb}$ & $\begin{array}{c}0,41 \\
12,8\end{array}$ & $\begin{array}{c}0,25 \\
19,8\end{array}$ & $\begin{array}{c}0,25 \\
17,6\end{array}$ & $\begin{array}{c}0,27 \\
19,0\end{array}$ & $\begin{array}{c}0,29 \\
14,2\end{array}$ & $\begin{array}{c}0,27 \\
15,5\end{array}$ & $\begin{array}{c}0,30 \\
13,0\end{array}$ & $\begin{array}{c}0,19 \\
18,7\end{array}$ & $\begin{array}{c}0,36 \\
15,7\end{array}$ & $\begin{array}{c}0,22 \\
18,9\end{array}$ \\
\hline Th & $\begin{array}{c}11,4 \\
4,2\end{array}$ & $\begin{array}{c}10,7 \\
4,0\end{array}$ & $\begin{array}{c}11,2 \\
4,0\end{array}$ & $\begin{array}{c}11,2 \\
4,2\end{array}$ & $\begin{array}{c}10,7 \\
4,2\end{array}$ & $\begin{array}{c}11,7 \\
5,8\end{array}$ & $\begin{array}{c}11,3 \\
5,2\end{array}$ & $\begin{array}{c}10,7 \\
5,2\end{array}$ & $\begin{array}{c}13,2 \\
5,8\end{array}$ & $\begin{array}{c}10,9 \\
4,2\end{array}$ \\
\hline $\mathrm{U}$ & $\begin{array}{c}1,88 \\
21,8\end{array}$ & $\begin{array}{c}1,67 \\
23,4\end{array}$ & $\begin{array}{r}1,82 \\
25,4\end{array}$ & $\begin{array}{c}1,58 \\
27,2\end{array}$ & $\begin{array}{c}1,75 \\
20,4\end{array}$ & $\begin{array}{c}2,09 \\
21,2\end{array}$ & $\begin{array}{c}1,73 \\
17,8\end{array}$ & $\begin{array}{c}1,60 \\
30,4\end{array}$ & $\begin{array}{c}2,40 \\
20,6\end{array}$ & $\begin{array}{c}1,65 \\
20,2\end{array}$ \\
\hline $\mathrm{Yb}$ & $\begin{array}{r}2,2 \\
3,8\end{array}$ & $\begin{array}{c}1,3 \\
7,2\end{array}$ & $\begin{array}{c}1,4 \\
4,8\end{array}$ & $\begin{array}{l}1,7 \\
4,2\end{array}$ & $\begin{array}{c}1,5 \\
4,8\end{array}$ & $\begin{array}{c}1,8 \\
4,6\end{array}$ & $\begin{array}{l}1,8 \\
4,4\end{array}$ & $\begin{array}{l}1,3 \\
4,8\end{array}$ & $\begin{array}{c}2,0 \\
5,2\end{array}$ & $\begin{array}{l}1,3 \\
4,4\end{array}$ \\
\hline $\mathrm{Zn}$ & $\begin{array}{c}35 \\
20,0\end{array}$ & $\begin{array}{c}41 \\
18,1\end{array}$ & $\begin{array}{c}32 \\
25,1\end{array}$ & $\begin{array}{c}31 \\
23,9\end{array}$ & $\begin{array}{c}32 \\
22,1\end{array}$ & $\begin{array}{c}28 \\
79,6\end{array}$ & $\begin{array}{c}26 \\
46,2\end{array}$ & $\begin{array}{c}24 \\
40,0\end{array}$ & $\begin{array}{c}29 \\
32,0\end{array}$ & $\begin{array}{c}33 \\
28,5\end{array}$ \\
\hline
\end{tabular}


APÊNDICE 2. Concentração de elementos químicos $\left(m g \cdot \mathrm{kg}^{-1}\right)$ e incertezas relativas $(k=2)$ em amostras de solo sob cultivo convencional

\begin{tabular}{|c|c|c|c|c|c|c|c|c|c|c|}
\hline & $\begin{array}{c}\text { Planta } \\
21 \\
\end{array}$ & $\begin{array}{c}\text { Planta } \\
22 \\
\end{array}$ & $\begin{array}{c}\text { Planta } \\
23 \\
\end{array}$ & $\begin{array}{c}\text { Planta } \\
24 \\
\end{array}$ & $\begin{array}{c}\text { Planta } \\
25 \\
\end{array}$ & $\begin{array}{c}\text { Planta } \\
26 \\
\end{array}$ & $\begin{array}{c}\text { Planta } \\
27 \\
\end{array}$ & $\begin{array}{c}\text { Planta } \\
28 \\
\end{array}$ & $\begin{array}{c}\text { Planta } \\
29 \\
\end{array}$ & $\begin{array}{c}\text { Planta } \\
30 \\
\end{array}$ \\
\hline \multirow[t]{2}{*}{ As } & 3,4 & 3,7 & 3,3 & 3,8 & 3,5 & 3,7 & 3,4 & 3,5 & 4,3 & 3,7 \\
\hline & 6,2 & 5,2 & 17,2 & 8,4 & 5,8 & 6,6 & 6,4 & 6,6 & 6,6 & 6,0 \\
\hline \multirow[t]{2}{*}{$\mathrm{Br}$} & 4 & 4 & 4 & 4 & 4 & 4 & 4 & 4 & 5 & 4 \\
\hline & 5,4 & 5,0 & 5,4 & 5,4 & 5,4 & 5,8 & 5,6 & 5,2 & 5,4 & 5,4 \\
\hline \multirow[t]{2}{*}{$\mathrm{Ce}$} & 80 & 90 & 87 & 93 & 83 & 86 & 75 & 82 & 106 & 85 \\
\hline & 3,8 & 7,0 & 8,0 & 6,8 & 3,6 & 3,8 & 7,4 & 6,2 & 9,8 & 8,0 \\
\hline \multirow[t]{2}{*}{ Co } & 2,79 & 3,19 & 3,17 & 3,18 & 2,83 & 2,98 & 2,70 & 2,90 & 3,65 & 3,2 \\
\hline & 3,8 & 4,4 & 4,8 & 5,8 & 4,0 & 4,4 & 4,0 & 4,4 & 5,0 & 4,2 \\
\hline \multirow[t]{2}{*}{$\mathrm{Cr}$} & 98 & 98 & 106 & 105 & 106 & 105 & 134 & 99 & 132 & 113 \\
\hline & 3,7 & 3,5 & 3,7 & 3,7 & 3,7 & 4,1 & 3,4 & 4,1 & 4,3 & 3,9 \\
\hline \multirow[t]{2}{*}{ Cs } & 0,60 & 0,73 & 0,65 & 0,71 & 0,69 & 0,69 & 0,63 & 0,60 & 0,82 & 0,68 \\
\hline & 13,8 & 11,0 & 10,8 & 11,6 & 10,8 & 10,8 & 11,4 & 12,0 & 10,6 & 15,4 \\
\hline \multirow[t]{2}{*}{$\mathrm{Eu}$} & 0,58 & 0,67 & 0,67 & 0,71 & 0,64 & 0,65 & 0,60 & 0,63 & 0,81 & 0,69 \\
\hline & 5,0 & 4,2 & 5,8 & 4,6 & 5,2 & 4,4 & 5,2 & 5,4 & 4,6 & 4,2 \\
\hline \multirow[t]{2}{*}{$\mathrm{Fe}$} & 25214 & 28324 & 27632 & 28829 & 26178 & 26656 & 24309 & 26429 & 32621 & 27642 \\
\hline & 4,2 & 3,8 & 4,6 & 3,8 & 3,8 & 3,8 & 3,8 & 4,2 & 4,0 & 3,8 \\
\hline \multirow[t]{2}{*}{$\mathrm{Hf}$} & 11,6 & 11,9 & 9,6 & 12,6 & 9,9 & 11,2 & 9,7 & 9,1 & 13,4 & 12,7 \\
\hline & 4,6 & 5,0 & 4,8 & 4,6 & 4,8 & 4,6 & 5,4 & 4,8 & 4,4 & 4,8 \\
\hline \multirow[t]{2}{*}{$\mathrm{K}$} & 218 & 289 & 274 & 269 & 246 & 242 & 230 & 254 & 342 & 241 \\
\hline & 12,6 & 10,2 & 10,2 & 11,0 & 12,8 & 12,6 & 9,8 & 9,0 & 13,6 & 20,0 \\
\hline \multirow[t]{2}{*}{$\mathrm{La}$} & 20,2 & 26,4 & 25,3 & 27,3 & 23,3 & 23,1 & 22,1 & 24,5 & 30,9 & 26,3 \\
\hline & 2,4 & 2,6 & 2,6 & 2,6 & 2,6 & 2,6 & 2,6 & 2,4 & 2,4 & 2,6 \\
\hline \multirow[t]{2}{*}{$\mathrm{Na}$} & 37 & 51 & 42 & 38 & 39 & 38 & 37 & 40 & 47 & 47 \\
\hline & 12,4 & 7,6 & 7,6 & 8,3 & 6,2 & 7,6 & 7,2 & 6,6 & 4,3 & 8,8 \\
\hline \multirow[t]{2}{*}{$\mathrm{Nd}$} & 17,4 & 19,2 & 15,0 & 19,7 & 20,8 & 19,0 & 14,2 & 17,5 & 18,6 & 17,4 \\
\hline & 34,6 & 38,2 & 30,0 & 38,6 & 42,8 & 37,4 & 27,6 & 34,4 & 36,6 & 34,4 \\
\hline \multirow[t]{2}{*}{ Sc } & 8,08 & 9,16 & 9,07 & 9,62 & 8,75 & 9,06 & 8,21 & 8,60 & 11,24 & 9,33 \\
\hline & 3,6 & 3,6 & 3,6 & 3,8 & 3,6 & 3,8 & 3,6 & 3,6 & 3,6 & 3,6 \\
\hline \multirow[t]{2}{*}{$\mathrm{Sm}$} & 2,34 & 2,86 & 2,77 & 2,98 & 2,76 & 2,66 & 2,50 & 2,69 & 3,31 & 2,91 \\
\hline & 5,4 & 5,4 & 5,4 & 5,2 & 7,0 & 5,8 & 5,8 & 5,4 & 6,6 & 6,0 \\
\hline \multirow[t]{2}{*}{$\mathrm{Ta}$} & 2,48 & 2,85 & 2,78 & 2,94 & 2,76 & 2,71 & 2,53 & 2,62 & 3,46 & 3,25 \\
\hline & 8,0 & 8,0 & 7,8 & 8,0 & 8,6 & 8,0 & 8,2 & 8,4 & 8,2 & 8,2 \\
\hline \multirow[t]{2}{*}{$\mathrm{Tb}$} & 0,19 & 0,25 & 0,26 & 0,25 & 0,35 & 0,29 & 0,23 & 0,23 & 0,32 & 0,31 \\
\hline & 17,9 & 20,0 & 17,3 & 16,5 & 12,1 & 12,2 & 15,3 & 31,7 & 12,0 & 13,4 \\
\hline \multirow[t]{2}{*}{ Th } & 10,2 & 11,9 & 11,5 & 12,3 & 10,9 & 11,1 & 10,5 & 11,2 & 14,0 & 11,9 \\
\hline & 4,2 & 5,2 & 5,0 & 5,2 & 4,4 & 4,2 & 5,4 & 6,2 & 5,8 & 5,4 \\
\hline \multirow[t]{2}{*}{$\mathrm{U}$} & 1,97 & 1,72 & 1,74 & 1,93 & 1,43 & 1,60 & 2,00 & 1,47 & 2,11 & 2,05 \\
\hline & 18,8 & 17,4 & 39,0 & 19,0 & 28,4 & 21,8 & 20,2 & 21,8 & 17,4 & 19,4 \\
\hline \multirow[t]{2}{*}{$\mathrm{Yb}$} & 1,2 & 1,5 & 1,6 & 1,4 & 2,2 & 1,6 & 1,3 & 1,2 & 1,7 & 1,8 \\
\hline & 4,4 & 4,6 & 4,4 & 5,4 & 4,0 & 3,8 & 4,8 & 5,4 & 5,4 & 4,4 \\
\hline \multirow[t]{2}{*}{$\mathrm{Zn}$} & 39 & 34 & 27 & 40 & 30 & 34 & 20 & 29 & 26 & 30 \\
\hline & 21,7 & 30,3 & 25,7 & 32,1 & 87,8 & 19,9 & 43,5 & 37,1 & 92,9 & 28,9 \\
\hline
\end{tabular}


APÊNDICE 3. Concentração de elementos químicos $\left(m g \cdot \mathrm{kg}^{-1}\right)$ e incertezas relativas $(k=2)$ em amostras de folhas sob cultivo orgânico

\begin{tabular}{|c|c|c|c|c|c|c|c|c|c|c|}
\hline & $\begin{array}{c}\text { Planta } \\
1 \\
\end{array}$ & $\begin{array}{c}\text { Planta } \\
2 \\
\end{array}$ & $\begin{array}{c}\text { Planta } \\
3 \\
\end{array}$ & $\begin{array}{c}\text { Planta } \\
4 \\
\end{array}$ & $\begin{array}{c}\text { Planta } \\
5 \\
\end{array}$ & $\begin{array}{c}\text { Planta } \\
6 \\
\end{array}$ & $\begin{array}{c}\text { Planta } \\
7 \\
\end{array}$ & $\begin{array}{c}\text { Planta } \\
8 \\
\end{array}$ & $\begin{array}{c}\text { Planta } \\
9 \\
\end{array}$ & $\begin{array}{c}\text { Planta } \\
10 \\
\end{array}$ \\
\hline \multirow[t]{2}{*}{$\mathrm{Ba}$} & 199 & 381 & 127 & 121 & 184 & 259 & 206 & 180 & 184 & 152 \\
\hline & 8,0 & 7,4 & 9,0 & 8,0 & 8,8 & 7,6 & 8,8 & 6,4 & 6,4 & 8,4 \\
\hline \multirow[t]{2}{*}{$\mathrm{Br}$} & 10,0 & 9,4 & 11,3 & 10,7 & 13,7 & 13,6 & 9,2 & 13,5 & 7,0 & 12,2 \\
\hline & 5,0 & 5,0 & 5,0 & 5,0 & 5,0 & 5,0 & 5,0 & 5,0 & 5,0 & 5,0 \\
\hline \multirow[t]{2}{*}{$\mathrm{Ca}$} & 39825 & 32194 & 39662 & 27272 & 47996 & 40008 & 35648 & 34782 & 34930 & 39577 \\
\hline & 4,2 & 4,6 & 5 & 4,8 & 4,4 & 5 & 4,4 & 4,8 & 5,4 & 4,6 \\
\hline \multirow[t]{2}{*}{$\mathrm{Ce}$} & 24,4 & 6,1 & 26,5 & 7,9 & 22,2 & 9,9 & 7,7 & 8,2 & 7,8 & 23,2 \\
\hline & 8,0 & 5,6 & 6,8 & 7,0 & 8,0 & 6,2 & 8,8 & 5,1 & 4,8 & 4,7 \\
\hline \multirow[t]{2}{*}{ Co } & 0,19 & 0,20 & 0,16 & 0,27 & 0,23 & 0,28 & 0,25 & 0,21 & 0,23 & 0,23 \\
\hline & 8,0 & 4,2 & 6,8 & 4,4 & 4,2 & 4,2 & 5,4 & 5,2 & 5,4 & 5,0 \\
\hline \multirow[t]{2}{*}{ Cs } & 0,029 & 0,035 & 0,026 & 0,043 & 0,021 & 0,034 & 0,041 & 0,045 & 0,043 & 0,027 \\
\hline & 22,4 & 13,8 & 28,6 & 15,0 & 26,0 & 16,2 & 12,6 & 15,0 & 14,4 & 35,2 \\
\hline \multirow[t]{2}{*}{$\mathrm{Eu}$} & 0,94 & 0,34 & 0,95 & 0,41 & 0,84 & 0,44 & 0,32 & 0,32 & 0,34 & 0,64 \\
\hline & 4,4 & 4,0 & 4,6 & 3,8 & 4,6 & 3,6 & 3,6 & 3,6 & 3,4 & 3,4 \\
\hline \multirow[t]{2}{*}{$\mathrm{Fe}$} & 198 & 165 & 156 & 224 & 268 & 267 & 236 & 240 & 222 & 248 \\
\hline & 4,2 & 4,8 & 4,8 & 4,6 & 4,6 & 4,4 & 4,4 & 3,2 & 3,6 & 3,6 \\
\hline \multirow[t]{2}{*}{$\mathrm{K}$} & 14765 & 13632 & 14232 & 17307 & 9870 & 10335 & 12503 & 11284 & 9092 & 12706 \\
\hline & 3,6 & 3,4 & 3,4 & 3,4 & 3,6 & 3,2 & 4,4 & 7 & 6 & 6 \\
\hline \multirow[t]{2}{*}{$\mathrm{La}$} & 45 & 13 & 47 & 18 & 48 & 21 & 17 & 17 & 17 & 45 \\
\hline & 2,8 & 2,6 & 2,8 & 2,6 & 2,8 & 2,6 & 2,6 & 2,6 & 2,6 & 3 \\
\hline \multirow[t]{2}{*}{$\mathrm{Na}$} & 63 & 72 & 67 & 50 & 52 & 54 & 52 & 50 & 74 & 49 \\
\hline & 4,0 & 5,0 & 5,4 & 3,8 & 5,0 & 4,0 & 3,8 & 6,0 & 5,6 & 6,0 \\
\hline \multirow[t]{2}{*}{$\mathrm{Nd}$} & 36 & 13 & 37 & 16 & 34 & 18 & 13 & 13 & 14 & 27 \\
\hline & 5,8 & 6,0 & 6,0 & 5,8 & 5,6 & 6,2 & 6,0 & 5,3 & 5,3 & 5,2 \\
\hline \multirow[t]{2}{*}{$\mathrm{Rb}$} & 9,3 & 12,6 & 7,0 & 10,7 & 6,5 & 7,8 & 9,5 & 8,8 & 5,4 & 6,9 \\
\hline & 6,2 & 5,6 & 6 & 6,4 & 7,6 & 6 & 5,8 & 7 & 7,2 & 6,2 \\
\hline \multirow[t]{2}{*}{ Sc } & 0,040 & 0,029 & 0,026 & 0,058 & 0,064 & 0,074 & 0,060 & 0,066 & 0,063 & 0,068 \\
\hline & 4,2 & 4,6 & 5,2 & 3,8 & 4,6 & 3,8 & 3,6 & 3,8 & 3,4 & 4,4 \\
\hline \multirow[t]{2}{*}{$\mathrm{Sm}$} & 3,84 & 1,36 & 3,97 & 1,69 & 3,55 & 1,77 & 1,34 & 1,30 & 1,45 & 2,78 \\
\hline & 10,6 & 6,2 & 13,2 & 8,4 & 11 & 7,2 & 6,6 & 6,6 & 6,4 & 6,8 \\
\hline \multirow[t]{2}{*}{$\mathrm{Sr}$} & 274 & 329 & 221 & 188 & 309 & 326 & 244 & 262 & 260 & 279 \\
\hline & 6,4 & 5,8 & 5,8 & 7,4 & 5,8 & 5,6 & 5,8 & 5,6 & 5,2 & 5,8 \\
\hline \multirow[t]{2}{*}{$\mathrm{Tb}$} & 0,35 & 0,17 & 0,37 & 0,18 & 0,32 & 0,20 & 0,14 & 0,14 & 0,15 & 0,23 \\
\hline & 6,4 & 6,6 & 6,4 & 6,8 & 6,8 & 6,8 & 6,6 & 7,4 & 6,4 & 6,2 \\
\hline \multirow[t]{2}{*}{ Th } & 0,031 & 0,028 & 0,023 & 0,037 & 0,048 & 0,048 & 0,042 & 0,043 & 0,044 & 0,052 \\
\hline & 21,0 & 18,6 & 43,8 & 17,0 & 12,4 & 10,2 & 11,8 & 11,8 & 12,4 & 11,8 \\
\hline \multirow[t]{2}{*}{$\mathrm{Yb}$} & 0,33 & 0,31 & 0,41 & 0,31 & 0,31 & 0,31 & 0,22 & 0,24 & 0,25 & 0,19 \\
\hline & 6,2 & 5,6 & 8,6 & 6,8 & 9,0 & 6,4 & 6,0 & 9,0 & 9,0 & 6,2 \\
\hline \multirow[t]{2}{*}{$\mathrm{Zn}$} & 22,7 & 23,1 & 22,1 & 23,5 & 19,4 & 26,9 & 24,4 & 23,5 & 26,9 & 27,3 \\
\hline & 4,8 & 4,2 & 5,0 & 4,2 & 6,2 & 4,2 & 3,8 & 4,9 & 4,1 & 4,2 \\
\hline
\end{tabular}


APÊNDICE 3. Concentração de elementos químicos $\left(m g \cdot \mathrm{kg}^{-1}\right)$ e incertezas relativas $(k=2)$ em amostras de folhas sob cultivo orgânico

\begin{tabular}{|c|c|c|c|c|c|c|c|c|c|c|}
\hline & $\begin{array}{c}\text { Planta } \\
11 \\
\end{array}$ & $\begin{array}{c}\text { Planta } \\
12 \\
\end{array}$ & $\begin{array}{c}\text { Planta } \\
13 \\
\end{array}$ & $\begin{array}{c}\text { Planta } \\
14 \\
\end{array}$ & $\begin{array}{c}\text { Planta } \\
15 \\
\end{array}$ & $\begin{array}{c}\text { Planta } \\
16 \\
\end{array}$ & $\begin{array}{c}\text { Planta } \\
17 \\
\end{array}$ & $\begin{array}{c}\text { Planta } \\
18 \\
\end{array}$ & $\begin{array}{c}\text { Planta } \\
19 \\
\end{array}$ & $\begin{array}{c}\text { Planta } \\
20 \\
\end{array}$ \\
\hline $\mathrm{Ba}$ & $\begin{array}{c}318 \\
6,2\end{array}$ & $\begin{array}{c}536 \\
6,0\end{array}$ & $\begin{array}{c}365 \\
6,0\end{array}$ & $\begin{array}{c}276 \\
6,4\end{array}$ & $\begin{array}{c}225 \\
6,8\end{array}$ & $\begin{array}{c}348 \\
6,2\end{array}$ & $\begin{array}{c}157 \\
6,8\end{array}$ & $\begin{array}{c}150 \\
7,2\end{array}$ & $\begin{array}{c}155 \\
7,6\end{array}$ & $\begin{array}{c}211 \\
7,0\end{array}$ \\
\hline $\mathrm{Br}$ & $\begin{array}{c}17,2 \\
5,0\end{array}$ & $\begin{array}{c}14,1 \\
4,8\end{array}$ & $\begin{array}{c}14,7 \\
5,0\end{array}$ & $\begin{array}{c}10,3 \\
5,0\end{array}$ & $\begin{array}{c}11,5 \\
5,0\end{array}$ & $\begin{array}{c}13,1 \\
4,8\end{array}$ & $\begin{array}{c}13,3 \\
4,8\end{array}$ & $\begin{array}{c}16,7 \\
4,8\end{array}$ & $\begin{array}{c}13,6 \\
4,6\end{array}$ & $\begin{array}{c}10,4 \\
4,8\end{array}$ \\
\hline $\mathrm{Ca}$ & $\begin{array}{c}29967 \\
4,6\end{array}$ & $\begin{array}{c}42195 \\
4,6\end{array}$ & $\begin{array}{c}33214 \\
4,4\end{array}$ & $\begin{array}{c}35090 \\
5\end{array}$ & $\begin{array}{c}36091 \\
4,4\end{array}$ & $\begin{array}{c}41002 \\
4,6\end{array}$ & $\begin{array}{c}36595 \\
5,6\end{array}$ & $\begin{array}{c}32206 \\
5,4\end{array}$ & $\begin{array}{c}33156 \\
4,8\end{array}$ & $\begin{array}{c}33936 \\
5\end{array}$ \\
\hline $\mathrm{Ce}$ & $\begin{array}{r}8,5 \\
4,9\end{array}$ & $\begin{array}{c}11,8 \\
4,8\end{array}$ & $\begin{array}{r}9,1 \\
4,8\end{array}$ & $\begin{array}{c}11,2 \\
4,8\end{array}$ & $\begin{array}{c}12,2 \\
5,0\end{array}$ & $\begin{array}{c}16,4 \\
4,4\end{array}$ & $\begin{array}{c}10,3 \\
5,8\end{array}$ & $\begin{array}{c}7,2 \\
5,0\end{array}$ & $\begin{array}{c}7,4 \\
5,0\end{array}$ & $\begin{array}{c}10,4 \\
4,4\end{array}$ \\
\hline Co & $\begin{array}{c}0,22 \\
5,4\end{array}$ & $\begin{array}{c}0,34 \\
4,2\end{array}$ & $\begin{array}{c}0,29 \\
4,2\end{array}$ & $\begin{array}{c}0,28 \\
4,2\end{array}$ & $\begin{array}{c}0,21 \\
5,2\end{array}$ & $\begin{array}{c}0,20 \\
5,4\end{array}$ & $\begin{array}{c}0,19 \\
5,0\end{array}$ & $\begin{array}{c}0,18 \\
6,0\end{array}$ & $\begin{array}{c}0,15 \\
5,4\end{array}$ & $\begin{array}{c}0,18 \\
5,4\end{array}$ \\
\hline Cs & $\begin{array}{c}0,021 \\
25,6\end{array}$ & $\begin{array}{c}0,037 \\
16,8\end{array}$ & $\begin{array}{c}0,029 \\
18,0\end{array}$ & $\begin{array}{c}0,052 \\
13,6\end{array}$ & $\begin{array}{c}0,054 \\
12,0\end{array}$ & $\begin{array}{c}0,049 \\
12,4\end{array}$ & $\begin{array}{c}0,037 \\
15,0\end{array}$ & $\begin{array}{c}0,046 \\
12,6\end{array}$ & $\begin{array}{c}0,059 \\
10,4\end{array}$ & $\begin{array}{c}0,052 \\
10,4\end{array}$ \\
\hline $\mathrm{Eu}$ & $\begin{array}{c}0,25 \\
3,8\end{array}$ & $\begin{array}{c}0,33 \\
3,4\end{array}$ & $\begin{array}{c}0,26 \\
3,6\end{array}$ & $\begin{array}{c}0,39 \\
5,2\end{array}$ & $\begin{array}{c}0,37 \\
3,4\end{array}$ & $\begin{array}{c}0,37 \\
3,4\end{array}$ & $\begin{array}{c}0,49 \\
3,6\end{array}$ & $\begin{array}{c}0,40 \\
3,4\end{array}$ & $\begin{array}{c}0,36 \\
3,6\end{array}$ & $\begin{array}{c}0,40 \\
3,8\end{array}$ \\
\hline $\mathrm{Fe}$ & $\begin{array}{c}157 \\
3,6\end{array}$ & $\begin{array}{c}305 \\
3,4\end{array}$ & $\begin{array}{c}158 \\
3,4\end{array}$ & $\begin{array}{c}267 \\
3,4\end{array}$ & $\begin{array}{c}267 \\
3,2\end{array}$ & $\begin{array}{c}276 \\
3,4\end{array}$ & $\begin{array}{c}148 \\
4,2\end{array}$ & $\begin{array}{c}162 \\
4\end{array}$ & $\begin{array}{c}139 \\
4,8\end{array}$ & $\begin{array}{c}155 \\
4\end{array}$ \\
\hline $\mathrm{K}$ & $\begin{array}{c}13470 \\
7,4\end{array}$ & $\begin{array}{c}9497 \\
4,8\end{array}$ & $\begin{array}{c}12494 \\
6\end{array}$ & $\begin{array}{c}13600 \\
4,6\end{array}$ & $\begin{array}{c}11926 \\
5,8\end{array}$ & $\begin{array}{c}13146 \\
3,2\end{array}$ & $\begin{array}{c}13607 \\
2,8\end{array}$ & $\begin{array}{c}13638 \\
3\end{array}$ & $\begin{array}{c}13988 \\
3,6\end{array}$ & $\begin{array}{c}14782 \\
2,8\end{array}$ \\
\hline $\mathrm{La}$ & $\begin{array}{l}16 \\
2,8\end{array}$ & $\begin{array}{l}22 \\
2,8\end{array}$ & $\begin{array}{l}16 \\
2,6\end{array}$ & $\begin{array}{l}25 \\
2,8\end{array}$ & $\begin{array}{l}25 \\
2,8\end{array}$ & $\begin{array}{l}24 \\
2,4\end{array}$ & $\begin{array}{l}27 \\
2,4\end{array}$ & $\begin{array}{l}21 \\
2,4\end{array}$ & $\begin{array}{l}19 \\
2,8\end{array}$ & $\begin{array}{l}24 \\
2,6\end{array}$ \\
\hline $\mathrm{Na}$ & $\begin{array}{l}78 \\
6,0\end{array}$ & $\begin{array}{l}52 \\
5,4\end{array}$ & $\begin{array}{l}70 \\
5,4\end{array}$ & $\begin{array}{l}55 \\
5,8\end{array}$ & $\begin{array}{l}56 \\
7,0\end{array}$ & $\begin{array}{l}58 \\
6,8\end{array}$ & $\begin{array}{l}62 \\
9,2\end{array}$ & $\begin{array}{c}124 \\
4,2\end{array}$ & $\begin{array}{l}75 \\
4,8\end{array}$ & $\begin{array}{l}59 \\
6,6\end{array}$ \\
\hline $\mathrm{Nd}$ & $\begin{array}{l}13 \\
7,7\end{array}$ & $\begin{array}{l}14 \\
5,8\end{array}$ & $\begin{array}{l}11 \\
5,7\end{array}$ & $\begin{array}{l}16 \\
6,7\end{array}$ & $\begin{array}{l}16 \\
5,2\end{array}$ & $\begin{array}{l}15 \\
7,8\end{array}$ & $\begin{array}{l}21 \\
5,4\end{array}$ & $\begin{array}{l}16 \\
6,0\end{array}$ & $\begin{array}{l}15 \\
5,6\end{array}$ & $\begin{array}{l}17 \\
5,2\end{array}$ \\
\hline $\mathrm{Rb}$ & $\begin{array}{c}10,5 \\
6,4\end{array}$ & $\begin{array}{r}8,6 \\
6,6\end{array}$ & $\begin{array}{c}11,5 \\
5,6\end{array}$ & $\begin{array}{c}14,3 \\
6\end{array}$ & $\begin{array}{c}11,9 \\
5,8\end{array}$ & $\begin{array}{c}12,4 \\
5,6\end{array}$ & $\begin{array}{c}11,6 \\
5,8\end{array}$ & $\begin{array}{c}11,3 \\
6\end{array}$ & $\begin{array}{c}12,5 \\
5,4\end{array}$ & $\begin{array}{c}11,5 \\
6\end{array}$ \\
\hline $\mathrm{Sc}$ & $\begin{array}{c}0,044 \\
3,8\end{array}$ & $\begin{array}{c}0,097 \\
3,6\end{array}$ & $\begin{array}{c}0,020 \\
4,0\end{array}$ & $\begin{array}{c}0,069 \\
4,4\end{array}$ & $\begin{array}{c}0,074 \\
3,4\end{array}$ & $\begin{array}{c}0,084 \\
4,0\end{array}$ & $\begin{array}{c}0,031 \\
5,0\end{array}$ & $\begin{array}{c}0,039 \\
5,0\end{array}$ & $\begin{array}{c}0,030 \\
4,8\end{array}$ & $\begin{array}{c}0,032 \\
4,6\end{array}$ \\
\hline $\mathrm{Sm}$ & $\begin{array}{c}1,08 \\
6,2\end{array}$ & $\begin{array}{c}1,36 \\
6,2\end{array}$ & $\begin{array}{c}1,11 \\
6\end{array}$ & $\begin{array}{c}1,81 \\
6\end{array}$ & $\begin{array}{c}1,61 \\
6\end{array}$ & $\begin{array}{c}1,62 \\
5,6\end{array}$ & $\begin{array}{c}2,10 \\
6\end{array}$ & $\begin{array}{c}1,68 \\
5,2\end{array}$ & $\begin{array}{c}1,52 \\
5,4\end{array}$ & $\begin{array}{c}1,72 \\
6,4\end{array}$ \\
\hline $\mathrm{Sr}$ & $\begin{array}{c}273 \\
5,2\end{array}$ & $\begin{array}{c}484 \\
5,0\end{array}$ & $\begin{array}{c}341 \\
5,4\end{array}$ & $\begin{array}{c}312 \\
6,0\end{array}$ & $\begin{array}{c}288 \\
5,4\end{array}$ & $\begin{array}{c}342 \\
5,0\end{array}$ & $\begin{array}{c}224 \\
6,0\end{array}$ & $\begin{array}{c}216 \\
5,8\end{array}$ & $\begin{array}{r}212 \\
5,4\end{array}$ & $\begin{array}{c}200 \\
5,4\end{array}$ \\
\hline $\mathrm{Tb}$ & $\begin{array}{c}0,09 \\
7,0\end{array}$ & $\begin{array}{c}0,12 \\
7,0\end{array}$ & $\begin{array}{c}0,10 \\
7,4\end{array}$ & $\begin{array}{c}0,17 \\
6,6\end{array}$ & $\begin{array}{c}0,15 \\
6,8\end{array}$ & $\begin{array}{c}0,16 \\
6,8\end{array}$ & $\begin{array}{c}0,20 \\
6,2\end{array}$ & $\begin{array}{c}0,17 \\
7,2\end{array}$ & $\begin{array}{c}0,16 \\
6,6\end{array}$ & $\begin{array}{c}0,17 \\
6,6\end{array}$ \\
\hline Th & $\begin{array}{c}0,029 \\
18,0\end{array}$ & $\begin{array}{c}0,064 \\
10,6\end{array}$ & $\begin{array}{c}0,018 \\
31,6\end{array}$ & $\begin{array}{c}0,056 \\
12,6\end{array}$ & $\begin{array}{c}0,055 \\
9,6\end{array}$ & $\begin{array}{c}0,054 \\
9,8\end{array}$ & $\begin{array}{c}0,019 \\
19,4\end{array}$ & $\begin{array}{c}0,029 \\
19,0\end{array}$ & $\begin{array}{c}0,019 \\
27,8\end{array}$ & $\begin{array}{c}0,022 \\
24,0\end{array}$ \\
\hline $\mathrm{Yb}$ & $\begin{array}{c}0,11 \\
10,8\end{array}$ & $\begin{array}{c}0,20 \\
16,8\end{array}$ & $\begin{array}{c}0,12 \\
8,0\end{array}$ & $\begin{array}{c}0,18 \\
7,8\end{array}$ & $\begin{array}{c}0,17 \\
7,2\end{array}$ & $\begin{array}{c}0,19 \\
10,0\end{array}$ & $\begin{array}{c}0,29 \\
8,8\end{array}$ & $\begin{array}{c}0,26 \\
6,8\end{array}$ & $\begin{array}{c}0,24 \\
6,8\end{array}$ & $\begin{array}{c}0,22 \\
7,4\end{array}$ \\
\hline $\mathrm{Zn}$ & $\begin{array}{c}22,8 \\
4,7\end{array}$ & $\begin{array}{c}37,3 \\
3,7\end{array}$ & $\begin{array}{c}26,7 \\
3,8\end{array}$ & $\begin{array}{c}31,7 \\
4,4\end{array}$ & $\begin{array}{c}45,7 \\
3,5\end{array}$ & $\begin{array}{c}26,7 \\
5,3\end{array}$ & $\begin{array}{c}28,5 \\
5,0\end{array}$ & $\begin{array}{c}25,2 \\
4,9\end{array}$ & $\begin{array}{c}22,3 \\
5,1\end{array}$ & $\begin{array}{c}29,3 \\
5,0\end{array}$ \\
\hline
\end{tabular}


APÊNDICE 3. Concentração de elementos químicos (mg.kg-1) e incertezas relativas (k=2) em amostras de folhas sob cultivo orgânico

\begin{tabular}{|c|c|c|c|c|c|c|c|c|c|c|}
\hline & $\begin{array}{c}\text { Planta } \\
21\end{array}$ & $\begin{array}{c}\text { Planta } \\
22\end{array}$ & $\begin{array}{c}\text { Planta } \\
23\end{array}$ & $\begin{array}{c}\text { Planta } \\
24\end{array}$ & $\begin{array}{c}\text { Planta } \\
25\end{array}$ & $\begin{array}{c}\text { Planta } \\
26\end{array}$ & $\begin{array}{c}\text { Planta } \\
27\end{array}$ & $\begin{array}{c}\text { Planta } \\
28\end{array}$ & $\begin{array}{c}\text { Planta } \\
29\end{array}$ & $\begin{array}{c}\text { Planta } \\
30\end{array}$ \\
\hline $\mathrm{Ba}$ & $\begin{array}{c}149 \\
7,8\end{array}$ & $\begin{array}{c}162 \\
6,8\end{array}$ & $\begin{array}{c}159 \\
5,8\end{array}$ & $\begin{array}{c}291 \\
5,6\end{array}$ & $\begin{array}{c}223 \\
5,6\end{array}$ & $\begin{array}{c}263 \\
5,8\end{array}$ & $\begin{array}{c}218 \\
6,0\end{array}$ & $\begin{array}{c}380 \\
5,4\end{array}$ & $\begin{array}{c}234 \\
5,6\end{array}$ & $\begin{array}{c}221 \\
5,8\end{array}$ \\
\hline $\mathrm{Br}$ & $\begin{array}{c}21,3 \\
4,6\end{array}$ & $\begin{array}{c}7,8 \\
5,0\end{array}$ & $\begin{array}{c}11,7 \\
4,8\end{array}$ & $\begin{array}{c}13,0 \\
4,6\end{array}$ & $\begin{array}{c}15,1 \\
4,6\end{array}$ & $\begin{array}{c}18,4 \\
4,6\end{array}$ & $\begin{array}{c}12,9 \\
4,8\end{array}$ & $\begin{array}{c}16,1 \\
4,6\end{array}$ & $\begin{array}{c}9,0 \\
5,0\end{array}$ & $\begin{array}{l}9,7 \\
4,6\end{array}$ \\
\hline Ca & $\begin{array}{c}31536 \\
4,4\end{array}$ & $\begin{array}{c}33947 \\
5\end{array}$ & $\begin{array}{c}30018 \\
4,4\end{array}$ & $\begin{array}{c}34063 \\
4,4\end{array}$ & $\begin{array}{c}40267 \\
4,2\end{array}$ & $\begin{array}{c}38457 \\
4,2\end{array}$ & $\begin{array}{c}35511 \\
4,6\end{array}$ & $\begin{array}{c}41766 \\
4,2\end{array}$ & $\begin{array}{c}37164 \\
4,4\end{array}$ & $\begin{array}{c}28103 \\
4,4\end{array}$ \\
\hline $\mathrm{Ce}$ & $\begin{array}{r}9,8 \\
4,4\end{array}$ & $\begin{array}{r}9,0 \\
4,6\end{array}$ & $\begin{array}{c}5,9 \\
4,0\end{array}$ & $\begin{array}{l}7,9 \\
4,4\end{array}$ & $\begin{array}{c}21,6 \\
4,6\end{array}$ & $\begin{array}{c}19,9 \\
4,4\end{array}$ & $\begin{array}{c}16,2 \\
4,4\end{array}$ & $\begin{array}{c}18,5 \\
4,4\end{array}$ & $\begin{array}{c}13,7 \\
4,4\end{array}$ & $\begin{array}{c}10,2 \\
4,6\end{array}$ \\
\hline Co & $\begin{array}{c}0,15 \\
5,6\end{array}$ & $\begin{array}{c}0,17 \\
6,0\end{array}$ & $\begin{array}{c}0,18 \\
4,6\end{array}$ & $\begin{array}{c}0,18 \\
4,4\end{array}$ & $\begin{array}{c}0,24 \\
4,6\end{array}$ & $\begin{array}{c}0,21 \\
4,4\end{array}$ & $\begin{array}{c}0,20 \\
4,6\end{array}$ & $\begin{array}{c}0,21 \\
5,0\end{array}$ & $\begin{array}{c}0,23 \\
4,2\end{array}$ & $\begin{array}{c}0,29 \\
4,2\end{array}$ \\
\hline Cs & $\begin{array}{c}0,042 \\
10,6\end{array}$ & $\begin{array}{c}0,024 \\
22,8\end{array}$ & $\begin{array}{c}0,035 \\
16,0\end{array}$ & $\begin{array}{c}0,042 \\
14,2\end{array}$ & $\begin{array}{c}0,035 \\
10,6\end{array}$ & $\begin{array}{c}0,019 \\
42,6\end{array}$ & $\begin{array}{c}0,019 \\
36,0\end{array}$ & $\begin{array}{c}0,026 \\
50,2\end{array}$ & $\begin{array}{c}0,023 \\
46,4\end{array}$ & $\begin{array}{c}0,030 \\
18,6\end{array}$ \\
\hline $\mathrm{Eu}$ & $\begin{array}{c}0,40 \\
3,8\end{array}$ & $\begin{array}{c}0,31 \\
4,0\end{array}$ & $\begin{array}{c}0,29 \\
3,4\end{array}$ & $\begin{array}{c}0,54 \\
4,0\end{array}$ & $\begin{array}{c}0,82 \\
3,8\end{array}$ & $\begin{array}{c}0,77 \\
3,8\end{array}$ & $\begin{array}{c}0,83 \\
3,8\end{array}$ & $\begin{array}{c}0,73 \\
3,8\end{array}$ & $\begin{array}{c}0,63 \\
3,4\end{array}$ & $\begin{array}{c}0,60 \\
3,4\end{array}$ \\
\hline $\mathrm{Fe}$ & $\begin{array}{c}121 \\
3,6\end{array}$ & $\begin{array}{c}161 \\
4\end{array}$ & $\begin{array}{c}119 \\
4,6\end{array}$ & $\begin{array}{c}250 \\
4,4\end{array}$ & $\begin{array}{c}356 \\
4,2\end{array}$ & $\begin{array}{c}115 \\
5,2\end{array}$ & $\begin{array}{c}149 \\
5,4\end{array}$ & $\begin{array}{c}147 \\
4,8\end{array}$ & $\begin{array}{c}247 \\
4,4\end{array}$ & $\begin{array}{c}183 \\
4,4\end{array}$ \\
\hline K & $\begin{array}{c}15300 \\
2,4\end{array}$ & $\begin{array}{c}18384 \\
3,4\end{array}$ & $\begin{array}{c}17302 \\
4,8\end{array}$ & $\begin{array}{c}14271 \\
4,4\end{array}$ & $\begin{array}{c}13144 \\
4,8\end{array}$ & $\begin{array}{c}12958 \\
4,2\end{array}$ & $\begin{array}{c}15116 \\
4,6\end{array}$ & $\begin{array}{c}12082 \\
4,8\end{array}$ & $\begin{array}{c}11284 \\
5,2\end{array}$ & $\begin{array}{c}19464 \\
3,8\end{array}$ \\
\hline $\mathrm{La}$ & $\begin{array}{l}20 \\
2,4\end{array}$ & $\begin{array}{l}18 \\
2,6\end{array}$ & $\begin{array}{l}15 \\
2,6\end{array}$ & $\begin{array}{l}24 \\
2,6\end{array}$ & $\begin{array}{l}49 \\
2,8\end{array}$ & $\begin{array}{l}46 \\
2,8\end{array}$ & $\begin{array}{l}43 \\
2,8\end{array}$ & $\begin{array}{l}42 \\
2,8\end{array}$ & $\begin{array}{l}33 \\
3,2\end{array}$ & $\begin{array}{l}21 \\
2,8\end{array}$ \\
\hline $\mathrm{Na}$ & $\begin{array}{l}60 \\
4,0\end{array}$ & $\begin{array}{l}73 \\
5,8\end{array}$ & $\begin{array}{l}50 \\
6,6\end{array}$ & $\begin{array}{l}46 \\
6,2\end{array}$ & $\begin{array}{l}49 \\
3,2\end{array}$ & $\begin{array}{l}66 \\
8,4\end{array}$ & $\begin{array}{l}58 \\
4,8\end{array}$ & $\begin{array}{l}43 \\
4,6\end{array}$ & $\begin{array}{l}49 \\
5,0\end{array}$ & $\begin{array}{c}319 \\
7,0\end{array}$ \\
\hline $\mathrm{Nd}$ & $\begin{array}{l}16 \\
5,6\end{array}$ & $\begin{array}{l}13 \\
5,4\end{array}$ & $\begin{array}{l}13 \\
5,0\end{array}$ & $\begin{array}{l}22 \\
4,6\end{array}$ & $\begin{array}{l}35 \\
4,8\end{array}$ & $\begin{array}{l}34 \\
4,4\end{array}$ & $\begin{array}{l}34 \\
4,4\end{array}$ & $\begin{array}{l}31 \\
4,6\end{array}$ & $\begin{array}{l}26 \\
4,4\end{array}$ & $\begin{array}{l}23 \\
4,8\end{array}$ \\
\hline $\mathrm{Rb}$ & $\begin{array}{c}11,9 \\
5,8\end{array}$ & $\begin{array}{c}11,3 \\
6,2\end{array}$ & $\begin{array}{c}14,5 \\
5\end{array}$ & $\begin{array}{c}11,9 \\
5,2\end{array}$ & $\begin{array}{c}10,2 \\
5,6\end{array}$ & $\begin{array}{c}10,8 \\
5,2\end{array}$ & $\begin{array}{c}10,6 \\
5,6\end{array}$ & $\begin{array}{r}9,8 \\
5,4\end{array}$ & $\begin{array}{c}9,8 \\
5,2\end{array}$ & $\begin{array}{c}14,6 \\
5\end{array}$ \\
\hline Sc & $\begin{array}{c}0,029 \\
4,8\end{array}$ & $\begin{array}{c}0,039 \\
4,8\end{array}$ & $\begin{array}{c}0,024 \\
5,2\end{array}$ & $\begin{array}{c}0,065 \\
4,0\end{array}$ & $\begin{array}{c}0,111 \\
3,6\end{array}$ & $\begin{array}{c}0,016 \\
5,8\end{array}$ & $\begin{array}{c}0,025 \\
7,6\end{array}$ & $\begin{array}{c}0,030 \\
4,8\end{array}$ & $\begin{array}{c}0,064 \\
4,0\end{array}$ & $\begin{array}{c}0,033 \\
4,2\end{array}$ \\
\hline $\mathrm{Sm}$ & $\begin{array}{c}1,76 \\
5,8\end{array}$ & $\begin{array}{c}1,32 \\
5,4\end{array}$ & $\begin{array}{c}1,20 \\
5,4\end{array}$ & $\begin{array}{c}2,27 \\
6,4\end{array}$ & $\begin{array}{c}3,52 \\
6\end{array}$ & $\begin{array}{c}3,35 \\
6,4\end{array}$ & $\begin{array}{c}3,52 \\
6,4\end{array}$ & $\begin{array}{c}3,11 \\
6,2\end{array}$ & $\begin{array}{c}2,44 \\
6,4\end{array}$ & $\begin{array}{c}2,39 \\
5,8\end{array}$ \\
\hline $\mathrm{Sr}$ & $\begin{array}{c}180 \\
5,6\end{array}$ & $\begin{array}{c}172 \\
6,6\end{array}$ & $\begin{array}{c}174 \\
5,4\end{array}$ & $\begin{array}{c}305 \\
4,6\end{array}$ & $\begin{array}{c}233 \\
4,6\end{array}$ & $\begin{array}{c}214 \\
4,8\end{array}$ & $\begin{array}{c}205 \\
5,4\end{array}$ & $\begin{array}{c}298 \\
4,6\end{array}$ & $\begin{array}{c}228 \\
4,6\end{array}$ & $\begin{array}{c}165 \\
5,2\end{array}$ \\
\hline $\mathrm{Tb}$ & $\begin{array}{c}0,18 \\
6,0\end{array}$ & $\begin{array}{c}0,13 \\
6,8\end{array}$ & $\begin{array}{c}0,13 \\
6,4\end{array}$ & $\begin{array}{c}0,24 \\
5,8\end{array}$ & $\begin{array}{c}0,30 \\
6,0\end{array}$ & $\begin{array}{c}0,28 \\
6,0\end{array}$ & $\begin{array}{c}0,30 \\
6,2\end{array}$ & $\begin{array}{c}0,26 \\
5,8\end{array}$ & $\begin{array}{c}0,23 \\
6,0\end{array}$ & $\begin{array}{c}0,26 \\
6,0\end{array}$ \\
\hline Th & $\begin{array}{c}0,022 \\
21,2\end{array}$ & $\begin{array}{c}0,030 \\
18,0\end{array}$ & $\begin{array}{c}0,021 \\
29,8\end{array}$ & $\begin{array}{c}0,054 \\
9,8\end{array}$ & $\begin{array}{c}0,075 \\
7,2\end{array}$ & $\begin{array}{c}0,013 \\
63,4\end{array}$ & $\begin{array}{c}0,025 \\
24,2\end{array}$ & $\begin{array}{c}0,019 \\
42,0\end{array}$ & $\begin{array}{c}0,040 \\
10,8\end{array}$ & $\begin{array}{c}0,021 \\
21,4\end{array}$ \\
\hline $\mathrm{Yb}$ & $\begin{array}{c}0,26 \\
7,2\end{array}$ & $\begin{array}{c}0,21 \\
9,0\end{array}$ & $\begin{array}{c}0,21 \\
9,2\end{array}$ & $\begin{array}{c}0,40 \\
5,2\end{array}$ & $\begin{array}{c}0,29 \\
6,6\end{array}$ & $\begin{array}{c}0,26 \\
8,6\end{array}$ & $\begin{array}{c}0,36 \\
10,4\end{array}$ & $\begin{array}{c}0,26 \\
7,2\end{array}$ & $\begin{array}{c}0,25 \\
8,6\end{array}$ & $\begin{array}{c}0,44 \\
5,8\end{array}$ \\
\hline $\mathrm{Zn}$ & $\begin{array}{l}22 \\
5,0\end{array}$ & $\begin{array}{l}28 \\
4,7\end{array}$ & $\begin{array}{l}23 \\
3,7\end{array}$ & $\begin{array}{l}26 \\
3,7\end{array}$ & $\begin{array}{l}26 \\
4,7\end{array}$ & $\begin{array}{l}23 \\
3,9\end{array}$ & $\begin{array}{l}21 \\
4,4\end{array}$ & $\begin{array}{l}22 \\
4,8\end{array}$ & $\begin{array}{l}23 \\
4,1\end{array}$ & $\begin{array}{l}27 \\
3,5\end{array}$ \\
\hline
\end{tabular}


APÊNDICE 4. Concentração de elementos químicos (mg.kg-1) e incertezas relativas (k=2) em amostras de folhas sob cultivo convencional

\begin{tabular}{|c|c|c|c|c|c|c|c|c|c|c|}
\hline & $\begin{array}{c}\text { Planta } \\
1\end{array}$ & $\begin{array}{c}\text { Planta } \\
2\end{array}$ & $\begin{array}{c}\text { Planta } \\
3\end{array}$ & $\begin{array}{c}\text { Planta } \\
4\end{array}$ & $\begin{array}{c}\text { Planta } \\
5\end{array}$ & $\begin{array}{c}\text { Planta } \\
6\end{array}$ & $\begin{array}{c}\text { Planta } \\
7\end{array}$ & $\begin{array}{c}\text { Planta } \\
8\end{array}$ & $\begin{array}{c}\text { Planta } \\
9\end{array}$ & $\begin{array}{c}\text { Planta } \\
10\end{array}$ \\
\hline $\mathrm{Ba}$ & $\begin{array}{c}74 \\
10,0\end{array}$ & $\begin{array}{c}154 \\
7,4\end{array}$ & $\begin{array}{c}63 \\
11,4\end{array}$ & $\begin{array}{l}74 \\
8,6\end{array}$ & $\begin{array}{l}43 \\
8,0\end{array}$ & $\begin{array}{l}51 \\
8,6\end{array}$ & $\begin{array}{l}59 \\
8,6\end{array}$ & $\begin{array}{l}68 \\
8,6\end{array}$ & $\begin{array}{l}68 \\
9,0\end{array}$ & $\begin{array}{l}51 \\
7,6\end{array}$ \\
\hline $\mathrm{Br}$ & $\begin{array}{c}8,7 \\
5,0\end{array}$ & $\begin{array}{c}6,6 \\
5,0\end{array}$ & $\begin{array}{c}7,1 \\
5,0\end{array}$ & $\begin{array}{c}8,5 \\
5,0\end{array}$ & $\begin{array}{c}7,9 \\
5,0\end{array}$ & $\begin{array}{c}8,9 \\
5,0\end{array}$ & $\begin{array}{c}7,5 \\
5,0\end{array}$ & $\begin{array}{l}6,0 \\
5,0\end{array}$ & $\begin{array}{c}4,4 \\
5,0\end{array}$ & $\begin{array}{l}6,5 \\
5,0\end{array}$ \\
\hline $\mathrm{Ca}$ & $\begin{array}{c}32595 \\
4,4\end{array}$ & $\begin{array}{c}29998 \\
4,2\end{array}$ & $\begin{array}{c}30104 \\
4,4\end{array}$ & $\begin{array}{c}33568 \\
4,4\end{array}$ & $\begin{array}{c}29821 \\
4,2\end{array}$ & $\begin{array}{c}34670 \\
4,4\end{array}$ & $\begin{array}{c}33999 \\
4,4\end{array}$ & $\begin{array}{c}33403 \\
4,6\end{array}$ & $\begin{array}{c}36077 \\
4,6\end{array}$ & $\begin{array}{c}33264 \\
4,2\end{array}$ \\
\hline $\mathrm{Ce}$ & $\begin{array}{c}4,7 \\
5,8\end{array}$ & $\begin{array}{l}5,4 \\
5,6\end{array}$ & $\begin{array}{r}5,5 \\
6,4\end{array}$ & $\begin{array}{c}7,5 \\
5,6\end{array}$ & $\begin{array}{c}3,8 \\
5,4\end{array}$ & $\begin{array}{r}4,5 \\
6,8\end{array}$ & $\begin{array}{c}4,8 \\
5,4\end{array}$ & $\begin{array}{c}4,2 \\
5,2\end{array}$ & $\begin{array}{c}5,0 \\
5,1\end{array}$ & $\begin{array}{c}4,3 \\
5,5\end{array}$ \\
\hline Co & $\begin{array}{c}0,05 \\
8,2\end{array}$ & $\begin{array}{c}0,03 \\
8,6\end{array}$ & $\begin{array}{r}0,04 \\
10,6\end{array}$ & $\begin{array}{c}0,03 \\
9,8\end{array}$ & $\begin{array}{c}0,02 \\
11,0\end{array}$ & $\begin{array}{c}0,03 \\
9,6\end{array}$ & $\begin{array}{c}0,03 \\
8,6\end{array}$ & $\begin{array}{c}0,04 \\
9,4\end{array}$ & $\begin{array}{c}0,04 \\
14,2\end{array}$ & $\begin{array}{c}0,05 \\
7,4\end{array}$ \\
\hline Cs & $\begin{array}{c}0,063 \\
11,2\end{array}$ & $\begin{array}{c}0,050 \\
9,0\end{array}$ & $\begin{array}{c}0,060 \\
9,0\end{array}$ & $\begin{array}{c}0,045 \\
10,0\end{array}$ & $\begin{array}{c}0,061 \\
8,0\end{array}$ & $\begin{array}{c}0,072 \\
7,8\end{array}$ & $\begin{array}{c}0,037 \\
12,0\end{array}$ & $\begin{array}{c}0,060 \\
9,4\end{array}$ & $\begin{array}{c}0,049 \\
14,2\end{array}$ & $\begin{array}{c}0,062 \\
8,6\end{array}$ \\
\hline $\mathrm{Eu}$ & $\begin{array}{c}0,06 \\
4,0\end{array}$ & $\begin{array}{c}0,07 \\
3,8\end{array}$ & $\begin{array}{c}0,06 \\
4,4\end{array}$ & $\begin{array}{c}0,08 \\
4,0\end{array}$ & $\begin{array}{c}0,06 \\
4,2\end{array}$ & $\begin{array}{c}0,07 \\
3,6\end{array}$ & $\begin{array}{c}0,06 \\
4,2\end{array}$ & $\begin{array}{c}0,06 \\
3,8\end{array}$ & $\begin{array}{c}0,09 \\
4,6\end{array}$ & $\begin{array}{c}0,06 \\
4,8\end{array}$ \\
\hline $\mathrm{Fe}$ & $\begin{array}{c}287 \\
4\end{array}$ & $\begin{array}{c}137 \\
4\end{array}$ & $\begin{array}{c}184 \\
4,2\end{array}$ & $\begin{array}{c}152 \\
4\end{array}$ & $\begin{array}{c}124 \\
4,6\end{array}$ & $\begin{array}{c}140 \\
4,6\end{array}$ & $\begin{array}{c}150 \\
4,4\end{array}$ & $\begin{array}{c}233 \\
4\end{array}$ & $\begin{array}{c}203 \\
3,6\end{array}$ & $\begin{array}{c}261 \\
3,2\end{array}$ \\
\hline K & 8606 & 10078 & 13035 & 9753 & 7383 & 8110 & 8124 & 12486 & 7701 & 9450 \\
\hline La & $\begin{array}{l}3,8 \\
72\end{array}$ & $\begin{array}{l}3,2 \\
7,5\end{array}$ & $\begin{array}{l}3,2 \\
58\end{array}$ & $\begin{array}{l}5,4 \\
8,8\end{array}$ & $\begin{array}{l}3,4 \\
7,1\end{array}$ & $\begin{array}{l}3,4 \\
81\end{array}$ & $\begin{array}{c}4 \\
65\end{array}$ & $\begin{array}{l}3,8 \\
70\end{array}$ & $\begin{array}{l}8,6 \\
95\end{array}$ & $\begin{array}{l}7,6 \\
68\end{array}$ \\
\hline & 2,6 & 2,6 & 2,6 & 2,6 & 2,6 & 2,6 & 2,6 & 2,6 & 2,6 & 2,6 \\
\hline $\mathrm{Na}$ & $\begin{array}{l}65 \\
46\end{array}$ & $\begin{array}{l}60 \\
36\end{array}$ & $\begin{array}{l}71 \\
42\end{array}$ & $\begin{array}{l}78 \\
34\end{array}$ & $\begin{array}{l}69 \\
46\end{array}$ & $\begin{array}{l}76 \\
34\end{array}$ & $\begin{array}{r}66 \\
32\end{array}$ & $\begin{array}{r}65 \\
38\end{array}$ & 46 & $\begin{array}{l}52 \\
74\end{array}$ \\
\hline $\mathrm{Nd}$ & 3,9 & 4,2 & 3,5 & 5,1 & 3,6 & 4,1 & 3,4 & 3,6 & 4,6 & 3,2 \\
\hline & 7,8 & 6,8 & 7,6 & 8,4 & 7,4 & 7,4 & 7,2 & 8,2 & 8,0 & 9,5 \\
\hline $\mathrm{Rb}$ & $\begin{array}{l}3,1 \\
7.6\end{array}$ & $\begin{array}{l}4,4 \\
6,6\end{array}$ & $\begin{array}{l}6,6 \\
5,8\end{array}$ & $\begin{array}{l}4,4 \\
6,8\end{array}$ & $\begin{array}{l}3,4 \\
6,8\end{array}$ & $\begin{array}{l}4,0 \\
7.6\end{array}$ & $\begin{array}{l}2,4 \\
8,2\end{array}$ & $\begin{array}{l}4,9 \\
6,8\end{array}$ & $\begin{array}{l}3,4 \\
8,4\end{array}$ & $\begin{array}{l}3,9 \\
7,6\end{array}$ \\
\hline Sc & 0,088 & 0,032 & 0,055 & $\begin{array}{c}0,036 \\
42\end{array}$ & $\begin{array}{c}0,029 \\
44\end{array}$ & $\begin{array}{c}0,034 \\
40\end{array}$ & $\begin{array}{c}0,033 \\
4.4\end{array}$ & 0,063 & 0,059 & 0,076 \\
\hline Sm & 0,27 & 0,32 & 0,28 & 0,39 & 0,29 & 0,33 & 0,28 & 0,30 & 0,42 & 0,28 \\
\hline & 6,4 & 6,6 & 6,4 & 6,8 & 6,2 & 6,2 & 6,2 & 6,4 & 6,2 & 6 \\
\hline $\mathrm{Sr}$ & 135 & 119 & 116 & 130 & 123 & 140 & 128 & 155 & 157 & 136 \\
\hline & 11,0 & 10,2 & 6,2 & 6,4 & 13,6 & 10,2 & 11,6 & 7,4 & 5,6 & 5,0 \\
\hline $\mathrm{Tb}$ & 0,03 & 0,03 & 0,03 & 0,03 & 0,03 & 0,03 & 0,02 & 0,03 & 0,04 & 0,03 \\
\hline & 10,0 & 9,0 & 11,6 & 8,2 & 9,2 & 9,4 & 10,0 & 10,4 & 9,2 & 8,6 \\
\hline Th & 0,069 & 0,026 & 0,045 & 0,032 & 0,022 & 0,027 & 0,023 & 0,046 & 0,045 & 0,052 \\
\hline & 8,6 & 15,6 & 12,2 & 12,8 & 14,2 & 12,4 & 12,0 & 8,2 & 9,6 & 8,0 \\
\hline $\mathrm{Yb}$ & 0,03 & 0,03 & 0,04 & 0,04 & 0,04 & 0,03 & 0,03 & 0,04 & 0,04 & 0,03 \\
\hline & 26,0 & 16,2 & 14,2 & 15,6 & 16,0 & 17,8 & 15,8 & 16,2 & 17,0 & 15,6 \\
\hline Zn & 49 & 30 & 33 & 41 & 44 & 52 & 45 & 40 & 29 & 31 \\
\hline & 3,8 & 4,0 & 3,8 & 4,0 & 3,8 & 3,8 & 3,8 & 4,0 & 4,0 & 3,7 \\
\hline
\end{tabular}


APÊNDICE 4. Concentração de elementos químicos $\left(\mathrm{mg} \mathrm{kg}^{-1}\right)$ e incertezas relativas $(\mathrm{k}=2)$ em amostras de folhas sob cultivo convencional

\begin{tabular}{|c|c|c|c|c|c|c|c|c|c|c|}
\hline & $\begin{array}{c}\text { Planta } \\
11\end{array}$ & $\begin{array}{c}\text { Planta } \\
12\end{array}$ & $\begin{array}{c}\text { Planta } \\
13\end{array}$ & $\begin{array}{c}\text { Planta } \\
14\end{array}$ & $\begin{array}{c}\text { Planta } \\
15\end{array}$ & $\begin{array}{c}\text { Planta } \\
16\end{array}$ & $\begin{array}{c}\text { Planta } \\
17\end{array}$ & $\begin{array}{c}\text { Planta } \\
18\end{array}$ & $\begin{array}{c}\text { Planta } \\
19\end{array}$ & $\begin{array}{c}\text { Planta } \\
20\end{array}$ \\
\hline \multirow[t]{2}{*}{$\mathrm{Ba}$} & 65 & 93 & 58 & 60 & 63 & 64 & 52 & 72 & 64 & 57 \\
\hline & 7,2 & 7,0 & 7,8 & 7,7 & 7,4 & 7,0 & 7,8 & 8,2 & 6,8 & 8,0 \\
\hline $\mathrm{Br}$ & $\begin{array}{c}5,5 \\
5,0\end{array}$ & $\begin{array}{c}9,7 \\
5,0\end{array}$ & $\begin{array}{c}6,0 \\
5,0\end{array}$ & $\begin{array}{c}6,3 \\
5,0\end{array}$ & $\begin{array}{c}6,2 \\
5,0\end{array}$ & $\begin{array}{l}4,7 \\
5,2\end{array}$ & $\begin{array}{c}6,6 \\
5,0\end{array}$ & $\begin{array}{c}5,8 \\
5,0\end{array}$ & $\begin{array}{r}7,5 \\
4,8\end{array}$ & $\begin{array}{c}5,6 \\
5,0\end{array}$ \\
\hline $\mathrm{Ca}$ & $\begin{array}{c}32108 \\
4,6\end{array}$ & $\begin{array}{c}36798 \\
4,6\end{array}$ & $\begin{array}{c}34323 \\
4,8\end{array}$ & $\begin{array}{c}35081 \\
4,6\end{array}$ & $\begin{array}{c}32535 \\
4,8\end{array}$ & $\begin{array}{c}34083 \\
4,6\end{array}$ & $\begin{array}{c}29605 \\
5\end{array}$ & $\begin{array}{c}32661 \\
4,4\end{array}$ & $\begin{array}{c}31139 \\
4,6\end{array}$ & $\begin{array}{c}27995 \\
4,4\end{array}$ \\
\hline $\mathrm{Ce}$ & $\begin{array}{r}5,2 \\
5,2\end{array}$ & $\begin{array}{c}7,0 \\
4,9\end{array}$ & $\begin{array}{r}6,5 \\
5,2\end{array}$ & $\begin{array}{c}6,6 \\
5,3\end{array}$ & $\begin{array}{c}6,9 \\
5,0\end{array}$ & $\begin{array}{r}5,9 \\
4,4\end{array}$ & $\begin{array}{l}5,1 \\
4,6\end{array}$ & $\begin{array}{l}5,6 \\
4,4\end{array}$ & $\begin{array}{r}4,9 \\
4,6\end{array}$ & $\begin{array}{c}4,6 \\
5,0\end{array}$ \\
\hline Co & $\begin{array}{l}0,03 \\
130\end{array}$ & $\begin{array}{l}0,03 \\
110\end{array}$ & $\begin{array}{l}0,05 \\
156\end{array}$ & $\begin{array}{l}0,03 \\
104\end{array}$ & $\begin{array}{c}0,05 \\
9 ?\end{array}$ & $\begin{array}{c}0,04 \\
8.4\end{array}$ & $\begin{array}{l}0,03 \\
104\end{array}$ & 0,04 & $\begin{array}{l}0,04 \\
104\end{array}$ & $\begin{array}{l}0,04 \\
104\end{array}$ \\
\hline \multirow[t]{2}{*}{ Cs } & 0,061 & 0,101 & 0,056 & 0,052 & 0,059 & 0,062 & 0,055 & 0,053 & 0,057 & 0,071 \\
\hline & 10,2 & 7,6 & 11,6 & 10,0 & 10,6 & 9,0 & 9,0 & 10,4 & 9,0 & 8,4 \\
\hline \multirow[t]{2}{*}{$\mathrm{Eu}$} & 0,09 & 0,12 & 0,12 & 0,09 & 0,11 & 0,08 & 0,07 & 0,11 & 0,08 & 0,07 \\
\hline & 4,4 & 4,0 & 4,0 & 4,2 & 5,0 & 3,8 & 3,8 & 4,0 & 4,0 & 4,0 \\
\hline \multirow[t]{2}{*}{$\mathrm{Fe}$} & 127 & 117 & 209 & 180 & 265 & 231 & 113 & 238 & 212 & 187 \\
\hline & 3,8 & 3,8 & 3,4 & 3,6 & 3,2 & 3,6 & 4,2 & 3,4 & 3,6 & 3,8 \\
\hline \multirow[t]{2}{*}{$\mathrm{K}$} & 9726 & 7605 & 9845 & 10225 & 9573 & 13405 & 11307 & 11059 & 8735 & 13016 \\
\hline & 5 & 5,4 & 6,2 & 4,8 & 5,6 & 2,8 & 2,8 & 2,6 & 3,2 & 3 \\
\hline \multirow[t]{2}{*}{$\mathrm{La}$} & 7,8 & 12,2 & 8,8 & 9,7 & 9,1 & 6,7 & 6,4 & 8,4 & 6,9 & 6,6 \\
\hline & 2,6 & 2,6 & 2,6 & 2,6 & 2,6 & 2,8 & 2,8 & 2,6 & 2,8 & 2,6 \\
\hline \multirow[t]{2}{*}{$\mathrm{Na}$} & 50 & 50 & 47 & 61 & 60 & 54 & 53 & 60 & 59 & 55 \\
\hline & 4,8 & 5,4 & 5,2 & 4,8 & 5,8 & 7,8 & 4,0 & 3,8 & 5,2 & 4,8 \\
\hline \multirow[t]{2}{*}{$\mathrm{Nd}$} & 4,5 & 5,7 & 5,4 & 4,9 & 5,9 & 3,1 & 3,9 & 5,5 & 4,1 & 4,0 \\
\hline & 11,4 & 6,3 & 6,8 & 7,5 & 9,4 & 9,2 & 7,2 & 6,2 & 10,6 & 8,2 \\
\hline \multirow[t]{2}{*}{$\mathrm{Rb}$} & 4,0 & 3,8 & 4,7 & 4,5 & 3,6 & 4,7 & 4,3 & 5,5 & 4,1 & 5,4 \\
\hline & 7 & 7,2 & 8,4 & 7,4 & 7,2 & 6,4 & 7,2 & 6 & 7,8 & 7 \\
\hline \multirow[t]{2}{*}{ Sc } & 0,031 & 0,029 & 0,061 & 0,048 & 0,077 & 0,064 & 0,030 & 0,070 & 0,063 & 0,054 \\
\hline & 4,0 & 4,2 & 3,8 & 3,8 & 3,4 & 4,4 & 5,2 & 3,6 & 3,6 & 3,8 \\
\hline \multirow[t]{2}{*}{ Sm } & 0,42 & 0,53 & 0,52 & 0,42 & 0,48 & 0,38 & 0,32 & 0,54 & 0,37 & 0,35 \\
\hline & 5,8 & 6,8 & 6 & 5,8 & 5,8 & 6,2 & 6 & 6,2 & 7,2 & 7 \\
\hline \multirow[t]{2}{*}{$\mathrm{Sr}$} & 138 & 174 & 163 & 164 & 146 & 136 & 128 & 140 & 123 & 111 \\
\hline & 5,4 & 7,0 & 6,8 & 5,8 & 6,2 & 6,0 & 8,0 & 6,6 & 6,4 & 6,2 \\
\hline \multirow[t]{2}{*}{$\mathrm{Tb}$} & 0,04 & 0,04 & 0,05 & 0,04 & 0,04 & 0,03 & 0,03 & 0,04 & 0,03 & 0,03 \\
\hline & 7,6 & 9,2 & 8,8 & 8,4 & 7,6 & 8,4 & 8,6 & 7,8 & 8,0 & 13,0 \\
\hline \multirow[t]{2}{*}{ Th } & 0,023 & 0,019 & 0,046 & 0,036 & 0,054 & 0,049 & 0,024 & 0,049 & 0,042 & 0,038 \\
\hline & 18,6 & 17,2 & 10,0 & 11,6 & 12,6 & 8,0 & 12,2 & 8,4 & 8,8 & 8,6 \\
\hline \multirow[t]{2}{*}{$\mathrm{Yb}$} & 0,06 & 0,04 & 0,06 & 0,04 & 0,05 & 0,07 & 0,04 & 0,07 & 0,05 & 0,04 \\
\hline & 11,8 & 13,8 & 18,0 & 16,6 & 14,8 & 42,4 & 24,4 & 11,4 & 27,2 & 44,6 \\
\hline \multirow[t]{2}{*}{ Zn } & 33 & 35 & 38 & 30 & 40 & 32 & 36 & 35 & 56 & 33 \\
\hline & 3,8 & 3,9 & 3,7 & 4,0 & 3,5 & 4,5 & 3,8 & 3,8 & 4,0 & 4,1 \\
\hline
\end{tabular}


APÊNDICE 4 - Concentração de elementos químicos $\left(\mathrm{mg}^{\mathrm{k}} \mathrm{kg}^{-1}\right)$ e incertezas relativas $(\mathrm{k}=2)$ em amostras de folhas sob cultivo convencional

\begin{tabular}{|c|c|c|c|c|c|c|c|c|c|c|}
\hline & $\begin{array}{c}\text { Planta } \\
21\end{array}$ & $\begin{array}{c}\text { Planta } \\
22\end{array}$ & $\begin{array}{c}\text { Planta } \\
23\end{array}$ & $\begin{array}{c}\text { Planta } \\
24\end{array}$ & $\begin{array}{c}\text { Planta } \\
25\end{array}$ & $\begin{array}{c}\text { Planta } \\
26\end{array}$ & $\begin{array}{c}\text { Planta } \\
27\end{array}$ & $\begin{array}{c}\text { Planta } \\
28\end{array}$ & $\begin{array}{c}\text { Planta } \\
29\end{array}$ & $\begin{array}{c}\text { Planta } \\
30\end{array}$ \\
\hline \multirow[t]{2}{*}{$\mathrm{Ba}$} & 71 & 67 & 45 & 55 & 71 & 43 & 83 & 75 & 56 & 84 \\
\hline & 8,6 & 7,0 & 7,2 & 6,6 & 6,8 & 7,2 & 6,0 & 6,0 & 7,2 & 6,4 \\
\hline \multirow[t]{2}{*}{$\mathrm{Br}$} & 7,2 & 7,0 & 7,7 & 7,7 & 6,6 & 4,9 & 7,2 & 7,3 & 6,3 & 7,1 \\
\hline & 4,8 & 4,8 & 5,0 & 4,6 & 4,6 & 4,8 & 4,8 & 4,8 & 4,8 & 4,6 \\
\hline \multirow[t]{2}{*}{$\mathrm{Ca}$} & 30492 & 31269 & 33693 & 36354 & 36266 & 30879 & 36417 & 33092 & 32919 & 29537 \\
\hline & 4,4 & 4,6 & 4,6 & 4,4 & 3,6 & 3,8 & 3,6 & 3,6 & 4 & 3,8 \\
\hline \multirow[t]{2}{*}{ Ce } & 6,5 & 5,4 & 4,0 & 7,8 & 5,2 & 5,1 & 9,2 & 9,6 & 6,3 & 8,0 \\
\hline & 4,4 & 4,8 & 4,8 & 4,4 & 4,4 & 4,2 & 4,2 & 4,4 & 4,4 & 4,6 \\
\hline \multirow[t]{2}{*}{ Co } & 0,04 & 0,03 & 0,04 & 0,03 & 0,05 & 0,04 & 0,05 & 0,05 & 0,05 & 0,04 \\
\hline & 9,0 & 8,2 & 8,0 & 9,0 & 6,4 & 11,0 & 7,4 & 8,4 & 10,8 & 8,0 \\
\hline \multirow[t]{2}{*}{ Cs } & 0,061 & 0,054 & 0,050 & 0,075 & 0,054 & 0,060 & 0,098 & 0,069 & 0,066 & 0,097 \\
\hline & $\begin{array}{c}8,4 \\
0,10\end{array}$ & $\begin{array}{c}9,0 \\
0,08\end{array}$ & $\begin{array}{c}8,6 \\
0,05\end{array}$ & $\begin{array}{c}7,8 \\
0,11\end{array}$ & $\begin{array}{l}10,4 \\
0,08\end{array}$ & $\begin{array}{l}10,2 \\
0,07\end{array}$ & $\begin{array}{c}8,0 \\
0,14\end{array}$ & $\begin{array}{c}9,0 \\
0,12\end{array}$ & $\begin{array}{c}8,6 \\
0,11\end{array}$ & $\begin{array}{c}7,4 \\
0,11\end{array}$ \\
\hline $\mathrm{Eu}$ & 4,0 & 3,8 & 4,6 & 3,8 & 4,2 & 4,6 & 3,6 & 4,0 & 5,0 & 4,2 \\
\hline \multirow[t]{2}{*}{$\mathrm{Fe}$} & 234 & 130 & 216 & 145 & 283 & 226 & 271 & 231 & 240 & 191 \\
\hline & 3,6 & 3,8 & 3,6 & 4 & 3,8 & 4 & 3,8 & 4 & 3,8 & 4 \\
\hline \multirow[t]{2}{*}{ K } & 10714 & 11558 & 6842 & 9813 & 7131 & 7895 & 9413 & 8591 & 8991 & 10666 \\
\hline & 2,8 & 2,8 & 3,2 & 4,4 & 4,4 & 4,6 & 4,6 & 5,6 & 4,6 & 4,2 \\
\hline \multirow[t]{2}{*}{$\mathrm{La}$} & 8,9 & 7,6 & 4,9 & 11,3 & 7,5 & 6,4 & 11,9 & 11,4 & 10,8 & 9,6 \\
\hline & 2,6 & 2,6 & 2,8 & 2,6 & 2,6 & 2,6 & 2,8 & 2,8 & 2,6 & 2,6 \\
\hline \multirow[t]{2}{*}{$\mathrm{Na}$} & 53 & 58 & 51 & 63 & 69 & 53 & 63 & 55 & 50 & 50 \\
\hline & 4,8 & 5,4 & 5,4 & 6,0 & 7,2 & 8,0 & 6,8 & 5,4 & 4,0 & 5,0 \\
\hline \multirow[t]{2}{*}{ Nd } & 3,9 & 4,6 & 2,0 & 5,8 & 4,0 & 3,6 & 7,4 & 6,7 & 5,6 & 5,8 \\
\hline & 7,0 & 7,8 & 9,2 & 7,4 & 6,6 & 8,8 & 5,6 & 6,2 & 6,4 & 5,8 \\
\hline \multirow[t]{2}{*}{$\mathrm{Rb}$} & 3,5 & 4,9 & 2,7 & 3,8 & 2,6 & 2,5 & 3,5 & 3,0 & 2,8 & 3,8 \\
\hline & 7 & 6,6 & 7,2 & 6 & 8 & 7,4 & 6,4 & 6,8 & 7 & 6 \\
\hline \multirow[t]{2}{*}{ Sc } & 0,070 & 0,031 & 0,065 & 0,034 & 0,080 & 0,065 & 0,073 & 0,066 & 0,073 & 0,051 \\
\hline & 3,6 & 4,4 & 3,6 & 3,8 & 3,8 & 3,4 & 3,8 & 3,6 & 3,6 & 4,0 \\
\hline \multirow[t]{2}{*}{ Sm } & 0,46 & 0,40 & 0,23 & 0,51 & 0,36 & 0,31 & 0,66 & 0,56 & 0,49 & 0,50 \\
\hline & 7,6 & 6,4 & 6,4 & 6,2 & 5,6 & 5,8 & 6,2 & 6,4 & 6 & 5,8 \\
\hline \multirow[t]{2}{*}{$\mathrm{Sr}$} & 136 & 130 & 127 & 141 & 152 & 113 & 142 & 133 & 127 & 132 \\
\hline & 7,6 & 6,0 & 7,2 & 5,8 & 5,4 & 6,4 & 7,2 & 5,6 & 6,4 & 6,6 \\
\hline \multirow[t]{2}{*}{$\mathrm{Tb}$} & 0,05 & 0,04 & 0,02 & 0,04 & 0,03 & 0,03 & 0,06 & 0,05 & 0,04 & 0,05 \\
\hline & 8,8 & 7,8 & 11,8 & 8,4 & 8,8 & 8,8 & 8,0 & 7,2 & 8,0 & 8,8 \\
\hline \multirow[t]{2}{*}{ Th } & 0,054 & 0,023 & 0,048 & 0,024 & 0,059 & 0,045 & 0,052 & 0,048 & 0,051 & 0,040 \\
\hline & 8,0 & 13,8 & 7,4 & 10,0 & 7,0 & 7,4 & 8,6 & 8,8 & 9,4 & 11,0 \\
\hline \multirow[t]{2}{*}{$\mathrm{Yb}$} & 0,06 & 0,05 & 0,02 & 0,07 & 0,06 & 0,05 & 0,07 & 0,06 & 0,05 & 0,07 \\
\hline & 20,0 & 23,6 & 70,0 & 28,4 & 15,2 & 61,2 & 13,6 & 13,6 & 21,2 & 13,8 \\
\hline \multirow[t]{2}{*}{$\mathrm{Zn}$} & 34 & 40 & 34 & 39 & 44 & 39 & 50 & 39 & 35 & 37 \\
\hline & 3,9 & 4,2 & 3,9 & 3,3 & 3,0 & 3,1 & 3,0 & 3,3 & 3,3 & 3,3 \\
\hline
\end{tabular}


APÊNDICE 5 - Concentração de elementos químicos (mg. $\left.\mathrm{kg}^{-1}\right)$ e incertezas relativas $(\mathrm{k}=2)$ em amostras de sucos de laranja sob cultivo orgânico

\begin{tabular}{ccccccccccc}
\hline & Planta & Planta & Planta & Planta & Planta & Planta & Planta & Planta & Planta & Planta \\
\hline Br & $\mathbf{1}$ & $\mathbf{2}$ & $\mathbf{3}$ & $\mathbf{4}$ & $\mathbf{5}$ & $\mathbf{6}$ & $\mathbf{7}$ & $\mathbf{8}$ & $\mathbf{9}$ & $\mathbf{1 0}$ \\
& 7,39 & 2,16 & 3,79 & 2,31 & 2,83 & 3,73 & 3,88 & 1,72 & 1,39 & 4,88 \\
Ca & 4,6 & 6,7 & 5,5 & 5,7 & 5,5 & 6,3 & 5,1 & 4,9 & 5,8 & 5,6 \\
& 858 & 988 & 724 & 833 & 1429 & 690 & 808 & 746 & 750 & 1004 \\
& 58,2 & 58,2 & 64,4 & 62,8 & 63 & 66 & 56,6 & 21,6 & 63,8 & 16,9 \\
Co & 0,012 & 0,022 & 0,011 & 0,030 & 0,013 & 0,017 & 0,020 & 0,016 & 0,013 & 0,013 \\
& 32,3 & 9,4 & 14,2 & 8,0 & 18,3 & 24,7 & 11,4 & 15,6 & 13,9 & 13,5 \\
Cs & 0,031 & 0,036 & 0,035 & 0,061 & 0,050 & 0,030 & 0,042 & 0,083 & 0,042 & 0,024 \\
& 15 & 10 & 13,8 & 8,6 & 14 & 12,4 & 9,6 & 15 & 10,4 & 24,4 \\
Fe & 4,97 & 5,46 & 6,27 & 4,22 & 6,24 & 4,43 & 5,57 & 4,88 & 4,57 & 6,13 \\
& 20,7 & 14,1 & 12,6 & 15,7 & 16,2 & 19,0 & 15,7 & 23,6 & 16,4 & 13,2 \\
K & 12237 & 12481 & 13923 & 15905 & 13528 & 11861 & 12157 & 12604 & 10745 & 13345 \\
& 6,2 & 6,0 & 7,2 & 8,2 & 4,8 & 4,2 & 4,6 & 5,6 & 6,6 & 5,4 \\
La & 0,035 & 0,050 & 0,053 & 0,070 & 0,134 & 0,036 & 0,044 & 0,060 & 0,055 & 0,069 \\
& 27 & 12,4 & 15,6 & 14 & 11,4 & 41,8 & 21,6 & 10,8 & 17,4 & 8 \\
Rb & 4,54 & 4,82 & 9,67 & 3,60 & 5,80 & 3,13 & 5,02 & 3,13 & 2,52 & 4,25 \\
& 7,0 & 9,3 & 10,0 & 10,4 & 9,5 & 36,1 & 22,3 & 18,3 & 16,3 & 10,2 \\
Na & 15,4 & 22,0 & 14,0 & 21,2 & 17,6 & 21,2 & 21,8 & 25,6 & 15,8 & 13,9 \\
& 4,6 & 5,4 & 4,4 & 4,8 & 4,8 & 5,4 & 4,4 & 5,8 & 4,4 & 5,8 \\
Zn & 5,6 & 4,4 & 5,9 & 4,1 & 6,9 & 3,5 & 5,1 & 2,7 & 4,3 & 3,5 \\
& 4,5 & 5,2 & 5,2 & 4,8 & 4,6 & 8,7 & 5,6 & 14,9 & 5,9 & 9,3
\end{tabular}


APÊNDICE 5 - Concentração de elementos químicos (mg. $\left.\mathrm{kg}^{-1}\right)$ e incertezas relativas $(\mathrm{k}=2)$ em amostras de sucos de laranja sob cultivo orgânico

\begin{tabular}{ccccccccccc}
\hline & Planta & Planta & Planta & Planta & Planta & Planta & Planta & Planta & Planta & Planta \\
& $\mathbf{1 1}$ & $\mathbf{1 2}$ & $\mathbf{1 3}$ & $\mathbf{1 4}$ & $\mathbf{1 5}$ & $\mathbf{1 6}$ & $\mathbf{1 7}$ & $\mathbf{1 8}$ & $\mathbf{1 9}$ & $\mathbf{2 0}$ \\
\hline Br & 4,14 & 4,01 & 4,10 & 4,89 & 3,62 & 3,50 & 4,61 & 3,71 & 1,94 & 2,85 \\
& 4,6 & 4,6 & 6,3 & 4,4 & 5,7 & 4,6 & 6,7 & 4,6 & 4,9 & 5,9 \\
Ca & 1236 & 1333 & 1143 & 1154 & 622 & 991 & 878 & 706 & 750 & 1112 \\
& 30,4 & 17,3 & 59,0 & 16,6 & 29,8 & 19,0 & 66,0 & 28,4 & 23,1 & 22,4 \\
Co & 0,027 & 0,013 & 0,015 & 0,012 & 0,013 & 0,012 & 0,011 & 0,016 & 0,014 & 0,008 \\
& 12,1 & 16,0 & 17,0 & 18,9 & 15,0 & 22,4 & 40,0 & 18,5 & 19,8 & 16,3 \\
Cs & 0,024 & 0,027 & 0,040 & 0,056 & 0,062 & 0,080 & 0,056 & 0,079 & 0,114 & 0,125 \\
& 28,2 & 26 & 11,2 & 19,6 & 22,8 & 17,2 & 10,6 & 14,2 & 12,8 & 8,8 \\
Fe & 5,66 & 5,59 & 7,16 & 5,11 & 4,48 & 5,31 & 6,37 & 4,90 & 6,30 & 5,59 \\
& 22,5 & 19,1 & 50,7 & 18,4 & 20,3 & 20,7 & 31,8 & 18,6 & 18,6 & 11,8 \\
K & 15047 & 12952 & 11983 & 12390 & 14834 & 13735 & 14955 & 12756 & 12753 & 15113 \\
& 5,8 & 5,8 & 3,4 & 5,2 & 4,6 & 5,6 & 3,3 & 5,0 & 5,8 & 3,4 \\
La & 0,045 & 0,080 & 0,051 & 0,064 & 0,047 & 0,073 & 0,064 & 0,049 & 0,054 & 0,098 \\
& 16 & 8 & 41,6 & 10,6 & 10,6 & 9,6 & 55,8 & 11,2 & 10,6 & 7,6 \\
Rb & 2,92 & 4,79 & 4,07 & 2,20 & 4,22 & 3,84 & 3,50 & 3,70 & 3,31 & 4,75 \\
& 20,0 & 13,4 & 12,3 & 20,0 & 13,2 & 12,9 & 15,1 & 14,3 & 18,8 & 11,9 \\
Na & 31,7 & 25,6 & 21,1 & 22,6 & 28,1 & 30,7 & 30,3 & 28,7 & 31,2 & 30,0 \\
& 5,4 & 5,6 & 6,0 & 5,8 & 7,0 & 6,4 & 6,2 & 6,8 & 6,0 & 5,6 \\
Zn & 2,4 & 2,0 & 6,4 & 1,6 & 2,2 & 2,9 & 5,9 & 2,1 & 3,7 & 2,9 \\
& 17,3 & 19,1 & 4,0 & 24,8 & 19,7 & 13,7 & 3,4 & 15,6 & 13,5 & 14,3
\end{tabular}


APÊNDICE 5 - Concentração de elementos químicos $\left(\mathrm{mg}^{\mathrm{kg}} \mathrm{kg}^{-1}\right)$ e incertezas relativas $(\mathrm{k}=2)$ em amostras de sucos de laranja sob cultivo orgânico

\begin{tabular}{ccccccccccc}
\hline & Planta & Planta & Planta & Planta & Planta & Planta & Planta & Planta & Planta & Planta \\
& $\mathbf{2 1}$ & $\mathbf{2 2}$ & $\mathbf{2 3}$ & $\mathbf{2 4}$ & $\mathbf{2 5}$ & $\mathbf{2 6}$ & $\mathbf{2 7}$ & $\mathbf{2 8}$ & $\mathbf{2 9}$ & $\mathbf{3 0}$ \\
\hline $\mathbf{B r}$ & 2,66 & 3,33 & 4,45 & 3,26 & 4,67 & 6,65 & 5,02 & 2,90 & 5,31 & 3,98 \\
& 6,8 & 5,9 & 6,3 & 6,7 & 5,9 & 5,6 & 6,7 & 6,5 & 5,7 & 5,7 \\
$\mathbf{C a}$ & 727 & 1032 & 1024 & 654 & 1191 & 935 & 1294 & 952 & 1108 & 766 \\
& 16,6 & 11,2 & 63,8 & 70,6 & 13,2 & 12,2 & 63,8 & 14,7 & 15,3 & 20,1 \\
Co & 0,009 & 0,014 & 0,013 & 0,013 & 0,011 & 0,013 & 0,018 & 0,022 & 0,018 & 0,032 \\
& 31,6 & 17,8 & 18,6 & 20,2 & 22,0 & 23,6 & 17,4 & 20,3 & 21,8 & 19,7 \\
Cs & 0,078 & 0,044 & 0,035 & 0,043 & 0,042 & 0,030 & 0,021 & 0,031 & 0,019 & 0,020 \\
& 15 & 13 & 12,2 & 11,8 & 13,2 & 16,8 & 16 & 19,2 & 24,4 & 18,2 \\
Fe & 6,08 & 4,76 & 8,14 & 5,08 & 6,16 & 5,30 & 8,42 & 7,83 & 7,24 & 4,12 \\
& 13,0 & 19,8 & 18,5 & 56,8 & 11,2 & 12,0 & 25,4 & 17,1 & 12,4 & 18,3 \\
K & 12460 & 15117 & 15545 & 13990 & 16207 & 15028 & 14770 & 17188 & 15384 & 14969 \\
& 3,6 & 3,8 & 3,2 & 3,2 & 3,4 & 4,8 & 3,4 & 3,2 & 3,2 & 3,2 \\
La & 0,045 & 0,051 & 0,061 & 0,058 & 0,067 & 0,055 & 0,221 & 0,081 & 0,059 & 0,056 \\
& 14,6 & 10,0 & 22,6 & 19,2 & 8,4 & 9,0 & 8,6 & 7,8 & 7,8 & 8,8 \\
Rb & 3,63 & 4,35 & 4,27 & 4,03 & 4,46 & 4,40 & 6,94 & 8,35 & 3,39 & 2,83 \\
& 15,0 & 14,7 & 10,2 & 14,5 & 11,7 & 10,8 & 8,5 & 7,6 & 13,8 & 16,4 \\
Na & 24,5 & 23,0 & 23,3 & 25,6 & 24,3 & 22,2 & 22,1 & 25,9 & 21,8 & 24,4 \\
& 5,6 & 6,0 & 5,6 & 5,2 & 6,0 & 5,8 & 6,3 & 5,8 & 5,8 & 5,8 \\
& 1,5 & 2,3 & 5,2 & 6,3 & 3,0 & 2,8 & 7,9 & 4,4 & 2,8 & 3,1 \\
& 34,2 & 25,8 & 5,4 & 3,8 & 13,0 & 12,2 & 3,2 & 11,0 & 15,2 & 13,4 \\
\hline
\end{tabular}


APÊNDICE 6 - Concentração de elementos químicos (mg. $\left.\mathrm{kg}^{-1}\right)$ e incertezas relativas $(\mathrm{k}=2)$ em amostras de sucos de laranja sob cultivo convencional

\begin{tabular}{|c|c|c|c|c|c|c|c|c|c|c|}
\hline & $\begin{array}{c}\text { Planta } \\
1 \\
\end{array}$ & $\begin{array}{c}\text { Planta } \\
2 \\
\end{array}$ & $\begin{array}{c}\text { Planta } \\
\mathbf{3} \\
\end{array}$ & $\begin{array}{c}\text { Planta } \\
4 \\
\end{array}$ & $\begin{array}{c}\text { Planta } \\
5 \\
\end{array}$ & $\begin{array}{c}\text { Planta } \\
6 \\
\end{array}$ & $\begin{array}{c}\text { Planta } \\
7 \\
\end{array}$ & $\begin{array}{c}\text { Planta } \\
8 \\
\end{array}$ & $\begin{array}{c}\text { Planta } \\
9 \\
\end{array}$ & $\begin{array}{c}\text { Planta } \\
10\end{array}$ \\
\hline $\mathrm{Br}$ & 0,44 & 0,49 & 0,54 & 0,52 & 0,60 & 0,44 & 0,50 & 0,40 & 0,45 & 0,51 \\
\hline \multirow{3}{*}{$\mathrm{Ca}$} & 9,4 & 8,9 & 7,9 & 8,9 & 7,8 & 6,8 & 7,6 & 7,7 & 10,3 & 11,6 \\
\hline & $<569$ & 583 & 414 & 533 & 894 & 594,6 & 567 & 474 & 734 & $<265$ \\
\hline & 63,6 & 64,6 & 64,4 & 64,8 & 63,4 & 20,1 & 59,4 & 32,5 & 62,2 & 62,8 \\
\hline \multirow[t]{2}{*}{ Co } & 0,005 & 0,003 & 0,004 & 0,004 & 0,007 & 0,004 & 0,004 & 0,006 & 0,007 & 0,002 \\
\hline & 27,1 & 43,2 & 24,9 & 25,0 & 20,2 & 28,3 & 23,2 & 42,7 & 16,7 & 84,9 \\
\hline \multirow[t]{2}{*}{ Cs } & 0,20 & 0,12 & 0,09 & 0,10 & 0,16 & 0,17 & 0,08 & 0,09 & 0,08 & 0,09 \\
\hline & 6,8 & 6,8 & 6,8 & 8,2 & 6,8 & 9,2 & 6,8 & 15,6 & 7,2 & 9,4 \\
\hline \multirow{2}{*}{$\mathrm{Fe}$} & 7,0 & 5,5 & 6,4 & 6,3 & 8,2 & 5,8 & 5,1 & 5,8 & 5,7 & 4,1 \\
\hline & 19,9 & 14,0 & 13,7 & 10,3 & 13,1 & 14,3 & 12,9 & 19,4 & 12,5 & 23,2 \\
\hline \multirow[t]{2}{*}{$\mathbf{K}$} & 17443 & 14670 & 14368 & 13712 & 13399 & 13846 & 10309 & 15544 & 12307 & 13087 \\
\hline & 4,4 & 6,6 & 6,8 & 6,2 & 5,6 & 5,2 & 5,2 & 5,6 & 6,6 & 4,0 \\
\hline \multirow[t]{2}{*}{ La } & 0,039 & 0,026 & 0,016 & 0,039 & 0,061 & 0,037 & 0,020 & 0,025 & 0,027 & 0,033 \\
\hline & 24,8 & 37,8 & 49,2 & 27,4 & 14,2 & 10,4 & 48,4 & 19,4 & 30,6 & 44,0 \\
\hline \multirow[t]{2}{*}{ Rb } & 6,78 & 8,66 & 5,36 & 7,89 & 8,05 & 6,59 & 4,97 & 7,83 & 4,78 & 4,73 \\
\hline & 16,4 & 5,5 & 11,7 & 12,0 & 5,9 & 8,0 & 11,0 & 16,0 & 13,5 & 18,7 \\
\hline \multirow[t]{2}{*}{$\mathrm{Na}$} & 15,1 & 14,6 & 15,6 & 14,4 & 15,5 & 16,1 & 8,4 & 13,1 & 10,7 & 13,4 \\
\hline & 4,6 & 4,8 & 4,6 & 5,8 & 4,8 & 5,8 & 4,4 & 5,4 & 4,8 & 5,8 \\
\hline \multirow[t]{2}{*}{ Zn } & 6,11 & 5,86 & 6,00 & 5,54 & 11,21 & 2,30 & 2,95 & 3,54 & 8,21 & 4,38 \\
\hline & 5,1 & 5,0 & 4,4 & 4,4 & 3,7 & 13,5 & 6,0 & 12,4 & 3,9 & 7,8 \\
\hline
\end{tabular}


APÊNDICE 6 - Concentração de elementos químicos (mg.kg $\left.{ }^{-1}\right)$ e incertezas relativas $(\mathrm{k}=2)$ em amostras de sucos de laranja sob cultivo convencional

\begin{tabular}{ccccccccccc}
\hline & Planta & Planta & Planta & Planta & Planta & Planta & Planta & Planta & Planta & Planta \\
& $\mathbf{1 1}$ & $\mathbf{1 2}$ & $\mathbf{1 3}$ & $\mathbf{1 4}$ & $\mathbf{1 5}$ & $\mathbf{1 6}$ & $\mathbf{1 7}$ & $\mathbf{1 8}$ & $\mathbf{1 9}$ & $\mathbf{2 0}$ \\
\hline Br & 0,63 & 0,70 & 0,80 & 0,61 & 0,59 & 0,51 & 0,54 & 0,47 & 0,51 & 0,45 \\
& 5,9 & 7,7 & 7,0 & 8,7 & 6,3 & 6,9 & 7,0 & 6,9 & 7,0 & 7,3 \\
Ca & 459 & $<493,0$ & 571 & $<581,0$ & 553 & 330 & 592 & 462 & 589 & 528 \\
& 30,5 & 88 & 22,2 & 81 & 27,4 & 36,0 & 25,4 & 27,5 & 26,2 & 16,5 \\
Co & 0,006 & 0,006 & 0,003 & 0,007 & 0,009 & 0,008 & 0,008 & 0,005 & $<0,002$ & 0,004 \\
& 33,6 & 55,6 & 40,0 & 32,8 & 23,6 & 35,9 & 31,8 & 38,9 & 67,8 & 41,6 \\
Cs & 0,11 & 0,10 & 0,143 & 0,09 & 0,101 & 0,078 & 0,142 & 0,102 & 0,129 & 0,102 \\
& 11,0 & 10,4 & 10,2 & 10,2 & 11,2 & 13,8 & 10,8 & 13,8 & 11,2 & 12,0 \\
Fe & 5,9 & 4,80 & 4,86 & 8,36 & 4,20 & 5,43 & 6,68 & 5,62 & 5,33 & 6,09 \\
& 16,3 & 55,6 & 11,6 & 22,3 & 23,6 & 15,1 & 25,8 & 16,4 & 21,2 & 14,2 \\
K & 13150 & 11789 & 13758 & 14519 & 12654 & 13885 & 14014 & 15213 & 11862 & 13474 \\
& 5,2 & 3,3 & 3,6 & 4,2 & 5,4 & 5,4 & 5,6 & 5,0 & 6,0 & 6,2 \\
La & 0,141 & 0,030 & 0,038 & 0,031 & 0,028 & 0,026 & 0,035 & 0,021 & 0,032 & 0,030 \\
& 5,6 & 50,2 & 12,6 & 51,4 & 14,6 & 20,8 & 14,4 & 17,0 & 16,2 & 14,6 \\
Rb & 3,66 & 3,86 & 5,84 & 4,07 & 2,77 & 5,74 & 4,99 & 4,08 & 2,87 & 4,36 \\
& 12,4 & 12,2 & 8,9 & 12,8 & 14,8 & 8,8 & 10,8 & 11,0 & 17,8 & 11,3 \\
Na & 13,2 & 11,4 & 12,6 & 14,0 & 12,2 & 10,5 & 14,8 & 15,6 & 15,1 & 13,1 \\
& 6,4 & 5,5 & 5,4 & 6,1 & 4,8 & 6,2 & 4,4 & 4,8 & 4,8 & 5,6 \\
& 3,04 & 4,73 & 3,99 & 4,59 & 3,13 & 3,39 & 3,13 & 4,21 & 3,93 & 2,31 \\
& 11,6 & 4,2 & 8,7 & 5,6 & 12,0 & 12,4 & 13,4 & 8,9 & 11,6 & 16,7
\end{tabular}


APÊNDICE 6 - Concentração de elementos químicos $\left(\mathrm{mg}^{\mathrm{k}} \mathrm{kg}^{-1}\right)$ e incertezas relativas (k=2) em amostras de sucos de laranja sob cultivo convencional

\begin{tabular}{|c|c|c|c|c|c|c|c|c|c|}
\hline & $\begin{array}{c}\text { Planta } \\
21\end{array}$ & $\begin{array}{c}\text { Planta } \\
22\end{array}$ & $\begin{array}{c}\text { Planta } \\
23\end{array}$ & $\begin{array}{c}\text { Planta } \\
24\end{array}$ & $\begin{array}{c}\text { Planta } \\
25\end{array}$ & $\begin{array}{c}\text { Planta } \\
26\end{array}$ & $\begin{array}{c}\text { Planta } \\
27\end{array}$ & $\begin{array}{c}\text { Planta } \\
29\end{array}$ & $\begin{array}{c}\text { Planta } \\
30\end{array}$ \\
\hline \multirow[t]{2}{*}{$\mathrm{Br}$} & 0,67 & 0,53 & 0,51 & 0,73 & 0,41 & 0,40 & 0,40 & 0,55 & 0,63 \\
\hline & 7,8 & 8,4 & 8,0 & 7,4 & 12,8 & 8,7 & 8,9 & 8,3 & 7,2 \\
\hline \multirow[t]{2}{*}{$\mathrm{Ca}$} & 626 & $<512$ & 451 & 488 & 779 & 605 & 409 & 422 & 361 \\
\hline & 92,0 & 91,0 & 25,1 & 17,8 & 81,2 & 15,1 & 25,0 & 42,5 & 21,1 \\
\hline \multirow[t]{2}{*}{ Co } & 0,005 & 0,005 & 0,003 & 0,002 & 0,008 & 0,003 & 0,003 & 0,005 & 0,002 \\
\hline & 38,4 & 34,0 & 27,9 & 42,8 & 58,4 & 44,8 & 33,5 & 19,0 & 48,1 \\
\hline \multirow[t]{2}{*}{ Cs } & 0,115 & 0,096 & 0,104 & 0,132 & 0,142 & 0,137 & 0,144 & 0,104 & 0,113 \\
\hline & 10,0 & 9,0 & 10,0 & 11,8 & 13,6 & 9,6 & 11,8 & 10,4 & 8,6 \\
\hline \multirow[t]{2}{*}{$\mathbf{F e}$} & 5,07 & 7,70 & 4,91 & 4,34 & 16,78 & 5,50 & 5,58 & 8,08 & 3,77 \\
\hline & 34,4 & 19,6 & 12,4 & 12,5 & 16,3 & 8,4 & 32,3 & 11,8 & 21,7 \\
\hline \multirow[t]{2}{*}{$\mathbf{K}$} & 15070 & 14345 & 14047 & 13434 & 14425 & 12180 & 13892 & 14259 & 11824 \\
\hline & 4,0 & 3,8 & 3,4 & 3,4 & 3,3 & 3,6 & 3,4 & 4,0 & 3,2 \\
\hline \multirow[t]{2}{*}{ La } & 0,024 & 0,021 & 0,021 & 0,040 & $<0,028$ & 0,023 & 0,023 & 0,029 & 0,020 \\
\hline & 59,0 & 61,2 & 23,8 & 11,6 & 91 & 11,0 & 12,6 & 10 & 18,2 \\
\hline \multirow[t]{2}{*}{$\mathbf{R b}$} & 5,17 & 6,38 & 8,42 & 4,65 & 4,60 & 4,13 & 3,90 & 10,24 & 5,30 \\
\hline & 9,1 & 8,1 & 8,9 & 9,1 & 17,2 & 9,0 & 13,5 & 6,8 & 10,1 \\
\hline \multirow[t]{2}{*}{$\mathrm{Na}$} & 12,7 & 14,6 & 13,4 & 11,7 & 14,2 & 11,1 & 12,7 & 10,3 & 8,8 \\
\hline & 6,5 & 6,3 & 5,6 & 5,6 & 6,1 & 5,4 & 5,6 & 5,6 & 5,8 \\
\hline \multirow[t]{2}{*}{ Zn } & 5,21 & 4,53 & 3,36 & 3,4 & 5,8 & 2,7 & 3,29 & 5,03 & 1,78 \\
\hline & 4,4 & 3,8 & 11,0 & 9,7 & 3,8 & 13,6 & 13,8 & 7,8 & 21,3 \\
\hline
\end{tabular}


APÊNDICE 7 - Concentração de elementos químicos $\left(m g . \mathrm{kg}^{-1}\right)$ e incertezas relativas $(\mathrm{k}=2)$ em amostras de sucos de laranja comerciais

\begin{tabular}{|c|c|c|c|c|c|c|c|c|c|c|c|}
\hline Marca & $\mathrm{Br}$ & $\mathbf{C a}$ & Co & Cs & $\mathrm{Fe}$ & $\mathbf{K}$ & La & $\mathbf{N a}$ & $\mathbf{R b}$ & Sc & Zn \\
\hline \multirow[t]{2}{*}{ Barat. } & 0,99 & 446 & 0,007 & 0,12 & 6,4 & 13278 & 0,02 & 116 & 10,6 & $<0,00042$ & 2,6 \\
\hline & 6,2 & 48,7 & 22,4 & 7,8 & 8,8 & 2,8 & 24,8 & 3,9 & 5,2 & 194,1 & 6,5 \\
\hline \multirow[t]{2}{*}{ Barat. } & 0,90 & 417 & 0,007 & 0,12 & 9,9 & 12907 & 0,03 & 110 & 10,7 & $<0,00042$ & 3,1 \\
\hline & 6,3 & 66,8 & 28,8 & 7,8 & 7,8 & 2,6 & 21,9 & 3,6 & 4,2 & 185,3 & 7,7 \\
\hline \multirow[t]{2}{*}{ Barat. } & 0,94 & 585 & 0,005 & 0,10 & 8,8 & 12911 & 0,02 & 114 & 10,4 & $<0,00041$ & 3,2 \\
\hline & 6,3 & 51,3 & 59,5 & 9,0 & 9,2 & 2,6 & 26,6 & 3,9 & 7,2 & 163,9 & 10,6 \\
\hline \multirow[t]{2}{*}{ Carref. } & 1,41 & 530 & 0,011 & 0,064 & 4,91 & 13952 & 0,026 & 18 & 17 & $<0,00017$ & 3,1 \\
\hline & 5,5 & 64,8 & 12,2 & 10,6 & 14,2 & 3,8 & 39,7 & 5,7 & 5,4 & 211,4 & 6,3 \\
\hline \multirow[t]{2}{*}{ Carref. } & 1,43 & 550 & 0,011 & 0,060 & 4,64 & 14288 & 0,033 & 18 & 18 & $<0,00015$ & 2,56 \\
\hline & 5,4 & 49,9 & 11,9 & 9,8 & 12,5 & 4,0 & 33,5 & 4,6 & 4,6 & 215,5 & 6,5 \\
\hline \multirow[t]{2}{*}{ Carref. } & 1,48 & 596 & 0,011 & 0,061 & 6,3 & 14676 & 0,032 & 15 & 18 & 0,00018 & 2,78 \\
\hline & 5,7 & 56,2 & 13,6 & 11,2 & 12,3 & 4,0 & 39,2 & 4,8 & 4,8 & 82,8 & 7,6 \\
\hline \multirow[t]{2}{*}{ Coagro. } & 2,80 & 486 & 0,0067 & 0,062 & 12,2 & 14047 & 0,027 & 11,9 & 17 & $<0,00016$ & 2,88 \\
\hline & 4,9 & 58,0 & 18,1 & 10,2 & 8,6 & 4,2 & 37,0 & 6,8 & 5,6 & 89,8 & 5,3 \\
\hline \multirow[t]{2}{*}{ Coagro. } & 2,75 & $<518$ & 0,0068 & 0,065 & 10,2 & 14112 & 0,017 & 8,1 & 18 & 0,00031 & 3,17 \\
\hline & 5,1 & 70,5 & 34,7 & 11,8 & 7,9 & 4,2 & 64,1 & 6,6 & 5,8 & 87,2 & 6,9 \\
\hline \multirow[t]{2}{*}{ Coagro. } & 2,64 & 519 & 0,0071 & 0,064 & 9,7 & 13722 & 0,021 & 10,2 & 17 & $<0,00015$ & 3,02 \\
\hline & 5,3 & 62,8 & 15,0 & 9,4 & 8,8 & 5,4 & 52,6 & 6,7 & 4,8 & 133,5 & 6,6 \\
\hline \multirow[t]{2}{*}{ Danone } & 1,12 & 412 & 0,021 & 0,12 & 6,7 & 13961 & 0,031 & 128 & 8,8 & $<0,00053$ & 2,85 \\
\hline & 7 & 52,2 & 10,3 & 7,8 & 9,6 & 2,8 & 25,9 & 3,9 & 4,4 & 163,5 & 7,1 \\
\hline \multirow[t]{2}{*}{ Danone } & 1,15 & 344 & 0,011 & 0,12 & 6,9 & 13842 & 0,019 & 130 & 8,6 & $<0,00045$ & 2,19 \\
\hline & 6,6 & 60,7 & 15,4 & 8,0 & 7,4 & 2,8 & 19,4 & 3,5 & 4,4 & 189,4 & 8,9 \\
\hline \multirow[t]{2}{*}{ Danone } & 1,05 & 202 & 0,005 & 0,04 & 4,2 & 7032 & 0,018 & 96 & 9,1 & $<0,00025$ & 1,68 \\
\hline & 6,0 & 83,3 & 29,7 & 10,0 & 9,2 & 3,2 & 20,2 & 3,5 & 5,2 & 184,1 & 10,5 \\
\hline \multirow[t]{2}{*}{ Del Val. } & 0,70 & 438 & $<0,002$ & 0,084 & 5,40 & 7829 & 0,013 & 513 & 11,3 & $<0,00030$ & 3,16 \\
\hline & 7,0 & 62,2 & 181,7 & 7,8 & 8,8 & 3,0 & 42,0 & 4,2 & 5,2 & 53,3 & 7,0 \\
\hline \multirow[t]{2}{*}{ Del Val. } & 0,73 & 381 & $<0,002$ & 0,087 & 5,93 & 7533 & 0,009 & 506 & 11,0 & 0,00053 & 3,46 \\
\hline & 7,2 & 62,2 & 200,0 & 9,4 & 10,0 & 2,6 & 58,8 & 3,8 & 4,4 & 24,0 & 7,1 \\
\hline \multirow[t]{2}{*}{ Del Val. } & 0,76 & 443 & $<0,002$ & 0,084 & 6,84 & 7887 & 0,020 & 511 & 11,1 & $<0,00032$ & 3,79 \\
\hline & 6,7 & 61,4 & 118,1 & 8,4 & 7,4 & 3,4 & 53,1 & 3,4 & 4,8 & 55,5 & 6,8 \\
\hline \multirow[t]{2}{*}{ Extra } & 1,04 & 597 & 0,007 & 0,14 & 8,69 & 15024 & 0,029 & 126 & 10,1 & 0,00044 & 3,8 \\
\hline & 7,3 & 49,3 & 28,4 & 7,2 & 7,8 & 2,8 & 15,9 & 3,7 & 4,4 & 38,3 & 7,0 \\
\hline \multirow[t]{2}{*}{ Extra } & 1,42 & 770 & 0,013 & 0,21 & 12,57 & 21456 & 0,038 & 179 & 14,6 & $<0,00052$ & 5,1 \\
\hline & 6,0 & 39,3 & 19,1 & 7,6 & 6,6 & 2,4 & 27,6 & 3,5 & 4,6 & 44,6 & 6,3 \\
\hline \multirow[t]{2}{*}{ Extra } & 0,65 & 258 & 0,004 & 0,10 & 5,27 & 9894 & 0,018 & 81 & 6,6 & $<0,00036$ & 2,3 \\
\hline & 6,7 & 76,6 & 34,2 & 9,2 & 8,8 & 2,6 & 20,1 & 3,6 & 4,8 & 162,4 & 9,4 \\
\hline \multirow[t]{2}{*}{ Frutaki } & 1,0 & 274 & 0,013 & 0,10 & 5,43 & 12483 & 0,021 & 114 & 7,6 & $<0,00042$ & 2,2 \\
\hline & 5,6 & 67,0 & 13,6 & 7,8 & 8,4 & 3,8 & 27,7 & 4,1 & 4,6 & 188,6 & 8,8 \\
\hline \multirow[t]{2}{*}{ Frutaki } & 0,97 & 208 & 0,005 & 0,05 & 4,36 & 6525 & 0,019 & 88 & 8,4 & $<0,00039$ & 1,7 \\
\hline & 6,5 & 79,8 & 38,3 & 13 & 18 & 3,0 & 20,0 & 3,6 & 4,6 & 185,0 & 12,3 \\
\hline \multirow[t]{2}{*}{ Frutaki } & 1,0 & 280 & 0,005 & 0,04 & 3,29 & 6434 & 0,016 & 90 & 8,3 & $<0,00033$ & 1,3 \\
\hline & 6,0 & 73,3 & 29,6 & 12,4 & 11,4 & 3,0 & 27,3 & 4,2 & 5 & 160,6 & 16,9 \\
\hline
\end{tabular}


APÊNDICE 7 - Concentração de elementos químicos (mg. $\left.\mathrm{kg}^{-1}\right)$ e incertezas relativas $(\mathrm{k}=2)$ em amostras de sucos de laranja comerciais

\begin{tabular}{|c|c|c|c|c|c|c|c|c|c|c|c|}
\hline Marca & $\mathrm{Br}$ & $\mathrm{Ca}$ & Co & Cs & $\mathbf{F e}$ & $\mathbf{K}$ & La & $\mathrm{Na}$ & $\mathbf{R b}$ & Sc & Zn \\
\hline \multirow{2}{*}{ Granja } & 1,18 & 390 & 0,015 & 0,17 & 8,7 & 16050 & 0,03 & 120 & 12,9 & $<0,00066$ & 3,7 \\
\hline & 6,2 & 70,6 & 16,9 & 7,6 & 8,2 & 2,6 & 19,1 & 3,3 & 5,0 & 156,6 & 6,6 \\
\hline \multirow{2}{*}{ Granja } & 1,17 & 518 & 0,011 & 0,17 & 8,3 & 16093 & 0,03 & 120 & 12,6 & $<0,00034$ & 3,0 \\
\hline & 5,6 & 53,7 & 15,6 & 6,8 & 7,8 & 3,4 & 28,6 & 4,1 & 5,4 & 177,9 & 7,8 \\
\hline \multirow[t]{2}{*}{ Granja } & 1,17 & 416 & 0,012 & 0,17 & 8,1 & 15524 & 0,024 & 117 & 12,8 & $<0,00048$ & 3,26 \\
\hline & 6,4 & 59,0 & 16,1 & 7,8 & 8,8 & 2,4 & 22,2 & 3,9 & 5,4 & 196,7 & 6,0 \\
\hline \multirow[t]{2}{*}{ Lanjal } & 0,88 & 390 & 0,014 & 0,04 & 23,3 & 6788 & 0,025 & 82 & 8,19 & 0,02469 & 1,7 \\
\hline & 5,6 & 77,6 & 11,7 & 11,2 & 4,3 & 3,8 & 60,4 & 3,8 & 5,4 & 3,6 & 7,0 \\
\hline \multirow[t]{2}{*}{ Lanjal } & 0,91 & 554 & 0,017 & 0,04 & 22,5 & 6779 & 0,025 & 82 & 8,06 & 0,02372 & 1,7 \\
\hline & 6,1 & 84,6 & 12,3 & 13,8 & 5,0 & 4,0 & 60,1 & 4,1 & 5,0 & 3,6 & 9,4 \\
\hline \multirow{2}{*}{ Lanjal } & 0,90 & 397 & 0,013 & 0,05 & 22,6 & 6807 & 0,039 & 85 & 8,25 & 0,02398 & 1,9 \\
\hline & 5,8 & 59,5 & 12,8 & 10,8 & 5,4 & 4,0 & 27,7 & 4,5 & 4,6 & 3,4 & 7,1 \\
\hline \multirow[t]{2}{*}{ Maraú } & 2,47 & 511 & 0,009 & 0,07 & 11,1 & 15155 & 0,030 & 43 & 15,67 & $<0,00017$ & 2,8 \\
\hline & 7,0 & 53,8 & 22,6 & 11,0 & 6,8 & 3,2 & 15,9 & 5,0 & 4,6 & 2,8 & 8,1 \\
\hline \multirow[t]{2}{*}{ Maraú } & 2,56 & 624 & 0,009 & 0,07 & 8,6 & 16196 & 0,028 & 51 & 16,61 & $<0,00015$ & 2,9 \\
\hline & 5,7 & 27,9 & 25,0 & 12,2 & 14,6 & 2,6 & 26,9 & 3,9 & 4,6 & 2,9 & 8,0 \\
\hline \multirow[t]{2}{*}{ Maraú } & 3,09 & 628 & 0,023 & 0,08 & 13,2 & 15232 & 0,027 & 106 & 15,85 & $<0,00018$ & 3,6 \\
\hline & 5,3 & 52,6 & 13,7 & 10,2 & 6,0 & 3,2 & 20,9 & 4,0 & 5,2 & 3,6 & 8,0 \\
\hline \multirow[t]{2}{*}{ Native } & 2,27 & 949 & 0,010 & 0,06 & 7,30 & 14601 & 0,018 & 149 & 7,08 & $<0,00021$ & 3,6 \\
\hline & 5,4 & 54,2 & 15,6 & 13,2 & 14,1 & 4,2 & 59,9 & 3,8 & 4,8 & 82,5 & 5,3 \\
\hline \multirow[t]{2}{*}{ Native } & 2,18 & 692 & 0,007 & 0,06 & 5,55 & 14373 & 0,020 & 144 & 6,84 & $<0,00019$ & 2,6 \\
\hline & 5,6 & 74,8 & 24,5 & 10,4 & 16,4 & 4,0 & 60,1 & 3,8 & 5,8 & 105,5 & 6,8 \\
\hline \multirow[t]{2}{*}{ Native } & 2,18 & 599 & 0,013 & 0,06 & 5,80 & 14356 & 0,019 & 144 & 7,25 & $<0,00016$ & 2,7 \\
\hline & 4,9 & 48,8 & 15,5 & 9,8 & 11,2 & 4,4 & 66,8 & 4,0 & 5,8 & 97,5 & 8,0 \\
\hline \multirow[t]{2}{*}{ Salute } & 0,86 & 777 & 0,010 & 0,14 & 5,95 & 14461 & 0,029 & 110 & 10,19 & $<0,00018$ & 2,9 \\
\hline & 6,4 & 50,9 & 15,0 & 7,2 & 12,5 & 4,0 & 49,8 & 4,0 & 5,2 & 109,7 & 8,5 \\
\hline \multirow[t]{2}{*}{ Salute } & 0,78 & 647 & 0,010 & 0,15 & 8,21 & 15818 & 0,032 & 118 & 12,08 & $<0,00020$ & 3,1 \\
\hline & 6,9 & 70,7 & 24,3 & 9,8 & 11,0 & 4,0 & 56,8 & 3,8 & 4,6 & 45,1 & 5,9 \\
\hline \multirow[t]{2}{*}{ Salute } & 0,88 & 700 & 0,012 & 0,14 & 10,82 & 14626 & 0,033 & 111 & 10,11 & $<0,00019$ & 3,3 \\
\hline & 6,8 & 69,5 & 14,3 & 8,2 & 8,0 & 4,0 & 61,8 & 4,2 & 5,2 & 51,2 & 5,9 \\
\hline \multirow[t]{2}{*}{ Santal } & 0,94 & $<924$ & 0,010 & 0,07 & 22,9 & 9991 & $<0,009$ & 81 & 9,80 & $<0,00036$ & 2,3 \\
\hline & 7,2 & 99,5 & 25,7 & 10,2 & 7,3 & 4,6 & 72,0 & 4,3 & 4,8 & 30,5 & 11,5 \\
\hline \multirow[t]{2}{*}{ Santal } & 0,97 & $<436$ & 0,006 & 0,07 & 9,9 & 9879 & $<0,012$ & 80 & 9,85 & $<0,00015$ & 2,5 \\
\hline & 6,0 & 74,9 & 21,7 & 9,8 & 9,2 & 5,0 & 64,0 & 3,9 & 4,8 & 108,5 & 7,2 \\
\hline \multirow[t]{2}{*}{ Santal } & 0,95 & $<671$ & 0,007 & 0,07 & 5,9 & 9846 & 0,012 & 81 & 9,67 & $<0,00018$ & 2,6 \\
\hline & 6,6 & 76,0 & 19,0 & 10,6 & 13,9 & 4,6 & 66,0 & 4,3 & 6,4 & 118,4 & 7,2 \\
\hline \multirow[t]{2}{*}{ Yes } & 1,80 & $<777$ & 0,014 & 0,08 & 7,38 & 13571 & 0,040 & 95 & 17,62 & $<0,00025$ & 3,1 \\
\hline & 5,7 & 88,1 & 17,5 & 10,8 & 19,0 & 4,6 & 63,7 & 5,3 & 4,6 & 292,9 & 9,0 \\
\hline \multirow[t]{2}{*}{ Yes } & 1,82 & 742 & 0,015 & 0,07 & 4,82 & 13580 & 0,029 & 95 & 16,71 & $<0,00015$ & 3,0 \\
\hline & 5,4 & 50,7 & 10,7 & 9,0 & 11,6 & 4,0 & 36,4 & 4,0 & 5,2 & 147,8 & 6,8 \\
\hline \multirow[t]{2}{*}{ Yes } & 1,79 & 815 & 0,016 & 0,08 & 6,18 & 13911 & 0,042 & 95 & 16,97 & $<0,00018$ & 3,1 \\
\hline & 5,6 & 50,3 & 11,1 & 9,8 & 11,1 & 4,4 & 39,5 & 4,4 & 5,6 & 110,0 & 7,4 \\
\hline
\end{tabular}


Apêndice 8: Insumos permitidos na agricultura orgânica (Instrução Normativa 007, 1999)

Da Própria unidade de produção (desde que livre de contaminantes):

Composto orgânico
Vermicomposto
Restos orgânicos
Esterco: sólido ou líquido
Restos de cultura
Adubação verde
Biofertilizante
Fezes humanas (somente quando compostadas e não utilizadas em olerícolas)
Microrganismos benéficos ou enzimas desde que não sejam transgênicos/OGM
Outros resíduos orgânicos

Obtidos de fora da unidade de produção:

\begin{tabular}{c} 
Vermicomposto \\
Esterco composto ou líquido \\
Biomassa vegetal \\
Resíduos industriais, chifre, tortas \\
Pó de osso, pêlos e penas, vinhaça e semelhantes como complementação da adubação \\
Algas e derivados e outros produtos de origem marinha \\
Peixes e derivados \\
Pó de serra, cascas e derivados sem contaminação \\
Microrganismos, aminoácidos e enzimas, desde que não sejam OGM/transgênicos \\
Cinzas e carvões vegetais \\
Pó de rocha \\
Biofertilizantes \\
Argilas ou ainda vermiculita \\
Compostagem urbana, quando oriunda de coleta seletiva e comprovadamente livre de substâncias tóxicas \\
\hline
\end{tabular}


Somente se constatado a necessidade de utilização do adubo e do condicionador, através de análise, e se os mesmos estiverem livres de substâncias tóxicas:

\section{Termofosfatos}

Micronutrientes

Sulfato de magnésio

Carbonato, como fonte de micronutrientes

Adubos potássicos - sulfato de potássio, sulfato duplo de potássio e magnésio, este de origem mineral natural;

Ácido bórico quando não usado diretamente nas plantas e solo

Guano

\begin{tabular}{|c|c|}
\hline Meios contra doenças fúngicas: & Meios contra pragas: \\
\hline $\begin{array}{l}\text { Enxofre simples e suas preparações, a critério da } \\
\text { certificadora } \\
\text { Pó de pedra }\end{array}$ & $\begin{array}{c}\text { Preparados viróticos, fúngicos e bacteriológicos, que } \\
\text { não sejam OGM/transgênicos, e só com permissão } \\
\text { específica da certificadora } \\
\text { Extratos de insetos }\end{array}$ \\
\hline $\begin{array}{l}\text { Um terço de sulfato de alumínio e dois terços de argila } \\
\text { (caulim ou bentonita) em solução a 1\% } \\
\text { Sais de cobre na fruticultura }\end{array}$ & $\begin{array}{c}\text { Emulsões oleosas (sem inseticidas químico sintéticos) } \\
\text { Extratos de plantas }\end{array}$ \\
\hline Própolis & Sabão de origem natural \\
\hline Cal hidratado, somente como fungicida & Pó de café \\
\hline $\begin{array}{l}\text { Iodo } \\
\text { Extrato de plantas } \\
\text { Extrato de compostos }\end{array}$ & $\begin{array}{l}\text { Gelatina } \\
\text { Homeopatia } \\
\text { Pó de rocha } \\
\text { Álcool etílico }\end{array}$ \\
\hline Vermicomposto & Como emulsionante: lecitina de soja, não transgênica \\
\hline $\begin{array}{l}\text { Calda sulfocálcica e calda bordalesa, a critério da } \\
\text { certificadora } \\
\text { Homeopatia }\end{array}$ & $\begin{array}{c}\text { Terras diatomáceas, ceras naturais, própolis e óleos } \\
\text { essenciais, a critério da certificadora } \\
\text { Como solventes: álcool, acetona, óleos vegetais e } \\
\text { minerais }\end{array}$ \\
\hline
\end{tabular}


Meios de captura, meios de proteção e outras medidas biológicas:

Controle biológico

Feromônios, desde que utilizados em armadilhas

Armadilhas de insetos com inseticidas permitidos

Armadilhas anti-coagulantes para roedores

Meios repelentes mecânicos (armadilhas e outros similares)

Repelentes naturais (materiais repelentes e expulsantes)

Métodos vegetativos, quebra-vento, plantas companheiras e repelentes

Preparados que estimulem a resistência das plantas e que inibam certas pragas e doenças, tais como plantas medicinais, própolis, calcário e extratos de algas, bentonita, pó de pedra e similares

Cloreto de cálcio

Leite e derivados

Extratos de produtos de origem animal

Manejo de plantas invasoras:

Sementes e mudas, isentas de plantas invasoras

Técnicas mecânicas

Alelopatia

Cobertura morta e viva

Cobertura inerte, que não cause contaminação e poluição a critério da instituição certificadora

Solarização

Controle biológico como manejo de plantas invasoras 